Aus der Abteilung Mund-, Kiefer- und Gesichtschirurgie (Prof. Dr. med. Dr. med. dent. H. Schliephake) im Zentrum Zahn-, Mund- und Kieferheilkunde der Medizinischen Fakultät der Universität Göttingen

\title{
Histomorphometrische Evaluation der Knochenneubildung mit Hilfe eines osteoinduktiven Faktors bei der Sinusbodenaugmentation im Göttinger Minipig
}

\author{
INAUGURAL-DISSERTATION
}

zur Erlangung des Doktorgrades für Zahnheilkunde

der Medizinischen Fakultät der Georg-August-Universität zu Göttingen

vorgelegt

von

Phillipp Brockmeyer

aus

Hannover 
Dekan: Prof. Dr. rer. nat. H. K. Kroemer

I. Berichterstatter: PD Dr. med. Dr. med. dent. R. M. Gruber

II. Berichterstatter/in: Prof. Dr. rer. nat. J. Wilting

III. Berichterstatter/in:

Tag der mündlichen Prüfung: 04.12.2013 


\section{Inhaltsverzeichnis}

1 Einleitung 1

1.1 Vorwort ..................................................................................

1.2 Theoretische Grundlagen ...............................................

1.2.1 Knochenersatz ..........................................................

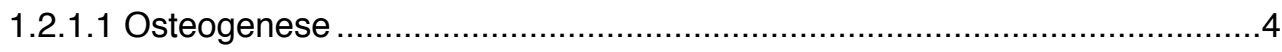

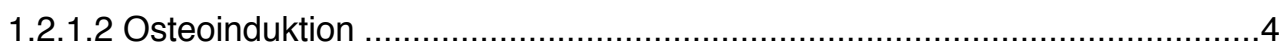

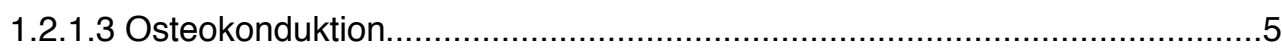

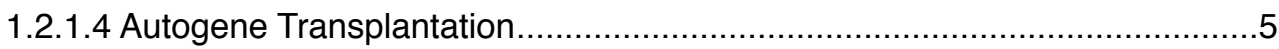

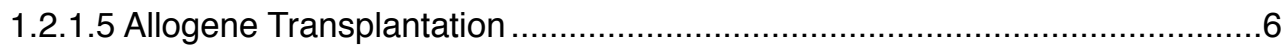

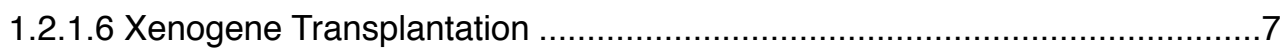

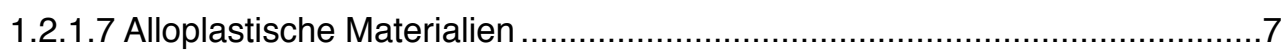

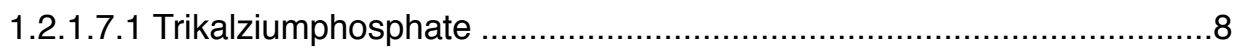

1.2.2 Wachstumsfaktoren .......................................................... 9

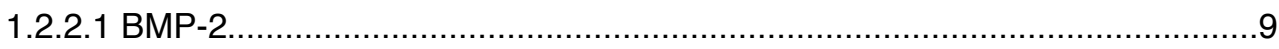

1.2.2.2 GDF-5

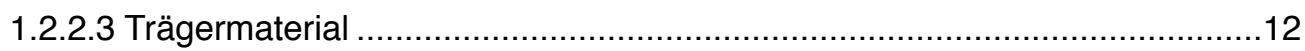

1.2.3 Sinusbodenaugmentation ................................................ 13

1.2.4 Histomorphometrie ........................................................ 14

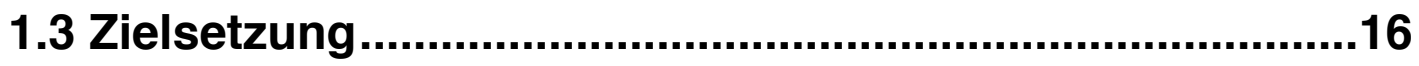

2 Material und Methoden 17 
2.1 Versuchstiere .................................................................17

2.1.1 Einteilung der Versuchstiere ...................................................17

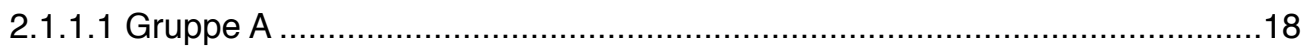

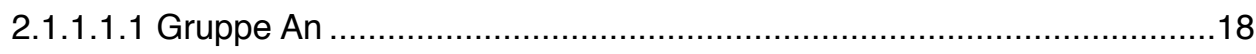

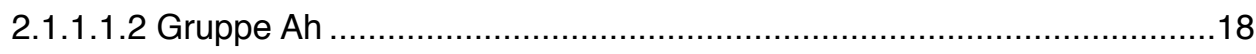

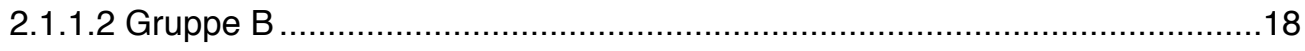

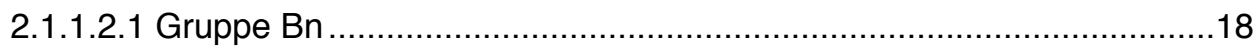

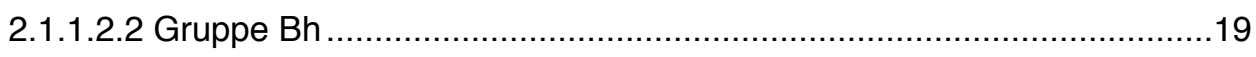

2.2 Augmentationsmaterialien ..............................................19

2.2.1 $\beta$-Trikalziumphosphat ................................................. 19

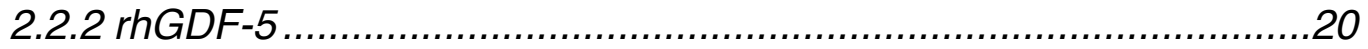

2.3 Medikation.......................................................................20

2.4 Operationsablauf .............................................................21

2.4.1 Euthanasie der Tiere ............................................................23

2.5 Herstellung der Schliffpräparate ...................................23

2.5.1 Histologische Färbung ..........................................................24

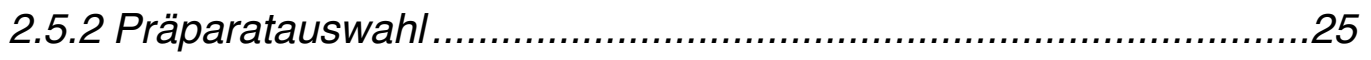

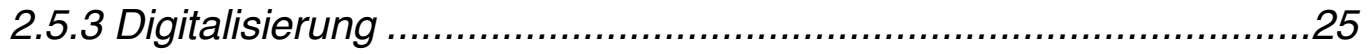

2.5.4 Gradient der Knochenneubildung .........................................26

2.6 Histomorphometrische Knochenmessung .....................28

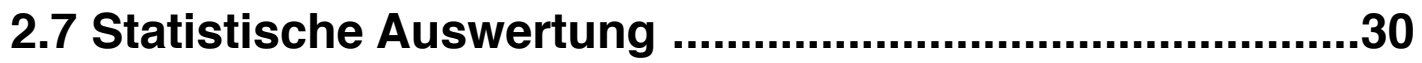

3 Ergebnisse 31 
3.1 Klinische Auswertung ..................................................31

3.2 Lichtmikroskopische Evaluation ...................................31

3.2.1 Vier Wochen Beobachtungszeitraum........................................31

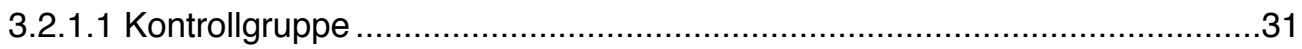

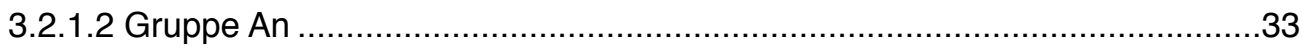

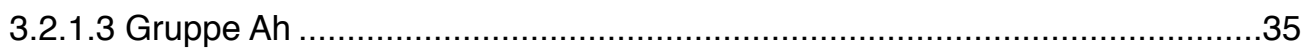

3.2.2 Zwölf Wochen Beobachtungszeitraum ..................................37

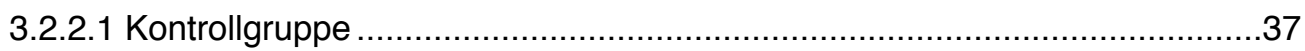

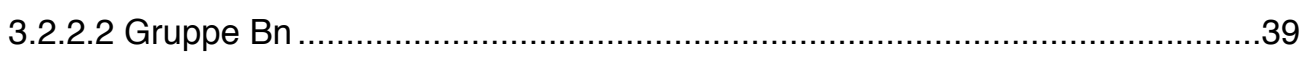

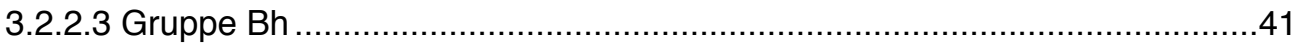

3.3 Histomorphometrische Evaluation .................................45

3.3.1 Vier Wochen Beobachtungszeitraum......................................45

3.3.2 Zwölf Wochen Beobachtungszeitraum ..................................48

4 Diskussion $\quad 53$

4.1 Studiendesign ................................................................53

4.2 Untersuchungsmethode ..............................................55

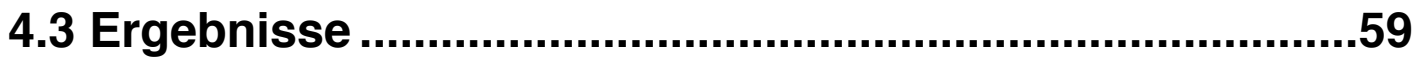

4.4 Schlussfolgerung ..........................................................63

5 Zusammenfassung $\quad 64$

6 Literaturverzeichnis $\quad 67$ 
7.1 Histomorphometrische Daten .........................................74

7.2 Statistische Daten .............................................................77

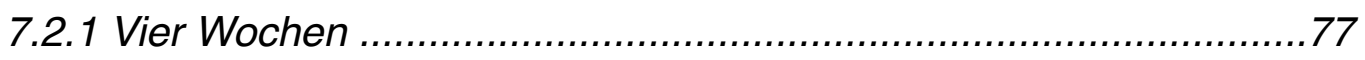

7.2.2 Zwölf Wochen ...................................................................... 78

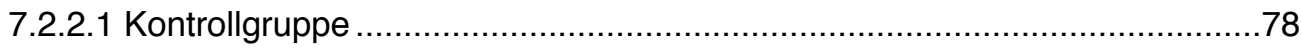

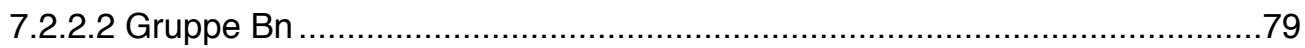

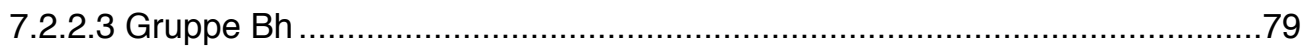




\section{Abkürzungsverzeichnis}

\begin{tabular}{|c|c|}
\hline$A_{n}$ & Untergruppe $A_{\text {niedrig }}(400 \mu \mathrm{g}$ rhGDF-5/1g $\beta$-TCP) \\
\hline$A_{h}$ & Untergruppe $A_{\text {hoch }}(800 \mu g$ rhGDF-5/1g $\beta$-TCP) \\
\hline Abb. & Abbildung/Abbildungen \\
\hline ACS & Absorbable collagen sponge \\
\hline ANCOVA & Analysis of covariance \\
\hline$\beta$-TCP & $\beta$-Trikalziumphosphat \\
\hline $\mathrm{BIC}$ & Bone implant contact \\
\hline $\mathrm{B}_{\mathrm{n}}$ & Untergruppe $B_{\text {niedrig }}(400 \mu \mathrm{g}$ rhGDF-5/1g $\beta$-TCP) \\
\hline $\mathrm{B}_{h}$ & Untergruppe $\mathrm{B}_{\text {hoch }}(800 \mu \mathrm{g}$ rhGDF-5/1g $\beta$-TCP) \\
\hline BMPs & Bone morphogenetic proteins \\
\hline BMP-2 & Bone morphogenetic protein 2 \\
\hline BMP-4 & Bone morphogenetic protein 4 \\
\hline BMP-7 & Bone morphogenetic protein 7 \\
\hline BMP-9 & Bone morphogenetic protein 9 \\
\hline${ }^{\circ} \mathrm{C}$ & Grad Celsius \\
\hline CDMP-1 & Cartilage derived morphogenetic protein 1 \\
\hline CDMP-2 & Cartilage derived morphogenetic protein 2 \\
\hline $\mathrm{cm}$ & Zentimeter \\
\hline CT & Computertomographie \\
\hline g & Gramm \\
\hline
\end{tabular}




\begin{tabular}{|c|c|}
\hline GDF-5 & Growth and differentiation factor 5 \\
\hline GDF-6 & Growth and differentiation factor 6 \\
\hline GDF-7 & Growth and differentiation factor 7 \\
\hline i.v. & intravenös \\
\hline kgKG & Kilogramm Körpergewicht \\
\hline$\mu \mathrm{g}$ & Mikrogramm \\
\hline$\mu \mathrm{m}$ & Mikrometer \\
\hline $\mathrm{m}$ & Meter \\
\hline $\mathrm{mg}$ & Milligramm \\
\hline $\mathrm{ml}$ & Milliliter \\
\hline $\mathrm{mm}$ & Millimeter \\
\hline OP-1 & Osteogenic protein 1 \\
\hline PDGF & Platelet derived growth factor \\
\hline PRP & Platelet-rich plasma \\
\hline PTH & Parathyroid hormone \\
\hline P-Wert & Probability value \\
\hline rhBMP-7 & Recombinant human bone morphogenetic protein 7 \\
\hline rhGDF-5 & Recombinant human growth and differentiation factor 5 \\
\hline ROI & Region of interest \\
\hline Tab. & Tabelle \\
\hline TCP & Trikalziumphosphat \\
\hline TGF- $\beta$ & Transforming growth factor $\beta$ \\
\hline
\end{tabular}




\section{Einleitung}

\subsection{Vorwort}

In den letzten Jahrzehnten hat die Implantologie eine wichtige Rolle in der zahnärztlichen Chirurgie eingenommen. Durch die großen Innovationen in diesem Fachgebiet ist es inzwischen möglich geworden, Situationen, die früher nur mit aufwendigen und teilweise herausnehmbaren prothetischen Restaurationen versorgt werden konnten, über die Insertion dentaler Implantate festsitzend zu behandeln und so die Lebensqualität zu verbessern. Bei der Insertion dentaler Implantate ist ein ausreichend starkes Knochenangebot notwendig. Ist ein gewisser Grad an Knochenquantität unterschritten, ist es nicht mehr möglich, das Implantat ausreichend stabil im Kieferknochen zu befestigen. Diese Problematik ist besonders im Oberkiefer zu beobachten, weil hier durch die Ausdehnung der Kieferhöhlen das lokale Knochenangebot möglicherweise begrenzt sein kann.

Schon 1918 transplantierte Blair vitalen Knochen zum Aufbau der Kieferregion (Blair 1918). Inzwischen hat sich die Sinusbodenaugmentation als Standardverfahren im Oberkiefer etabliert (Woo und Le 2004). In den letzten Jahren wurden diverse Knochenersatzmaterialien entwickelt, die die Nachteile einer autogenen Transplantatgewinnung wie z.B. die Entnahmemorbidität umgehen sollen. Neben der zahnärztlichen Implantologie werden derartige Materialien auch zur Rekonstruktion bei einer Vielzahl weiterer ossärer Defekte wie z.B. der alters- oder inaktivitätsbedingten Atrophie, im Rahmen der Traumatologie oder bei der Tumortherapie herangezogen (Kärcher 2000). Synthetisch hergestellte Knochenersatzmaterialien sind so aufgebaut, dass Gefäße und Osteoblasten von der Oberfläche her in sie einwachsen können und es danach innerhalb des Materials zu einer Knochenneubildung kommt (Khan et al. 2005). Weil eine solche rein osteokonduktive Knochenneubildung sehr langsam und inhomogen abläuft, wurden in den letzten Jahren verschiedene osteoinduktiv wirkende Wachstumsfaktoren beschrieben, die in Kombination mit dem osteokonduktiven Augmentationsmaterial zu einer stärke- 
ren und homogeneren Knochenneubildung innerhalb des Augmentats führen sollen. Neben den bone morphogenetic proteins (BMPs), die typischerweise Knochenwachstum induzieren können, scheint auch der growth and differentiation factor 5 (GDF-5), der ebenfalls Mitglied der TGF- $\beta$-Superfamilie ist, osteoinduktive Wirkung ausüben zu können (Boyapati und Wang 2006, Boyne et al. 2005, Gruber et al. 2008, Gruber et al. 2009, Herberg et al. 2008, Kim et al. 2009, Poehling et al. 2006, Urist 1965, Urist et al. 1983, Urist und Strates 1971, Weng et al. 2009). Bei der Verwendung derartiger Wachstumsfaktoren spielen sowohl die Dosierung als auch das verwendete Trägermaterial eine entscheidende Rolle. Obwohl in der Literatur noch kontrovers über die ideale Konzentration diskutiert wird, ist man sich einig, dass das Trägermaterial eine kontrollierte Abgabe des Wachstumsfaktors in einer ausreichend hohen Dosis gewährleisten soll (Schliephake 2010, Sigurdsson et al. 1996, Wikesjo et al. 1998).

Es ist problematisch, die Knochenneubildung innerhalb der Sinusbodenaugmentate klinisch zu evaluieren. Die meisten Tiermodelle begrenzten sich auf die histologische Untersuchung des direkten Knochen-Implantat-Kontaktes (BIC) und waren auf eine zweidimensionale Betrachtung begrenzt (Martuscelli et al. 2008). Durch solche Studien wird jedoch nur ein kleiner Bereich untersucht, der keine Aussagen über die Knochenneubildung innerhalb des gesamten räumlich komplex aufgebauten Augmentats machen kann. Solche Informationen sind nur durch experimentelle Studien möglich, in denen das Augmentat in verschiedenen Ebenen und unabhängig vom Knochen-Implantat-Kontakt evaluiert wird (Jung et al. 2008). Mehrere experimentell durchgeführte Studien über osteokonduktive Augmentationsmaterialien haben gezeigt, dass die Knochenneubildung innerhalb des Augmentats nach einem typischen Muster abläuft. Das meiste neu gebildete Knochengewebe wurde in allen Studien nahe dem ortsständigen Kieferknochen beobachtet. Mit zunehmendem Abstand zu dieser Region nahmen die Werte stetig ab und bildeten so einen Gradienten (Busenlechner et al. 2009, Fuerst et al. 2004, Roldan et al. 2004). Die Autoren wiesen darauf hin, dass es wichtig ist, den gesamten Augmentationsbereich zu untersuchen, um die Qualität der Augmentation bewerten zu können. Bis heute wurde keine Studie veröffentlicht, die die Knochenneubildung des gesamten Sinusbodenaugmentats unter der Wirkung eines osteoinduktiv wir- 
kenden Wachstumsfaktors beurteilt hat. Aufgrund des osteoinduktiven Charakters eines derartigen Faktors kann man eine stärkere und homogenere Knochenneubildung auch mit zunehmendem Abstand zum nativen Knochen erwarten. Das Ziel der vorliegenden Untersuchung war es, die osteoinduktive Wirkung des Wachstumsfaktor GDF-5, in Verbindung mit dem Augmentationsmaterial $\beta-T C P$, in der experimentell durchgeführten Sinusbodenaugmentation an einem Tiermodell zu evaluieren.

\subsection{Theoretische Grundlagen}

\subsubsection{Knochenersatz}

Der Ersatz von Knochengewebe bzw. die Transplantation von Knochen ist in der Medizin bei verschiedenen Indikationen ein weit verbreitetes Verfahren zur Rekonstruktion des Skelettsystems. Schon in früherer Zeit wurde damit begonnen, tierische Knochen zur Rekonstruktion des menschlichen Skeletts zu transplantieren. Die erste Literaturangabe zur Knochentransplantation wurde 1668 dokumentiert (Khan et al. 2005). Der niederländische Chirurg Job van Mee'kren führte eine Schädelkalotteplastik an einem Soldaten mit Hilfe einer Hundeschädelkalotte durch (Nussbaum 1875). 1821 wurde die erste experimentelle autogene Kranioplastik durchgeführt. 1879 führte Sir William MacEwen die erste allogene Knochentransplantation durch. Er ersetzte den proximalen Abschnitt des Humerus eines vier Jahre alten Jungen durch ein humanes Knochentransplantat (Khan et al. 2005). Seit 1859 wurde die Entwicklung der Knochentransplantation vor allem durch Ollier vorangetrieben. Durch seine Arbeit prägte er maßgeblich die noch heute gebräuchliche Unterteilung in autogene, allogene, xenogene und alloplastische Knochenersatzmaterialien (Ollier 1867). Auch in der Zahnmedizin und in der Mund-, Kiefer- und Gesichtschirurgie müssen verlorengegangene Anteile des knöchernen Gesichtsskeletts häufig rekonstruiert werden. Neben der alters- oder inaktivitätsbedingten Atrophie spielen hier besonders die Rekonstruktion von Skelettanteilen im Rahmen der Tumortherapie oder der Traumatologie eine entscheiden- 
de Rolle (Kärcher 2000). In Zusammenhang mit der Transplantation werden drei Wege der Knochenbildung beschrieben: Osteogenese, Osteoinduktion und Osteokonduktion.

\subsubsection{Osteogenese}

Bei der Transplantation von Knochen werden vitale knochenbildende Zellen mit dem Transplantat in das Empfängerlager eingebracht (Rogers und Greene 2012). Unter dem Begriff Osteogenese versteht man daher die Knochenneubildung aus diesen transplantierten Präosteoblasten und Osteoblasten (Albrektsson und Johansson 2001).

\subsubsection{Osteoinduktion}

Der Begriff Osteoinduktion beschreibt eine durch osteoinduktiv wirkende Faktoren hervorgerufene Knochenneubildung im Empfängerlager. Diese biologisch aktiven Moleküle rekrutieren undifferenzierte mesenchymale Vorläuferzellen aus der Umgebung in das Empfängerlager und induzieren deren Umwandlung in Osteoprogenitorzellen. Diese Zellen bewirken dann eine Knochenneubildung. Ein sicherer Hinweis auf die osteoinduktive Wirkung einer Materialkombination mit Wachstumsfaktoren ist der Nachweis neu gebildeten Knochengewebes in einem ektopen Lager, wie z.B. in einer Muskeltasche. Dieser Vorgang wird typischerweise durch so genannte bone morphogenetic proteins (BMPs) hervorgerufen. In der aktuellen Literatur werden noch weitere Faktoren wie z.B. der growth and differentiation factor 5 (GDF-5) diskutiert. Auch für diesen Wachstumsfaktor wurde eine osteoinduktive Wirkung beschrieben, die jedoch niedriger sein soll als die von BMP-2 und BMP-7 (Albrektsson und Johansson 2001, Boyapati und Wang 2006, Boyne et al. 2005, Gruber et al. 2008, Gruber et al. 2009, Herberg et al. 2008, Kim et al. 2009, Merten et al. 2003, Poehling et al. 2006, Urist 1965, Urist et al. 1983, Urist und Strates 1971, Weng et al. 2009). 


\subsubsection{Osteokonduktion}

Osteokonduktion beschreibt das Einwachsen von Kapillaren und Osteoblasten aus dem umliegenden Knochen in das Knochenersatzmaterial bzw. das transplantierte Knochengewebe. Dafür ist eine ausreichende Blut- und Nährstoffversorgung obligat. Das Material ist als Gerüst zu verstehen, das aufgrund typischer Charakteristika wie z.B. seiner porösen Oberflächenbeschaffenheit den Osteoblasten das Einwachsen ermöglicht. Typischerweise zeigen synthetische und xenogene Knochenersatzmaterialien osteokonduktiven Charakter. Eine Knochenregeneration auf diesem Wege geschieht jedoch relativ langsam. Aus diesem Grund ist es notwendig, dass die verwendeten Materialien über eine ausreichende Zeitspanne ihre Stabilität erhalten können, damit es zu keinen Veränderungen des gewünschten Rekonstruktionsvolumens kommt. Im Idealfall sollen Knochenersatzmaterialien im Verlauf der Einheilung in dem gleichen Maße resorbiert werden, wie neues Knochengewebe gebildet wird. Dadurch kann das Volumen bis zur vollständigen Substitution durch körpereigenen Knochen erhalten werden (Albrektsson und Johansson 2001, Merten et al. 2003).

\subsubsection{Autogene Transplantation}

Bei der freien autogenen Knochentransplantation sind Spender und Empfänger des Transplantates identisch. In der Mund-, Kiefer- und Gesichtschirurgie wird Knochengewebe sowohl von intra- als auch von extraoral transplantiert. Typische Entnahmeorte sind die Kinnprominenz, die Retromolarregion, die Schädelkalotte, die Rippen, der Beckenkamm und die Tibia (Kärcher 2000).

Die Fähigkeit autogener Knochentransplantate, neues Knochenwachstum zu induzieren, ist ein großer Vorteil im Vergleich zu den Knochenersatzmaterialien. Dies kann durch die mit dem Knochengewebe transplantierten Zellen erklärt werden (Albrektsson und Johansson 2001). Aus diesem Grund ist es wichtig, die innerhalb des Transplantats lebenden Osteozyten und Osteoblasten zu erhalten. Der Tod dieser Zellen tritt bereits nach einer Ischämiezeit von 25 Stunden auf und 
kann darüber hinaus eine Osteolyse des Transplantats auslösen (Rogers und Greene 2012). Das Überleben hängt davon ab, wie gut die Zellen innerhalb der ersten Tage von dem Empfängerlager mit Nährstoffen und Sauerstoff versorgt werden können. Weil eine Revaskularisierung des gesamten Transplantats nur sehr langsam fortschreitet, werden in der frühen Einheilungsphase nur die am Rand liegenden Zellen durch Diffusion vom Empfängerlager aus erreicht. Nur diese Zellen überleben die Transplantation und können die Knochenregeneration innerhalb des Transplantats vorantreiben. Der im Zentrum liegende devitale Knochen dient als Gerüst und wird später durch neu einwachsendes Knochengewebe substituiert. Weiterhin wird eine BMP-2-Freisetzung aus dem Knochen diskutiert, die anschließend innerhalb des osteokonduktiven Knochengerüsts zu einer Osteoinduktion führen kann (Rogers und Greene 2012). Bis dieser Prozess abgeschlossen ist, bleibt diese Region jedoch anfällig für Infektionen und strukturelle Schäden.

Die Entnahmeoperation eines autogenen Transplantats geht mit speziellen Risiken einher. Dazu gehören Wundinfektionen, eine verlängerte Wunddrainage, große Hämatome, starke Schmerzen, Sensibilitätsverlust und Narbenbildung. Neben dem notwendigen Zweiteingriff sind hier weiterhin die begrenzte Menge an Transplantationsmaterial, eine verlängerte Behandlungsdauer und die gesteigerten Behandlungskosten zu nennen. Aus diesen Gründen ist die autogene Knochentransplantation eines der aufwendigsten Verfahren und stellt eine besondere Belastung für die Patienten dar (Younger und Chapman 1989).

\subsubsection{Allogene Transplantation}

Allogene Knochentransplantate werden von einem anderen Individuum der gleichen Spezies gewonnen (Tomford und Mankin 1999). In Deutschland werden allogene Knochentransplantate im Sinne des Gesetzes über den Verkehr mit Arzneimitteln (AMG) als Medikamente angesehen (Pruss et al. 2005). Aufgrund der in der Vergangenheit aufgekommenen übertragbaren Infektionskrankheiten, wie HIV und Hepatitis, hat das Europäische Parlament in Zusammenarbeit mit dem Rat zur 
Festlegung von Qualitäts- und Sicherheitsstandards die Richtlinie 2004/23/EG erarbeitet. Diese legt die Qualitäts- und Sicherheitsstandards für die Spende, die Beschaffung, die Testung, die Verarbeitung, die Konservierung, die Lagerung und die Verteilung von menschlichem Gewebe und Zellen fest (Pruss et al. 2005). In der Mund-, Kiefer- und Gesichtschirurgie spielen allogene Knochentransplantate jedoch kaum eine Rolle, weil in diesem Bereich mit den autogenen Knochentransplantaten oder den alloplastischen Knochenersatzmaterialien genügend Alternativen zur Verfügung stehen (Kärcher 2000).

\subsubsection{Xenogene Transplantation}

Xenogene Transplantate werden von einem Individuum einer anderen Spezies wie z.B. Rindern oder Schweinen gewonnen (Hoexter 2002). Wie auch bei den allogenen Knochenersatzmaterialien besteht das Risiko der immunologischen Abstoßungsreaktion und der Infektion mit Viren- oder Prionenerkrankungen. Aus diesem Grund durchlaufen sie vor der Transplantation spezielle Vorbehandlungsverfahren, um die antigen wirkenden Proteine zu reduzieren bzw. vollständig zu entfernen (Hoexter 2002). Eines der weitest verbreiteten Knochenersatzmaterialien xenogenen Ursprungs, welches in der dentoalveolären Chirurgie häufig verwendet wird, ist Bio-Oss ${ }^{\circledR}$ der Firma Geistlich (Baldini et al. 2011, Cho et al. 2011). Dabei handelt es sich um ein spongiöses Knochenersatzmaterial, das aus denaturiertem Rinderknochen hergestellt und in Granula von 0,25-1mm Größe angeboten wird. Durch eine chemische Vorbehandlung und ein anschließendes Sterilisationsverfahren werden die antigen wirkenden Proteine und die organischen Anteile entfernt. Zurück bleibt ein Gerüst aus Hydroxylapatit, das eine vergleichbare Architektur aufweist wie die des menschlichen Knochens, mit einer hohen Porosität und einer Porengröße von 300-1500 $\mu \mathrm{m}$ (Benke et al. 2001).

\subsubsection{Alloplastische Materialien}

Unter alloplastischen Knochenersatzmaterialien versteht man vollsynthetisch hergestellte Materialien, die in den Organismus des Empfängers eingebracht werden. Weil es sich in diesem Fall um ein synthetisches Material handelt, das nicht von 
einem Individuum in ein anderes transplantiert wird, wird der beschriebene Vorgang demnach nicht mehr als Transplantation, sondern als Implantation bezeichnet (Kärcher 2000). Derartige Materialien haben den Vorteil, dass auf eine Operation zur Transplantatgewinnung mit den oben beschriebenen Risiken verzichtet werden kann. In den letzten Jahrzehnten wurden viele vollsynthetisch hergestellte Knochenersatzmaterialien entwickelt. Hervorzuheben sind vor allem die keramischen Knochenersatzmaterialien, die man nach der Fähigkeit der Resorption weiter unterteilen kann. Unter den geringer bis nicht resorbierbaren Keramiken ist das Hydroxylapatit der häufigste Vertreter. Zu den resorbierbaren Keramiken gehören die Kalziumphosphatkeramiken wie z.B. das Trikalziumphosphat (TCP) und die Siliziumoxidkeramiken, die auch als bioaktive Gläser bezeichnet werden (Sailer und Weber 2000).

\subsection{Trikalziumphosphate}

Trikalziumphosphate gehören zur Untergruppe der Kalziumphosphatkeramiken und werden synthetisch hergestellt. Bei der Herstellung diese Materialien wird versucht, eine hohe Phasenreinheit zu erreichen, wodurch die Resorption verbessert werden kann (Foitzik und Stamm 1997). Ihre Makro- und Mikroporosität erlaubt es dem angrenzenden Knochengewebe, in die Keramik einzuwachsen (Sailer und Weber 2000). Aufgrund ihrer kristallinen Struktur kann man sie in $\alpha$ - und $\beta$-Trikalziumphosphate einteilen (Katthagen 1986). Beide Arten haben ein für sie typisches physiologisch unterschiedliches Verhalten (Foitzik und Staus 1999). Der größte Unterschied liegt in dem Resorptionsverhalten. Während a-TCP sehr langsam resorbiert wird und noch nach vielen Jahren im Gewebe nachweisbar ist, wird $\beta$-TCP schnell resorbiert und im Idealfall durch natürlichen Knochen substituiert (Cameron et al. 1977, Foitzik und Staus 1999, Klein et al. 1984, Scher et al. 1999). Ursprünglich wurden die Trikalziumphosphate als Knochenersatzmaterial in der Zahnheilkunde und der Mund-, Kiefer- und Gesichtschirurgie entwickelt. Inzwischen hat sich das Indikationsspektrum allerdings auch auf die orthopädische Chirurgie ausgedehnt (Galois et al. 2000, Nakagawa et al. 2006, Sailer und Weber 2000). Kalziumphosphatkeramiken wurden in vielen Tierstudien untersucht und 
haben sich als Knochenersatzmaterial bewährt (Galois et al. 2002, Horch et al. 2004, Sagawa et al. 2010, Schuckert und Osadnik 2011).

\subsubsection{Wachstumsfaktoren}

Um die Qualität der Knochenersatzmaterialien weiter zu verbessern, wurden in den letzten Jahren zunehmend biologisch aktive Botenstoffe auf ihre osteoinduktive Wirkung hin untersucht (Reddi et al. 1987, Urist 1965). Besonders bei den bone morphogenetic proteins (BMPs) (Boyne et al. 2005, Urist 1965, Urist et al. 1983, Urist und Strates 1971), den plateletderived growth factors (PDGF) (Boyapati und Wang 2006) und den transforming growth factors $\beta$ (TGF- $\beta$ ) konnte ein osteoinduktiver Charakter nachgewiesen werden. Auch der rekombinante growth and differentiation factor 5 (rhGDF-5) zeigte in mehreren Untersuchungen eine osteoinduktive Wirkung (Gruber et al. 2008, Gruber et al. 2009, Herberg et al. 2008, Kim et al. 2009, Poehling et al. 2006, Weng et al. 2009).

\subsubsection{BMP-2}

Die molekulare Funktion der BMPs wurde zum ersten Mal 1965 von Urist beschrieben. Der Autor entdeckte, dass demineralisierte Knochenstücke nach subkutaner oder intramuskulärer Implantation zu einer Knochenneubildung im umliegenden Gewebe führte (Urist 1965, Urist und Strates 1971). Inzwischen wurden mehr als 30 BMPs identifiziert und charakterisiert (Bramlage et al. 2005). Von den identifizierten BMPs zeigten allerdings nur BMP-2, BMP-4, BMP-7 und BMP-9 eine deutlich osteoinduktive Wirkung (Cheng et al. 2003). Besonders gut wurden die molekularen Mechanismen des BMP-2 untersucht (Boyne et al. 1997, Cochran et al. 2000, Jung RE et al. 2003). Mittlerweile wurde das synthetisch hergestellte Knochenersatzmaterial InFuse $C$, eine Kombination aus rhBMP-2 und ACS, in den USA durch die Food and Drug Administration (FDA) für die Behandlung offener Tibiafrakturen, degenerativer Bandscheibenerkrankungen und die Sinusbodenund lokalisierte Alveolarkammaugmentation zugelassen (U.S. Food and Drug Administration. Zulassungen: P050053, P000054, P000058. Zulassungsdatum: 
09.03.2007, 30.04.2004, 02.07.2002). Boyne untersuchte 1997 an zwölf Patienten eine Kombination aus resorbierbaren Kollagenschwämmen (ACS) und rhBMP-2 als Augmentationsmaterial. Der Wachstumsfaktor lag in einer Konzentration von 3,40 mg pro Patient vor. Nach erfolgreicher Einheilungszeit wertete er die Knochendichte mit Hilfe von CT-Aufnahmen aus und beobachtete eine signifikant verstärkte Knochenneubildung gegenüber der Kontrollgruppe. Nach der Insertion der Implantate untersuchte er die angefallenen Bohrspäne histologisch. Die mit rhBMP-2 behandelten Augmentate wiesen eine hohe Knochenqualität auf (Boyne et al. 1997). Ähnliche Ergebnisse wurden von Cochran beschrieben. Auch er untersuchte die Wirkung von rhBMP-2 in Verbindung mit resorbierbaren Kollagenschwämmen an zwölf Patienten. Nach erfolgreicher Implantation wurde die Qualität der Augmentation durch klinische Untersuchungen und periapikale Röntgenaufnahmen über einen Zeitraum von drei Jahren untersucht. In diesem Zeitraum beschrieb der Autor nur Nebenwirkungen, die als normale Komplikationen einer Implantation bekannt sind. Zu diesen gehören postoperative Schmerzen und Nachblutungen, Entzündungen und Schäden an benachbarten Geweben wie den Zähnen, Nerven, des Kieferknochens und der Kieferhöhle. Im Anschluss daran wurden Stanzbiopsien der entsprechenden Regionen histologisch evaluiert. In allen Proben wurde physiologisch neu gebildetes Knochengewebe beobachtet (Cochran et al. 2000). Jung untersuchte 2003 die Wirkung des rhBMP-2 Proteins in Kombination mit dem xenogenen Augmentationsmaterial Bio-Oss ${ }^{\circledR}$. Er inserierte Implantate bei elf teilweise zahnlosen Patienten an zwei unterschiedlichen Orten des gleichen Kiefers (5 Oberkiefer, 6 Unterkiefer). Die einzelnen Regionen wurden randomisiert entweder als Test- oder als Kontrollregion verwendet. Während die Defekte der Testregionen mit einer Kombination aus Bio-Oss ${ }^{\circledR}$ und rhBMP-2 augmentiert wurden, verwendete er in den Kontrollregionen Bio-Oss ${ }^{\circledR}$ ohne Wachstumsfaktor. Nach erfolgreicher Implantation wurde die Höhe des periimplantären Knochendefekts zwischen Implantatschulter und dem ersten ImplantatKnochen-Kontakt evaluiert. In den Testregionen wurde ein geringerer initialer Knochendefekt gemessen als in den Kontrollregionen. Zusätzlich zeigte sich in den Testregionen eine über die gesamte Beobachtungszeit schnellere Regeneration (Jung RE et al. 2003). 
Neben dem verwendeten Trägermaterial (siehe Abschnitt 1.2.2.3) scheint auch die Dosierung des BMP-2 Einfluss auf dessen Wirkung zu nehmen. In drei klinischen Studien wurden jeweils zwei verschieden starke Konzentrationen miteinander verglichen $(0.75 \mathrm{mg} / \mathrm{ml}$ und $1.5 \mathrm{mg} / \mathrm{ml})$. Diese Dosierungen lagen jedoch deutlich über der physiologisch im Körper vorhandenen Konzentration des BMP-2 (200 ng/ ml) (Urist et al. 1983). Die höhere Dosierung führte zu einer stärkeren Knochenneubildung als die geringere Dosierung (Bianchi et al. 2004, Boyne et al. 2005, Fiorellini et al. 2005). Aus der aktuellen Literatur geht hervor, dass BMP-2 durch seine osteoinduktive Wirkung in der Lage war, die Knochenneubildung zu verstärken.

\subsubsection{GDF-5}

1994 wurde in der Literatur erstmals über das Knochenmatrixprotein GDF-5 berichtet. Strukturell ist es den bone morphogenetic proteins (BMPs) sehr ähnlich und gehört zu der Familie des transforming growth factor beta (TGF- $\beta$ ). 1994 isolierte Storm das Protein in Kombination mit GDF-6 und GDF-7. Die Arbeitsgruppe zeigte, dass ein GDF-5-Mangel bei den untersuchten Mäusen zu Brachypodismus führte (Storm et al. 1994). Im gleichen Jahr isolierten Chang et al. GDF-5 und GDF-6 aus Knorpelgewebe neugeborener Kälber und bezeichneten die Proteine aufgrund derer knorpelinduzierender Wirkung als cartilage derived morphogenetic proteins 1 und 2 (CDMP-1 und -2). Der Autor wies darauf hin, dass beide Proteine eine entscheidene Rolle während des Wachstums der langen Röhrenknochen spielen könnten (Chang et al. 1994). Buxton zeigte 2001 in seiner Untersuchung, dass GDF-5 die Rekrutierung mesenchymaler Stammzellen fördert und skelettale Prozesse wie z.B. die enchondrale Ossifikation, die Neubildung von Bändern und Gelenken und die Zahnentwicklung mit beeinflussen kann (Buxton et al. 2001). Everman erkannte 2002, dass Patienten mit Brachydaktylie vom Typ C heterozygote Träger einer Mutation des GDF-5-Gens waren, das sich auf dem menschlichen Chromosom 20 befindet (Everman et al. 2002). Sowohl Hurley als auch Clayton beschrieben eine neurotrophe und protektive Wirkung des GDF-5-Faktors auf dopaminerge Neurone. Dadurch könnte der Wachstumsfaktor in Zukunft für 
die Therapie der Parkinson-Krankheit von großem Interesse sein (Clayton und Sullivan 2007, Hurley et al. 2004). Aktuell wird das GDF-5-Protein jedoch in der Regeneration des Knochens, des Knorpelskeletts sowie der Gelenkoberflächen verwendet. In diesem Zusammenhang wurde in mehreren Studien eine rekombinant hergestellte Form (rhGDF-5) für die Therapie parodontaler Defekte in der Zahnheilkunde untersucht. Herberg et al. (2008) und Kim et al. (2009) zeigten, dass rhGDF-5 zu einer verstärkten Regeneration parodontaler Defekte führte und für die Therapie eingesetzt werden könnte (Herberg et al. 2008, Kim et al. 2009). Auch in anderen Teilgebieten der Zahnheilkunde und der Mund-, Kiefer- und Gesichtschirurgie ist die Anwendung von GDF-5 von großem Interesse. Weng untersuchte 2009 eine Kombination aus $\beta$-Trikalziumphosphat ( $\beta$-TCP) und rhGDF-5 bei der Behandlung periimplantärer ossärer Läsionen und kam zu dem Schluss, dass die Materialkombination zu einer verstärkten Knochenneubildung führt und deshalb in die Therapie integriert werden könnte (Weng et al. 2009). Vergleichbare Ergebnisse wurden von Poehling im Jahr 2006 beschrieben. Die Autorin präparierte knöcherne Defekte in die Schädelkalotte von Ratten und verglich verschiedene Knochenersatzmaterialien. Bei der Testgruppe verwendete sie eine Kombination aus $\beta$-TCP und rhGDF-5 und beobachtete eine fünf mal stärkere Knochenneubildung als bei den unbeschichteten Knochenersatzmaterialien (Poehling et al. 2006).

\subsubsection{Trägermaterial}

Bei der Verwendung von Wachstumsfaktoren scheint das Trägermaterial eine entscheidene Rolle zu spielen (Schliephake 2010, Sigurdsson et al. 1996, Wikesjo et al. 1998).

Ideale Trägermaterialien sollten in der anatomisch gewünschten Form definierbar sein, eine ausreichende mechanische Festigkeit besitzen, während der knöchernen Regeneration in dem gleichen Maße resorbiert werden und die kontrollierte Freisetzung der aktiven osteoinduktiven Wachstumsfaktoren gewährleisten. Als Trägermaterialien für Wachstumsfaktoren haben sich anorganischer boviner Knochen (Bio-Oss $\left.{ }^{\circledR}\right)$, synthetische poröse Hydroxylapatitkeramiken, demineralisierte 
allogene Knochenmatrices, degradierbare Polymere, synthetisches betaTrikalziumphosphat ( $\beta$-TCP) sowie resorbierbare Kollagenschwämme (ACS) bewährt (Schliephake 2010).

Diese Materialien lassen sich in anorganische und organische Trägermaterialien unterteilen. Anorganische Trägermaterialien werden wiederum in Metalle und mineralisierte, synthetische oder natürliche Trägermaterialien eingeteilt. Mineralische Materialien wie die synthetische Hydroxylapatitkeramik oder Bio-Oss $\subset$ werden als Carrier für osteoinduktive Faktoren eingesetzt (Furst et al. 2003, Jung RE et al. 2003). Metalle sind aufgrund der fehlenden Resorbierbarkeit als Carrier eher nicht geeignet. Wie die anorganischen Träger können auch die organischen Träger natürlichen oder synthetischen Ursprungs sein. $\mathrm{Zu}$ den organischen Trägern natürlichen Ursprungs zählt beispielsweise Kollagen. Kollagen wird als Knochenersatzmaterial häufig verwendet, weist jedoch wegen seiner mechanischen Instabilität ein eingeschränktes Indikationsspektrum auf. Demgegenüber können synthetische organische Polymere der a-Hydroxykarbonsäuren wie das Polylaktid (PLA) oder Polyglykolid als Trägermaterialien auch bei der Rekonstruktion größerer ossärer Defekte verwendet werden, weil sie eine ausreichende mechanische Stabilität besitzen. Obwohl Kollagen eines der am besten untersuchten Trägermaterialien für BMP-2 ist, weisen verschiedene Studien auf eine mangelhafte Knochenneubildung bei alleiniger Verwendung einer Kombination aus Kollagen und BMP-2 als Augmentationsmaterial hin (Barboza et al. 2000, Howell et al. 1997). Eine stärkere Wirkung wurde hingegen beobachtet, wenn neben der Kombination aus Kollagen und BMP-2 noch autogenes Knochengewebe augmentiert wurde (Arosarena und Collins 2005, Miranda et al. 2005).

\subsubsection{Sinusbodenaugmentation}

Besonders im Oberkiefer besteht das Problem, dass eine regelrechte Insertion dentaler Implantate durch den stark reduzierten Kieferknochen in vielen Fällen nicht mehr möglich ist (Atwood 1971). Nach dem Zahnverlust kommt es zu einem Kollaps der Alveole und in Folge dessen zu einer Minderung des Knochenvolumens (Cawood und Howell 1988). Neben den beschriebenen Abbauvorgängen 
können auch Tumore, Traumata oder Anomalien und Syndrome zu einem lokalen Knochendefizit führen (Cawood und Howell 1988, Ekert et al. 1999). Aus diesem Grund wurden in den letzten 30 Jahren diverse chirurgische Operationstechniken entwickelt, mit denen der Oberkieferknochen für die Insertion eines Implantates vorbereitet werden kann. In diesem Zusammenhang unterscheidet man einzeitige Techniken, bei denen Augmentation und Implantation innerhalb einer Operation durchgeführt wird, von den zweizeitigen Techniken, bei denen die Augmentation und die Implantation zeitlich voneinander getrennt werden. 1980 wurde die „laterale Window-Technik“ zum ersten Mal von Boyne beschrieben. Nach der Präparation eines Knochenfensters in die laterale Kieferhöhlenwand unter Erhaltung der Kieferhöhlenschleimhaut und Präparation der Kieferhöhlenschleimhaut nach kranial wurde der entstandene Hohlraum mit Beckenkammknochen aufgefüllt. Die Implantate wurden nach einer Einheilungszeit von über sechs Monaten inseriert (Boyne und James 1980). Auch Tatum beschrieb 1986 die Sinusbodenaugmentation und die Implantation als einzeitiges oder zweizeitiges Verfahren (Tatum 1986). Heutzutage hat sich die "laterale Window-Technik" weit verbreitet und hat sich vor allem bei der autogenen Knochentransplantation etabliert (Del Fabbro et al. 2004, Wallace und Froum 2003). Summers beschrieb eine weniger invasive Methode. Durch die Verwendung von Osteotomen zunehmenden Durchmessers konnte er die während der Bohrung anfallenden Knochenspäne nach subantral vorschieben und so das Knochenniveau erhöhen (Summers 1994, Summers 1995).

\subsubsection{Histomorphometrie}

Lange Zeit war eine histologische Untersuchung von Knochengewebe wegen dessen Härte nur schwer möglich. Es konnten nur uneingebettete Präparate beurteilt werden oder das verwendete Gewebe mußte für die Einbettung demineralisiert werden. Durch die Demineralisation gingen jedoch wichtige Informationen über das Hartgewebe verloren (Linder et al. 1981). Nach der Entwicklung spezieller Epoxidharze zur Einbettung des Knochengewebes stellten Donath und Breuner im Jahre 1982 die Trenn-Dünnschlifftechnik vor (Donath und Breuner 1982). Dieses Verfahren hat sich inzwischen als Standardverfahren zur histologischen Unter- 
suchung von Knochengewebe etabliert.

Unter dem Begriff Histomorphometrie versteht man die quantitative Darstellung der Morphologie histologischer Strukturen in Teilbereichen eines Gewebes (Nafe und Schlote 2004). Unterschieden werden können statische und dynamische Verfahren. Zu den statischen Verfahren zählen die Identifikation von Zell- und Gewebekomponenten, die Vermessung von Längen und Flächen sowie die Bestimmung der Zellanzahl (Simunek et al. 2005). Bei der dynamischen Histomorphometrie werden metabolische Vorgänge innerhalb des Knochengewebes mit Hilfe bestimmter Fluorochrome wie z.B. Tetrazyklinen sichtbar gemacht und können so evaluiert werden (Simunek et al. 2005).

Neben der manuell durchgeführten Knochenhistomorphometrie, bei der das Gewebe vom Untersucher manuell markiert und ausgewertet wird, wurden in den letzten Jahren semi- und vollautomatische Bildanalysesysteme entwickelt, mit denen es in Kombination stereologischer Verfahren möglich ist, eine verbesserte räumliche Auswertung durchzuführen (Parfitt 1983). Die Knochenneubildung innerhalb des Sinusbodenaugmentats wurde inzwischen in vielen Studien mit Hilfe der Knochenhistomorphometrie untersucht (Busenlechner et al. 2009, Fuerst et al. 2004, Furst et al. 2003, Norton et al. 2003, Somanathan und Simunek 2006). 


\subsection{Zielsetzung}

Bis heute wurde keine Studie vorgestellt, in der der Gradient der Knochenneubildung innerhalb des gesamten Sinusbodenaugmentats unter der Wirkung eines osteoinduktiven Wachstumsfaktors evaluiert wurde. Es kann jedoch erwartet werden, dass der Einfluss eines derartigen Faktors zu einer stärkeren und homogeneren Knochenneubildung innerhalb des Augmentats führt.

Das Ziel der vorliegenden Untersuchung bestand darin, die Hypothese zu prüfen, inwieweit eine Materialkombination aus dem Knochenersatzmaterial $\beta$-TCP und dem Wachstumsfaktor GDF-5 zu einer stärkeren und homogeneren Knochenneubildung innerhalb des Sinusbodenaugmentats führt.

\section{Hypothesen}

- Der Wachstumsfaktor GDF-5 führt bei der Testgruppe zu einer stärkeren Knochenneubildung im Vergleich zu der Kontrollgruppe, bei der kein Wachstumsfaktor verwendet wird.

- GDF-5 führt zu einer homogeneren Knochenneubildung innerhalb des Knochenersatzmaterials. 


\section{Material und Methoden}

\subsection{Versuchstiere}

Die Untersuchungen wurden auf Basis des deutschen Tierschutzgesetzes durchgeführt und von der Bezirksregierung Braunschweig als Tierversuchsvorhaben unter der Nr. 509.42502/01-A-13.01 am 7.12.2001 genehmigt. Die Studie wurde an zwölf weiblichen Göttinger Minipigs (Ellegard Göttingen Minipigs ApS, Dalmose, Denmark) durchgeführt. Alle Tiere waren zwischen 1,75 und 5 Jahren alt und wogen zwischen 30,8 und $50 \mathrm{~kg}$. Als Nahrung wurde eine kommerziell erhältliche Schweinediät (Hemo, Scheden, Deutschland) und unkontaminiertes Trinkwasser ad libitum herangezogen. Durch eine Markierung im Ohr jedes Schweines konnten die Tiere identifiziert werden. Nach Ablauf einer einwöchigen Eingewöhnungszeit wurden die Operationen durchgeführt.

\subsubsection{Einteilung der Versuchstiere}

Die Tiere wurden randomisiert in zwei Hauptgruppen aufgeteilt, die aus jeweils sechs Schweinen bestanden (Gruppe A = 4 Wochen/Gruppe B = 12 Wochen). In jeder der beiden Hauptgruppen wurden drei Tiere randomisiert zu einer Untergruppe für die niedrige Dosierung $\left(400 \mu \mathrm{g}\right.$ rhGDF-5/1g $\left.\beta-\mathrm{TCP}=\mathrm{A} / \mathrm{B}_{\mathrm{n}}\right)$ und drei Tiere für die höhere Dosierung zugeteilt $\left(800 \mu g\right.$ rhGDF-5/1g $\left.\beta-T C P=A / B_{h}\right)$. Insgesamt ergaben sich vier Testgruppen $\left(A_{n}, A_{h}, B_{n}, B_{h}\right)$. Bei jedem Schwein wurde eine beidseitige Sinusbodenaugmentation in einem „split mouth design“ durchgeführt. Auf der randomisiert zugewiesenen Testseite wurde eine Kombination aus $\beta$ TCP und den zwei verschiedenen Konzentrationen des Wachstumsfaktors rhGDF5 als Augmentationsmaterial verwendet $(400 \mu \mathrm{g}$ und $800 \mu \mathrm{g}$ rhGDF-5/1g $\beta$-TCP). Auf der Kontrollseite wurde unbehandeltes $\beta$-TCP als Augmentationsmaterial eingebracht. Bei allen Tieren erfolgte die Zuteilung der Test- und Kontrollseite randomisiert. 


\subsubsection{Gruppe A}

Bei Gruppe A betrug die Einheilungszeit vier Wochen. Anschließend wurden die Präparate hergestellt.

\subsection{Gruppe $A_{n}$}

Die Augmentation wurde mit $\beta$-TCP in Kombination mit dem Faktor rhGDF-5 in einer Konzentration von $400 \mu \mathrm{g} / 1 \mathrm{~g} \beta$-TCP durchgeführt. Auf der Kontrollseite wurde unbeschichtetes $\beta$-TCP in gleicher Menge verwendet (3g).

\subsection{Gruppe $A_{h}$}

Die Augmentation wurde mit $\beta$-TCP in Kombination mit dem Faktor rhGDF-5 in einer Konzentration von $800 \mu \mathrm{g} / \mathrm{g}$ $\beta$-TCP durchgeführt. Auf der Kontrollseite wurde unbeschichtetes $\beta$-TCP in gleicher Menge verwendet $(3 g)$.

\begin{tabular}{|c|c|c|c|}
\hline $\mathbf{P}$ & OP-Gewicht in kg & linke Kieferhöhle & rechte Kieferhöhle \\
\hline 1 & 38 & Kontrolle & $400 \mu \mathrm{g}$ \\
\hline 2 & 41 & Kontrolle & $800 \mu \mathrm{g}$ \\
\hline 3 & 33 & $400 \mu \mathrm{g}$ & Kontrolle \\
\hline 4 & 36 & $800 \mu \mathrm{g}$ & Kontrolle \\
\hline 5 & 35 & Kontrolle & $800 \mu \mathrm{g}$ \\
\hline 6 & 31 & Kontrolle & $400 \mu \mathrm{g}$ \\
\hline
\end{tabular}

Tab. 2.1: Materialverteilung für Gruppe $A$

Kontrolle: $3 g$ $\beta$-TCP

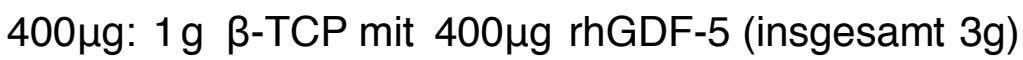

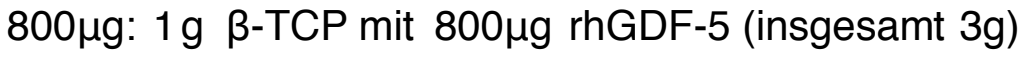

\subsubsection{Gruppe B}

Bei Gruppe B betrug die Einheilungszeit zwölf Wochen. Anschließend wurden die Präparate hergestellt.

\subsection{Gruppe $B_{n}$}

Die Augmentation wurde mit $\beta$-TCP in Kombination mit dem Faktor rhGDF-5 in ei- 
ner Konzentration von $400 \mu \mathrm{g} / 1 \mathrm{~g} \beta$-TCP durchgeführt. Auf der Kontrollseite wurde unbeschichtetes $\beta$-TCP in gleicher Menge verwendet (3g).

\subsection{Gruppe $B_{h}$}

Die Augmentation wurde mit $\beta$-TCP in Kombination mit dem Faktor rhGDF-5 in einer Konzentration von $800 \mu \mathrm{g} / 1 \mathrm{~g} \beta$-TCP durchgeführt. Auf der Kontrollseite wurde unbeschichtetes $\beta$-TCP in gleicher Menge verwendet $(3 g)$.

\begin{tabular}{|c|c|c|c|}
\hline $\mathbf{P}$ & OP-Gewicht in kg & linke Kieferhöhle & rechte Kieferhöhle \\
\hline 7 & 47 & $800 \mu \mathrm{g}$ & Kontrolle \\
\hline 8 & 37 & Kontrolle & $800 \mu \mathrm{g}$ \\
\hline 9 & 49 & Kontrolle & $400 \mu \mathrm{g}$ \\
\hline 10 & 41 & $400 \mu \mathrm{g}$ & Kontrolle \\
\hline 11 & 50 & $800 \mu \mathrm{g}$ & Kontrolle \\
\hline 12 & 48 & $400 \mu \mathrm{g}$ & Kontrolle \\
\hline
\end{tabular}

Tab. 2.2: Materialverteilung für Gruppe $B$

Kontrolle: $3 g$-TCP

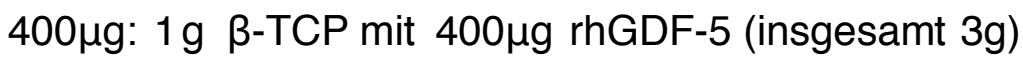

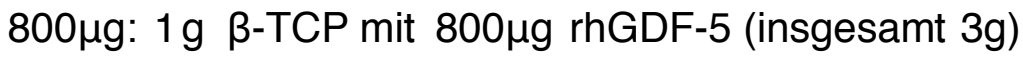

\subsection{Augmentationsmaterialien}

\subsection{1 $\beta$-Trikalziumphosphat}

Das bei den Augmentationen verwendete $\beta$-TCP (Calciresorb®), Ceraver, Frankreich) hatte eine Partikelgröße von $500-1000 \mu \mathrm{m}$ bei einer Phasenreinheit von $>95 \%$. Der Porendurchmesser betrug durchschnittliche 2,12 $\mu \mathrm{m}$ und die Gesamtfläche der Poren lag bei 0,647 m²/g. Die Makroporengröße betrug zwischen 100 und $400 \mu \mathrm{m}$. Das beschriebene $\beta$-TCP wurde für alle durchgeführten Operationen sowohl als Trägermaterial für den Wachstumsfaktor als auch als Knochenersatz- 
material ohne Beschichtung mit rhGDF-5 verwendet.

\subsection{2 rhGDF-5}

In der vorliegenden Studie wurde der synthetisch hergestellte humane Wachstumsfaktor rhGDF-5 für die Untersuchungen verwendet (http://www.sciltechnology.com/applications/dental-bone-substitute-materials-in-de ntal-implantology.html). Zwei verschiedene Konzentrationen wurden appliziert

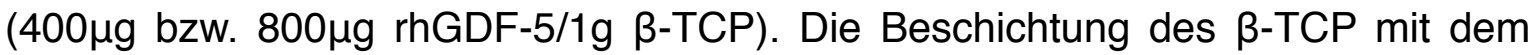
Wachstumsfaktor wurde durch die Scil Technology GmbH (Scil, Martinsried, Germany) durchgeführt. Während des Adsorptionsvorgangs wurde der Wachstumsfaktor zur Stabilisierung mit einer säuregepufferten Lösung verdünnt. Der Adsorptionsvorgang wurde unter aseptischen Bedingungen durchgeführt.

\subsection{Medikation}

Alle Operationen fanden in Intubationsnarkose statt. Die Einleitung wurde durch die intravenöse Gabe von $7 \mathrm{mg} / \mathrm{kgKG}$ Thiopental-Natrium (Trapanal®, Fa. BykGulden) in Verbindung mit einem Sauerstoff-Halothan-Gemisch (4 Vol.\% Halothan) herbeigeführt. Über einen zentralen Venenkatheter (Cavafix®, Braun, Melsungen) in der Vena auricularis caudalis wurde Atropin (0,3 $\mathrm{mg} / \mathrm{kgKG})$ appliziert. Die Schweine wurden intratracheal intubiert (Oral Tubus, Portex). Zur Schmerztherapie wurde Ketamin (WDT, Garbsen; 2,5 mg/kgKG pro Stunde) in Kombination mit Piritramid Dipidolor® (Janssen, Neuss; $110 \mu \mathrm{g} / \mathrm{kgKG}$ pro Stunde) intravenös verabreicht. Zur Aufrechterhaltung der Narkose wurde eine Kombination von ca. 0,6 Vol.\% Halothan mit einem Lachgas-Sauerstoffgemisch im Verhältnis 3:1 benutzt. Zur postoperativen Schmerztherapie wurde den Schweinen Temgesic ${ }^{\circledR}$ (Essex, 0,3 mg/d) subkutan injiziert. Die Tiere wurden bis zum dritten postoperativen Tag mit einer Penicillin-Streptomycin Kombination (Animedic ${ }^{\circledR}$, 40mg Penicillin/60mg Streptomycin/kgKG pro d) antibiotisch behandelt. 


\subsection{Operationsablauf}

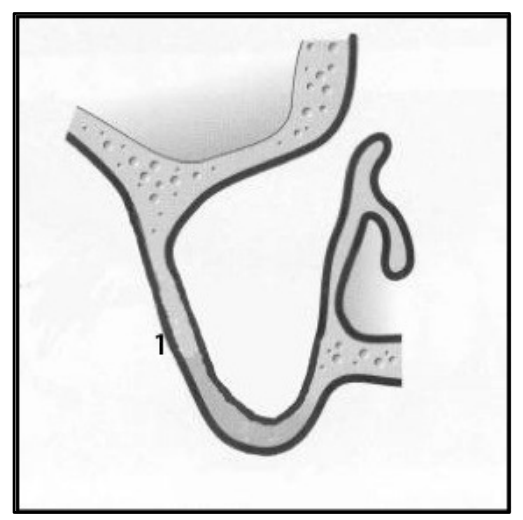

Abb. 2.1: Kieferhöhle; Laterale Kieferhöhlenwand(1)

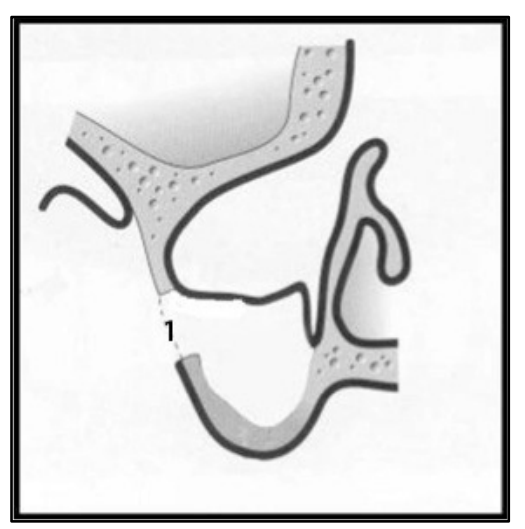

Abb. 2.2:

Eröffnete Kieferhöhle; Knochenfenster(1)

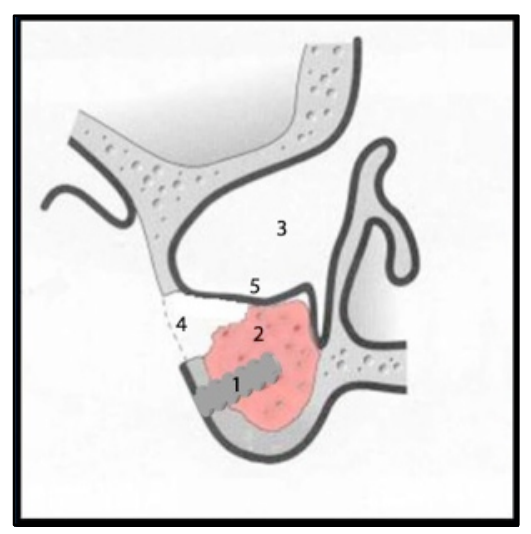

Abb. 2.3: Augmentierte Kieferhöhle;Implantat(1);Augmentat(2); Kieferhöhle(3);Knochenfenster(4); Kieferhöhlenschleimhaut(5)
Nach einer extraoralen Inzision unterhalb des Unterlids wurde die faziale Kieferhöhlenwand dargestellt. Zunächst wurde die laterale Kieferhöhlenwand mit einem rotierenden Rosenbohrer und einer diamantierten Kugelfräse unter Schonung der Kieferhöhlenschleimhaut entfernt. Danach wurde die Schleimhaut von der lateralen Wand und dem Boden vorsichtig abpräpariert. Der kompakte Knochen der ventrolateralen Sinuswand wurde mit Hilfe einer Fräse auf eine Stärke von $5 \mathrm{~mm}$ reduziert und das Implantat (TPS-ITIß-Schraubenimplantat, Straumann, Durchmesser 3,3 mm, Länge 12 $\mathrm{mm}$ ) mit Primärstabilität von lateral inseriert. Der Hohlraum um das Implantat herum wurde durch das jeweilige Augmentationsmaterial aufgefüllt. Das Knochenfenster wurde mit einer titanverstärkten Polytetrafluoroethylenmembran (trGTAM®, W.L. Gore \& Associates, Flagstaff, USA) abgedeckt, um einen ungewollten Austritt des Augmentationsmaterials zu verhindern. Die Wunde wurde mit einem resorbierbaren Nahtmaterial verschlossen (Vicryl R, 2-0 Ethiconß). 


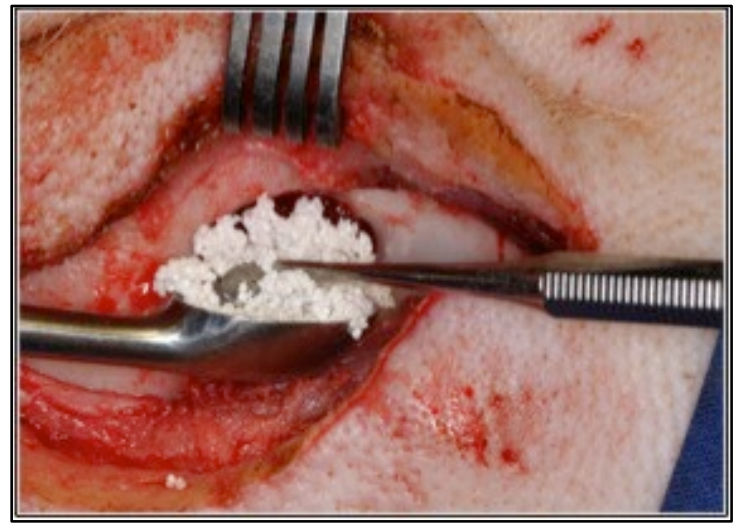

Abb. 2.4: Operationssitus mit Knochenersatzmaterial

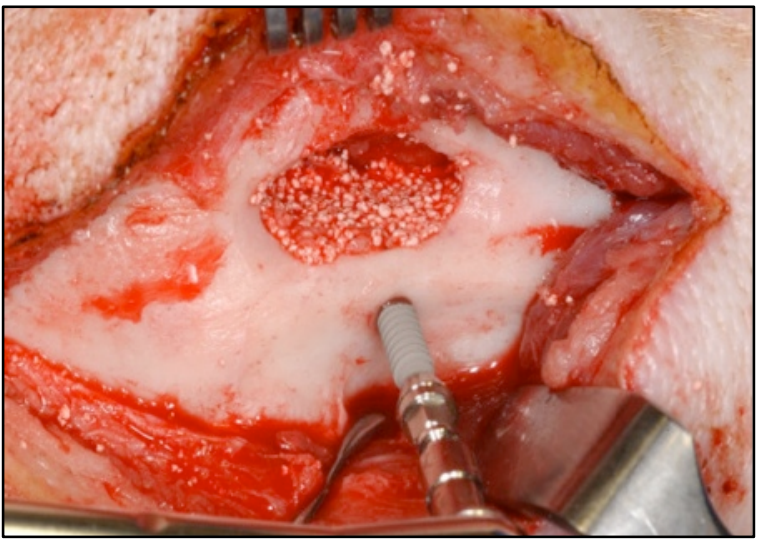

Abb. 2.5: Operationssitus mit augmentierter Kieferhöhle vor Implantation

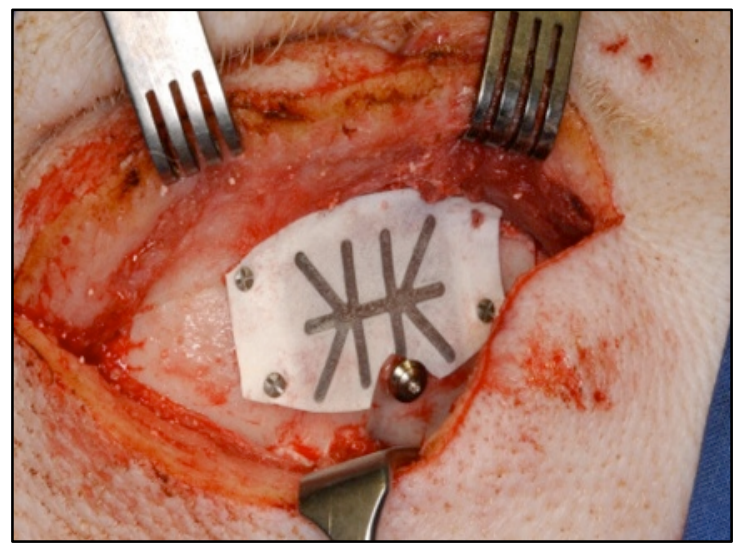

Abb. 2.6: Operationssitus mit Membranabdeckung 


\subsubsection{Euthanasie der Tiere}

Nach Ablauf der entsprechenden Einheilungszeiträume wurden die Versuchstiere erneut in Allgemeinnarkose versetzt. Durch die intravenöse Injektion von 15-prozentigem Kaliumchlorid (Merck, 40 nm i.v.) wurde die Euthanasie der Schweine herbeigeführt. Im Anschluss daran wurden die Schliffpräparate der Kieferhöhlen für die histomorphometrische Evaluation hergestellt.

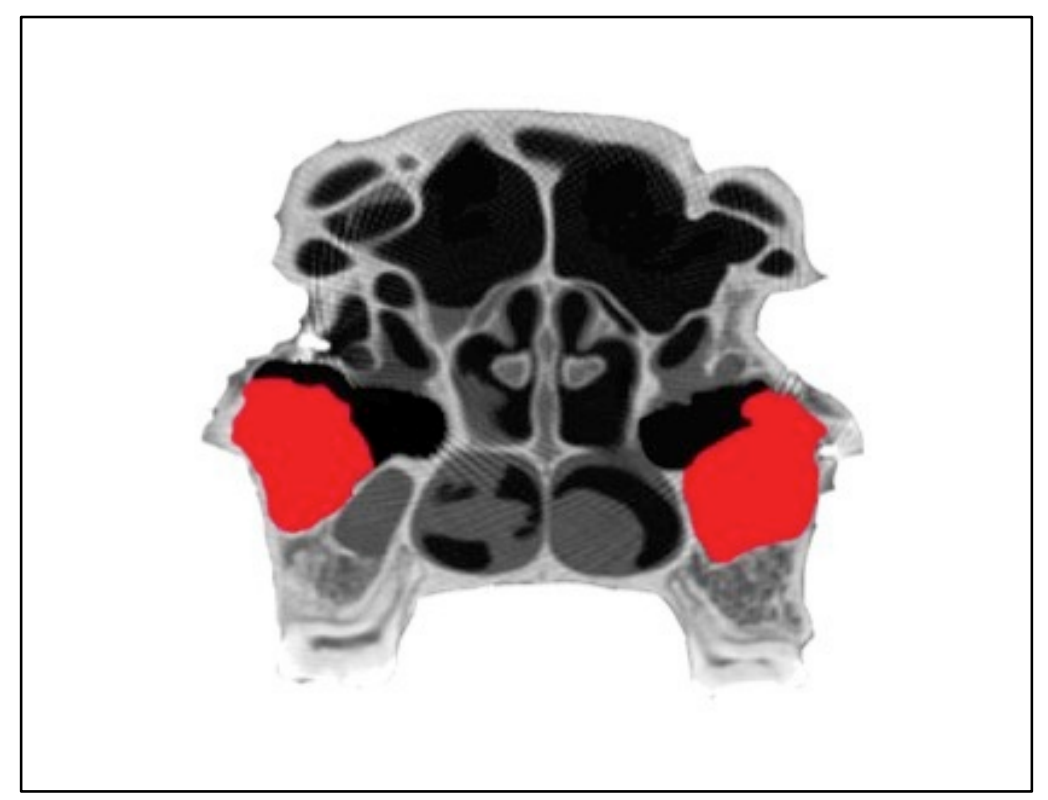

Abb. 2.7: Schädel-CT mit rot markiertem Augmentat

\subsection{Herstellung der Schliffpräparate}

Die histologischen Schliffpräparate wurden nach der von Donath und Breuner im Jahr 1982 vorgestellten Trenn-Dünnschlifftechnik hergestellt (Donath und Breuner 1982). Die Gewebeblöcke wurden zuerst in 10-prozentigem, neutralen, phosphatgepufferten Formalin fixiert und anschließend mit Hilfe aufsteigender Alkoholreihen dehydriert. Unter Vakuumumgebung wurden die Präparate mit dem Komposit Methacrylat (LR-White ${ }^{\circledR}$ Hard-Grade, Science Service, München) infiltriert und zuerst bei $30^{\circ} \mathrm{C}$ für acht Stunden, dann bei $50^{\circ} \mathrm{C}$ für zwölf Stunden und abschließend bei $60^{\circ} \mathrm{C}$ für vier Stunden polymerisiert. Danach wurden die Gewebeblöcke paral- 
lel zur Längsachse des inserierten Implantats mit Hilfe des Exact Sectioning System (Fa. Mesmer, Ost-Einbeck, Deutschland) in der Frontalebene von anterior nach posterior auf eine Stärke von $200 \mu \mathrm{m}$ geschnitten und anschließend auf eine Stärke von 20-30 $\mu \mathrm{m}$ geschliffen und poliert. Als letzter Schritt folgte die histologische Färbung.

\subsubsection{Histologische Färbung}

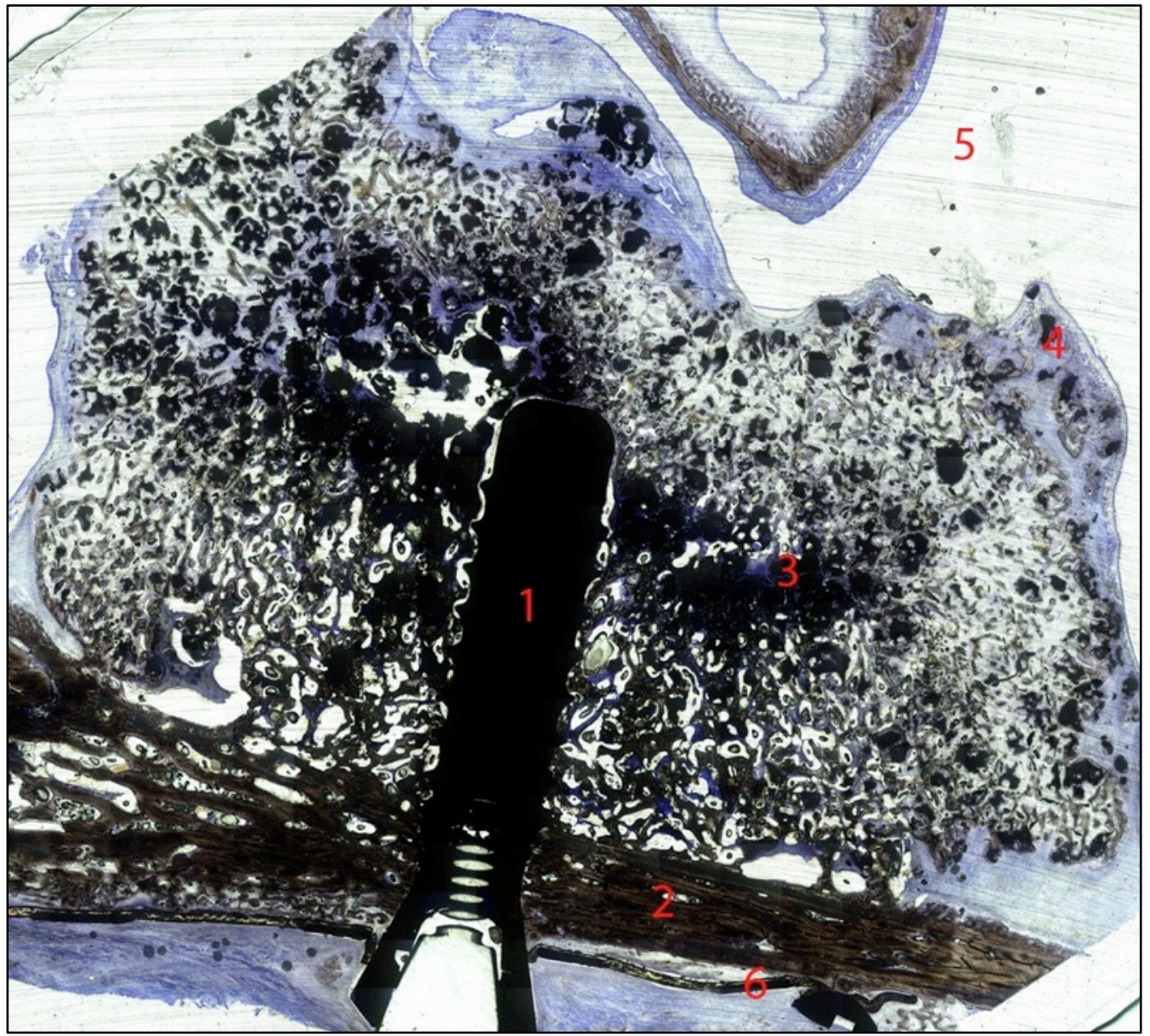

Abb. 2.8: Histologisch gefärbtes Trenn-Dünnschliffpräparat;Implantat(1);

Kieferknochen(2);Augmentat(3);Kieferhöhlenschleimhaut(4);Kieferhöhle(5);Titanverstärkte Polytetrafluoroethylenmembran(6);Original-Vergrößerung $x 5$

Als Farbstoff für die histologische Färbung diente ein Gemisch aus Toluidin-Blau und Pyronin G. Zunächst wurden zwei Stammlösungen angesetzt. Die erste Lösung setzte sich aus einprozentigem Toluidin-Blau in einprozentiger Boraxlösung zusammen. Die zweite Lösung bestand aus einprozentigem Pyronin G in Aqua destillata. Beide Ansätze wurden vor der Anwendung in einem Verhältnis von 4:1 
gemischt. Nach durchgeführter Färbung wurden die Schnitte in Aqua dest. gespült, kurzzeitig mit Ethanol behandelt und anschließend getrocknet.

\subsubsection{Präparatauswahl}

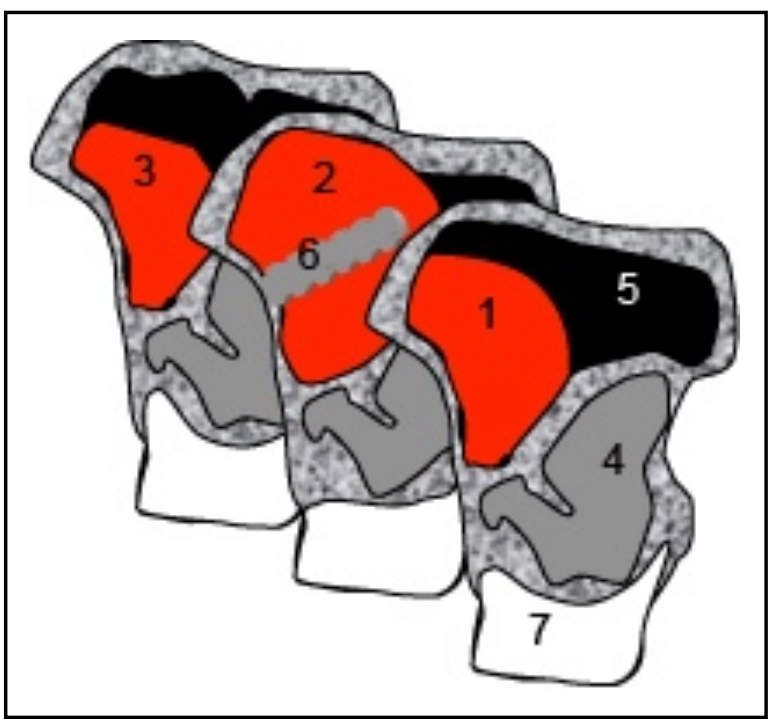

Abb. 2.9: Präparatauswahl; Anteriore Ebene(1); Zentrale Ebene(2); Posteriore Ebene(3); Kieferknochen(4); Kieferhöhle(5); Implantat(6);Zahn(7)
In den meisten in der Literatur beschriebenen Untersuchungen wurde ausschließlich der direkte KnochenImplantat-Kontakt (BIC) histologisch evaluiert. Ein Ziel der vorliegenden Arbeit war es, die histomorphometrische Knochenevaluation auf das gesamte Augmentat auszudehnen. $\mathrm{Zu}$ diesem Zweck wurden jeweils drei Präparate pro Kieferhöhle angefertigt, wodurch der Gradient der Knochenneubildung innerhalb des gesamten Augmentats berücksichtigt werden konnte. Das angeschnittene Implantat diente als Orientierungspunkt. Eine Schnittebene wurde zentral durch das inserierte Implantat geführt, die beiden anderen Ebenen lagen in einem Abstand von ca. 7-10 mm vor bzw. hinter dieser zentralen Ebene entfernt.

\subsubsection{Digitalisierung}

Die Digitalisierung der histologischen Schnitte wurde mit Hilfe eines vollautomatisierten Mikroskops der Firma Carl Zeiss (Axiovert 200M) und einer mit dem Mikroskop verbundenen Digitalkamera (Axiocam) realisiert (Zeiss, Oberkochen, Deutschland). Alle Präparate wurden mit einer fünffachen Vergrößerung aufgenommen. Weil das Abspeichern als Einzelbild aufgrund der erheblichen Bildgröße nicht möglich war, wurde das Gesamtpräparat in bis zu 350 kleinere Teilbereichs- 
bilder aufgeteilt. Diese Teilbilder wurden später mit der Software „Autopano giga” (Kolor, Challes- les-Eaux, Frankreich) wieder zu einem komprimierten Gesamtbild der Kieferhöhle zusammengefügt.

\subsubsection{Gradient der Knochenneubildung}

Ziel der vorliegenden Studie war es, die Knochenneubildung des gesamten Sinusbodenaugmentats unter der Wirkung eines osteoinduktiven Wachstumsfaktors zu evaluieren. Dazu wurden innerhalb der entsprechenden Ebene „regions of interest“" (ROls) definiert. Je nach Höhe des Augmentats wurden zwischen drei und fünf ROIs evaluiert:

- ROI 1: Basal am ortsständigen Kieferknochen

- ROI 2: Übergang zwischen basalem und zentralem Bereich (hohe Präparate)

- ROI 3: Zentraler Bereich

- ROI 4: Übergang zwischen zentralem und kranialem Bereich (hohe Präparate)

- ROI 5: Kranial unter der Kieferhöhlenschleimhaut

Mit Hilfe eines Vektorgrafikprogramms (Adobe Illustrator) wurde eine Säule aus fünf gleich großen übereinanderstehenden Quadraten konstruiert, bei denen die Kantenlänge $3 \mathrm{~mm}$ betrug. Diese Säule wurde bei allen Präparaten an der maximalen Augmentathöhe in der Achse der Implantate positioniert. In den Präparaten der zentralen Schnittebene, bei denen das Implantat angeschnitten war, wurde die Säule aus Gründen der gleichen Bearbeitung aller Bilder in einem Abstand von ca 3,5 mm neben dem Implantat platziert. Das unterste Quadrat (ROI 1) wurde an der Grenze zwischen nativem Kieferknochen und beginnendem Augmentationsmaterial ausgerichtet. Um die Knochenneubildung innerhalb der einzelnen Regionen unabhängig voneinander evaluieren zu können, wurden die von den Quadraten eingeschlossenen Bildinformationen als Einzelbilder abgespeichert. Bei 19 der 72 Schliffpräparate waren die Augmentate nur wenige Millimeter hoch. Damit auch bei diesen Präparaten der Gradient der Knochenneubildung evaluiert werden konnte, wurden nur die drei oben beschriebenen ROIs 1, 3 und 5 untersucht. Die Höhe der 
ROIs wurde dabei bei gleichem Flächeninhalt der Augmentathöhe angepasst.

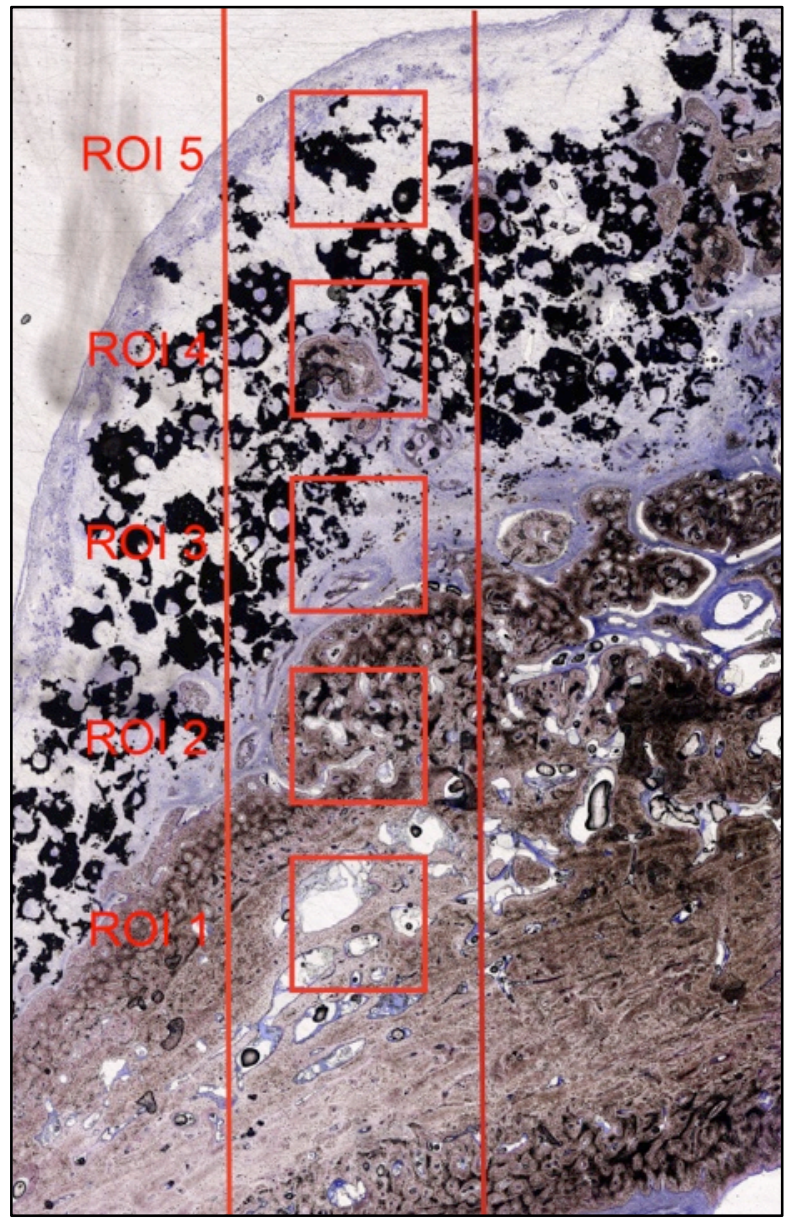

Abb. 2.10: Gradient der Knochenneubildung (5 ROIs); Original-Vergrößerung x5 


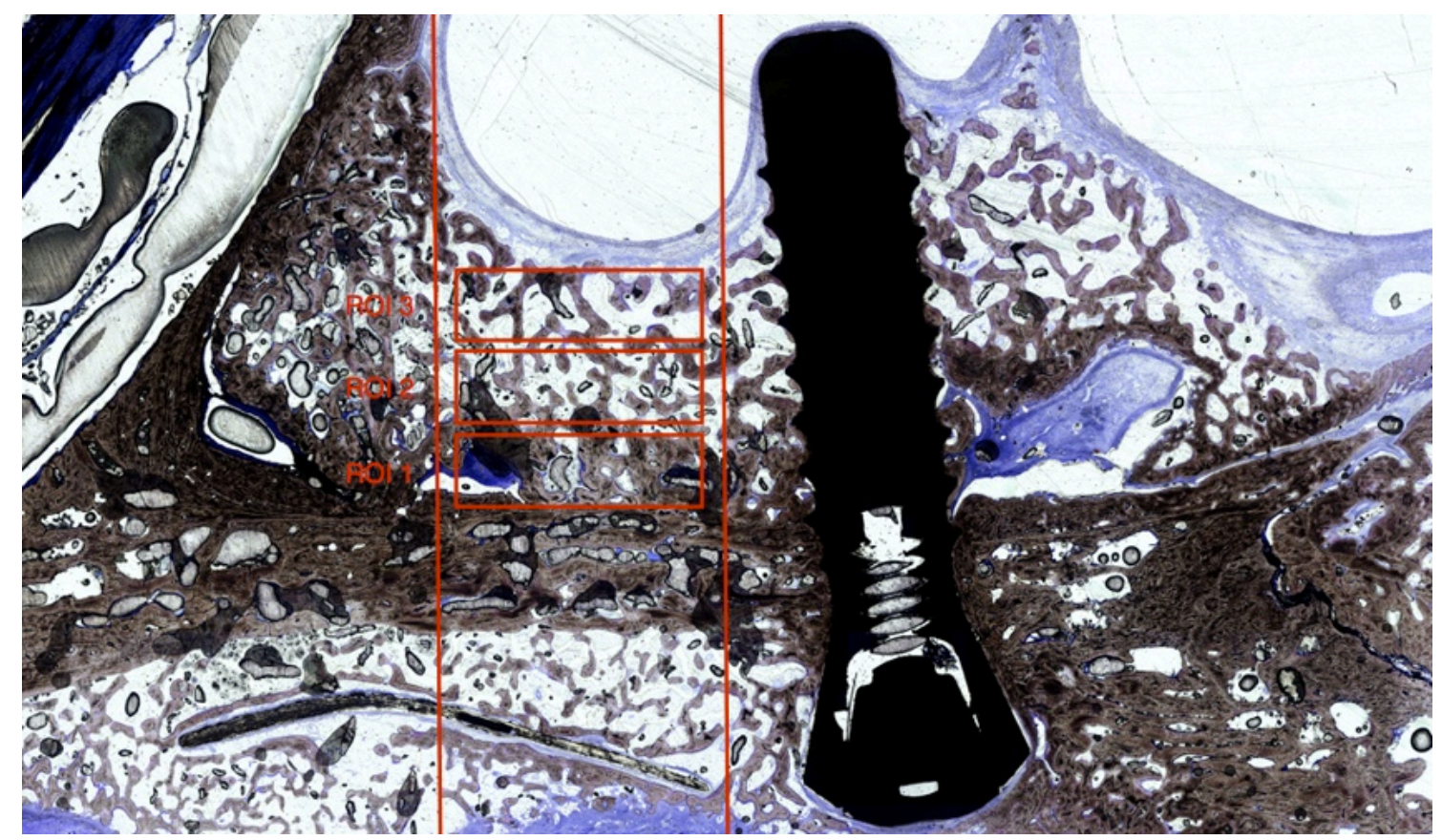

Abb. 2.11: Gradient der Knochenneubildung (3 ROIs);

Original-Vergrößerung x5

\subsection{Histomorphometrische Knochenmessung}

Die histomorphometrische Knochenevaluation wurde mit der frei erhältlichen Bildanalyse-Software „FIJI“ des

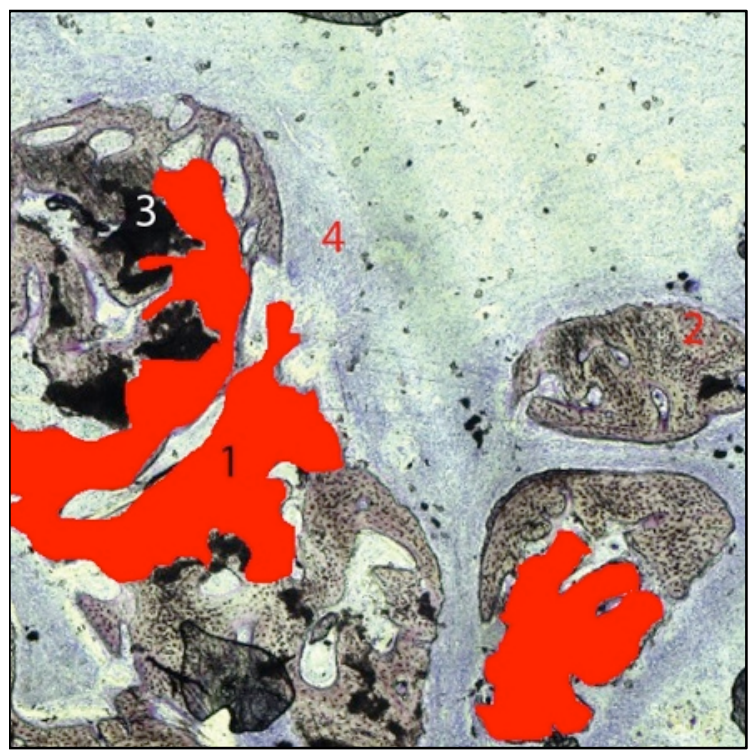

Abb. 2.12: Knochenhistomorphometrie; Markierte Knochenfläche(1);Nicht markierter Knochen(2); $\beta$-TCP(3);Bindegewebe(4); Original-Vergrößerung $x 5$
Max-Planck-Institute of Molecular Biology and Genetics realisiert (http://fiji.sc). Um die Software zu kalibrieren, wurden die Präparate der zentralen Schnittebene verwendet, auf denen das Implantat zu erkennen war und als Längenreferenz verwendet werden konnte. Zu Beginn jeder Messung wurde die Gesamtpixelfläche des zu untersuchenden Areals berechnet. Danach wurden das neu gebildete Knochengewebe manuell markiert und die jeweiligen Pixelflächen gemessen. Die Fläche des neu 
gebildeten Knochengewebes innerhalb jeder einzelnen Region wurde zur Gesamtfläche der Region in Relation gesetzt und so die prozentuale Knochenneubildung als Flächendichte bestimmt. Anschließend wurde die maximale Höhe der Sinusbodenaugmentate gemessen.

\begin{tabular}{|c|c|c|c|c|c|c|}
\hline $\mathbf{P}$ & $\begin{array}{c}\text { Anterior } \\
\text { (links) }\end{array}$ & $\begin{array}{c}\text { Zentral } \\
\text { (links) }\end{array}$ & $\begin{array}{c}\text { Posterior } \\
\text { (links) }\end{array}$ & $\begin{array}{c}\text { Anterior } \\
\text { (rechts) }\end{array}$ & $\begin{array}{c}\text { Zentral } \\
\text { (rechts) }\end{array}$ & $\begin{array}{c}\text { Posterior } \\
\text { (links) }\end{array}$ \\
\hline 1 & 15,59 & 5,47 & 12,48 & 18,74 & 18,3 & 14,07 \\
\hline 2 & 15,66 & 9,95 & 10,73 & 15,07 & 16,45 & 19,1 \\
\hline 3 & 12,62 & 20,23 & 16,85 & 9,81 & 12,16 & 12,87 \\
\hline 4 & 14,68 & 16,55 & 15,69 & 18,92 & 12,92 & 14,43 \\
\hline 5 & 12,99 & 13,43 & 12,09 & 17,34 & 17,08 & 15,15 \\
\hline 6 & 14,43 & 13,64 & 16,03 & 18,98 & 18,4 & 15,65 \\
\hline 7 & 13,01 & 14,01 & 13,31 & 6,9 & 8,55 & 10,93 \\
\hline 8 & 2,39 & 3,24 & 8,86 & 3,3 & 5,47 & 4,88 \\
\hline 9 & 12,52 & 12,68 & 12,18 & 9,42 & 8,42 & 6,28 \\
\hline 10 & 4,54 & 5,67 & 5,63 & 4,7 & 6,97 & 4,02 \\
\hline 11 & 12,16 & 10,03 & 8,6 & 3,4 & 5,86 & 6,93 \\
\hline 12 & 9,3 & 13,66 & 10,97 & 13,11 & 12,22 & 9,31 \\
\hline
\end{tabular}

Tab. 2.3: Maximale Höhe der Augmentate in $\mathrm{mm}$ 


\subsection{Statistische Auswertung}

Für die statistische Auswertung der histomorphometrisch erhobenen Daten wurde eine ANCOVA in einem „incomplete block design” mit den verwendetet Faktoren ROI und Dosis $(0 ; 400 \mu \mathrm{g} ; 800 \mu \mathrm{g})$ sowie der Kovariablen „Höhe des Augmentats“ (Mittelwerte über alle drei Schnittebenen) durchgeführt. Alle Regionen wurden mit Hilfe eines gemischten Modells mit dem Faktor „Dosis“ ausgewertet. Die Knochenneubildung wurde durch den Parameter „Volumendichte“ charakterisiert und durch adjustierte $p$-Werte angegeben $(a=0.05)$. Der paarweise Vergleich zwischen den unterschiedlichen Konzentrationen und zwischen den verschiedenen Regionen wurde mit Hilfe des Tukey-Kramer-post-hoc-Tests adjustiert. Die statistischen Berechnungen wurde mit der Software „SAS proc mixed“ (SAS 9.2,SAS Institute Inc.,Cary,NC,USA) und der frei erhältlichen Software „R“ (v2.6, www.r-project.org) mit den Bibliotheken Ime4 und multicomp (GNU-project, Bell Laboratories, Lucent Technologies) durchgeführt. 


\section{Ergebnisse}

\subsection{Klinische Auswertung}

Die Operationswunden heilten bei allen behandelten Tieren ohne jegliche Zwischenfälle ab. Postoperativ zeigte sich eine kurz anhaltende lokale Schwellung. Entzündungsreaktionen oder Wundinfektionen wurden nicht beobachtet.

\subsection{Lichtmikroskopische Evaluation}

\subsubsection{Vier Wochen Beobachtungszeitraum}

\subsubsection{Kontrollgruppe}

In den folgenden Abb. 3.1 bis 3.5 sind die oben beschriebenen ROls der Sinusbodenaugmentate dargestellt. Als Augmentationsmaterial wurde bei diesen Präparaten $\beta$-TCP ohne rhGDF-5 verwendet.

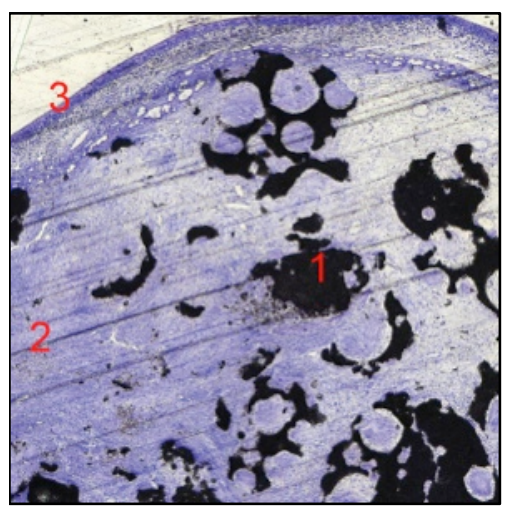

Abb. 3.1: ROI 5 nach 4 Wochen (Kontrollpräparat); $\beta-T C P(1) ;$ Bindegewebe(2); Kieferhöhlenschleimhaut(3); Original-Vergrößerung $x 5$
Auf Abb. 3.1 ist die oberste Region des Augmentats (ROI 5) dargestellt. Das Epithel der Kieferhöhlenschleimhaut ist als dunkelblaue Begrenzungslinie im oberen Bildabschnitt zu erkennen. Darunter liegen die lichtundurchlässigen dunklen $\beta$-TCP-Granula in dem durch das Toluidin-Blau eingefärbten Bindegewebe. Neu gebildetes Knochengewebe, das sich in dieser histologischen Färbung braun darstellt, ist in dieser Region nicht zu erkennen. 


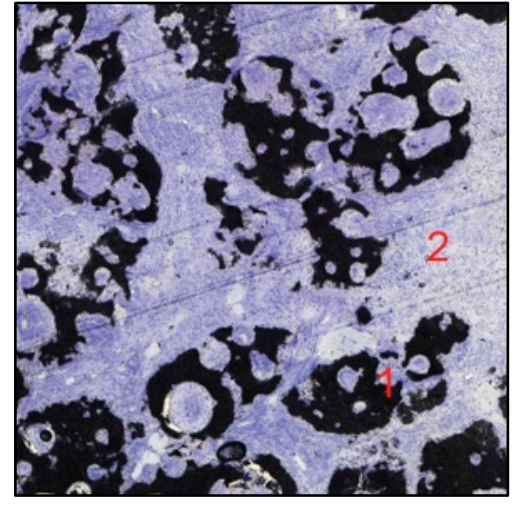

Abb. 3.2: ROI 4 nach 4 Wochen (Kontrollpräparat); $\beta-T C P(1)$; Bindegewebe(2); Original-Vergrößerung x5

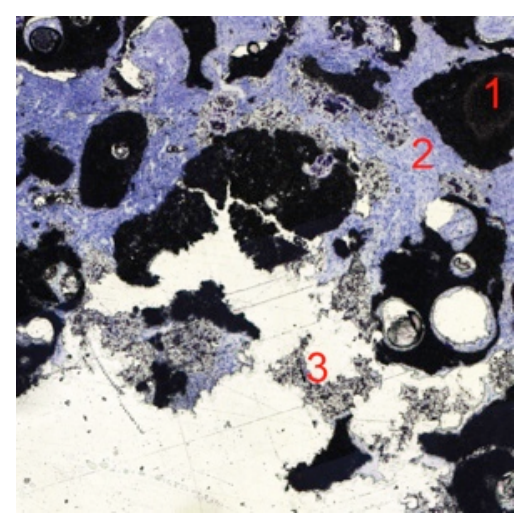

Abb. 3.3: ROI 3 nach 4 Wochen (Kontrollpräparat); $\beta-T C P(1) ;$ Bindegewebe(2); Resorption des $\beta$-TCP(3); Original-Vergrößerung $x 5$

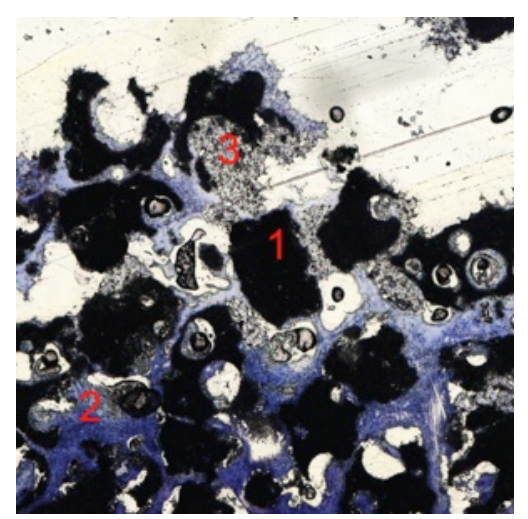

Abb. 3.4: ROI 2 nach 4 Wochen (Kontrollpräparat); $\beta$-TCP(1); Bindegewebe(2); Resorption des $\beta$-TCP(3); Original-Vergrößerung $x 5$
Auf Abb. 3.2 ist die Zwischenregion 4 dargestellt (ROI 4). Auch in dieser Region kann man unter dem Lichtmikroskop kein neu gebildetes Knochengewebe erkennen. Die oben beschriebenen $\beta$-TCP-Granula liegen als große schwarze, scharf begrenzte Strukturen in dem lockeren Bindegewebe.

Abb. 3.3 zeigt die zentrale Region des Augmentats (ROI 3). In diesem Bereich sind große Hohlräume zwischen dem Augmentationsmaterial zu erkennen. Neben den bereits definierten Strukturen ist auf dieser Abbildung kein neu gebildetes Knochengewebe dargestellt. Im unteren Bildabschnitt hat die Resorption der $\beta$-TCPGranula begonnen.

In Abb. 3.4 (ROI 2) ist kein neu gebildetes Knochengewebe abgebildet. In dem oberen Bildabschnitt sind große Hohlräume zu erkennen. Die dunklen $\beta$-TCP-Granula liegen in dem bläulichen, lockeren Bindegewebe. Im zentralen Bildabschnitt ist wieder die beginnende Resorption des Augmentationsmaterials zu erkennen. 


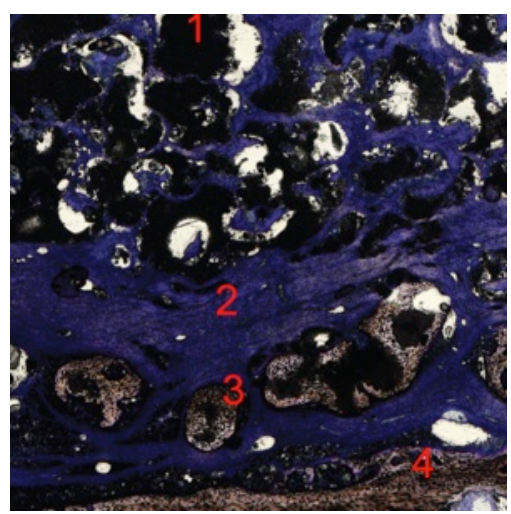

Abb. 3.5: ROI 1 nach 4 Wochen (Kontrollpräparat); $\beta-T C P(1)$; Bindegewebe(2); Knochentrabekel(3); Übergang zum ortsständigen Kieferknochen(4);

Original-Vergrößerung x5
Auf Abb. 3.5 ist die Region am Übergang zum ortsständigen Kieferknochen (ROI 1) zu erkennen. In diesem Bereich sind mehrere bräunlich gefärbte, jedoch noch isoliert und relativ klein erscheinende Knocheninseln abgebildet. Bei dem neu gebildeten Knochengewebe handelt es sich um Geflechtknochen. Lamellärer Knochen ist auf dieser Abbildung nicht zu erkennen. Im unteren Bildabschnitt ist der Übergang zum ortsständigen Kieferknochen abgebildet.

\subsubsection{Gruppe $A_{n}$}

Die anschließend dargestellten Abb. 3.6 bis 3.10 präsentieren ein Sinusbodenaugmentat, bei dem der Wachstumsfaktor in einer Konzentration von $400 \mu \mathrm{g} / \mathrm{gg}$ $\beta$-TCP verwendet wurde.

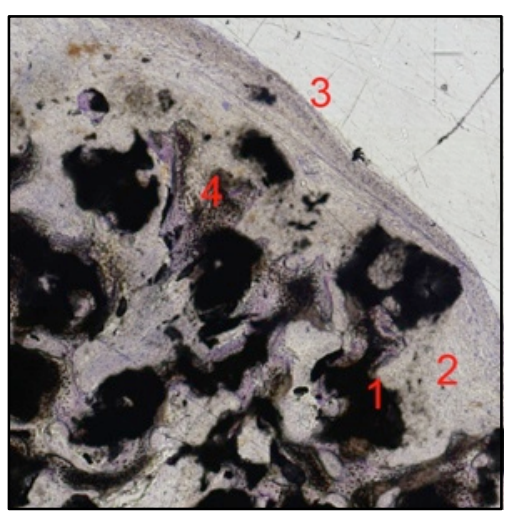

Abb. 3.6: ROI 5 nach 4 Wochen (400 $\mu \mathrm{g} / 1 \mathrm{~g} \beta-\mathrm{TCP}) ; \beta-T C P(1)$; Bindegewebe(2); Kieferhöhlenschleimhaut(3); Knochentrabekel(4); Original-Vergrößerung x5
Auf Abb. 3.6 ist ROI 5 zu erkennen. Die Membran ist als hellbläulich gefärbte Begrenzungslinie zwischen dem Augmentat und der mit Luft gefüllten Kieferhöhle dargestellt. Im Vergleich mit derselben Region der Kontrollgruppe ist in diesem Augmentat eine vereinzelte Knochenneubildung mit Osteoblasten und Osteozyten auf der Oberfläche der $\beta$-TCP-Granula zu erkennen. 


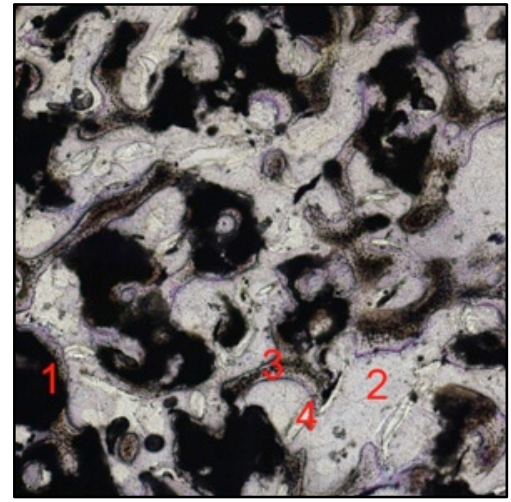

Abb. 3.7: ROI 4 nach 4 Wochen (400 $\mu \mathrm{g} / 1 \mathrm{~g} \beta-\mathrm{TCP}) ; \beta-T C P(1)$;

Bindegewebe(2);Knochentrabekel(3); Gefäßlumen(4);Original-Vergrößerung x5

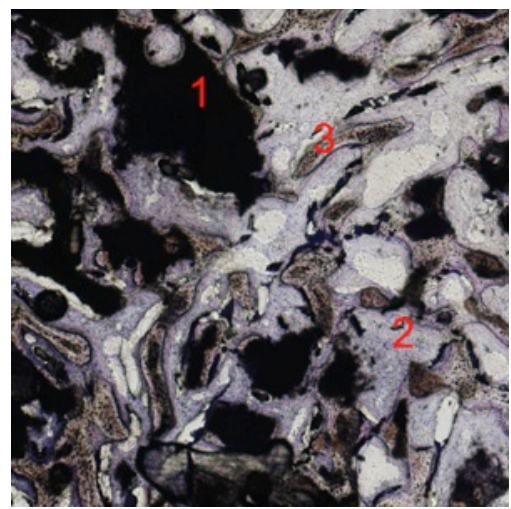

Abb. 3.8: ROI 3 nach 4 Wochen (400 $\mu \mathrm{g} / 1 \mathrm{~g} \beta-\mathrm{TCP}) ; \beta-T C P(1)$; Bindegewebe(2);Knochentrabekel(3); Original-Vergrößerung $x 5$

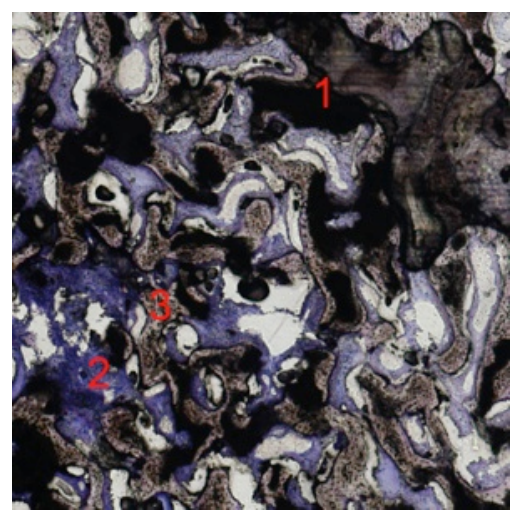

Abb. 3.9: ROI 2 nach 4 Wochen (400 $\mu \mathrm{g} / 1 \mathrm{~g} \beta-\mathrm{TCP}) ; \beta-T C P(1)$; Bindegewebe(2);Knochentrabekel(3); Original-Vergrößerung x 5
Auch auf Abb. 3.7 von ROI 4 ist neu gebildetes Knochengewebe zu erkennen, das die $\beta$-TCP-Granula z.T. vollständig umschlossen hat. Die Granula zeigen eine deutliche Resorption.

Auf Abb. 3.8 ist die Region aus dem Zentrum des Sinusbodenaugmentats dargestellt. Neben den schon beschriebenen $\beta$ TCP-Granula sind auch in dieser Region neu gebildete Knocheninseln lichtmikroskopisch zu erkennen. Das $\beta$-TCP wurde teilweise resorbiert und von dem neu gebildeten trabekulären Knochengewebe substituiert. Die Trabekel erscheinen im Lichtmikroskop kompakt.

In Abb. 3.9 von ROI 2 hat sich das Verhältnis zwischen neu gebildetem Knochengewebe und Augmentationsmaterial deutlich in Richtung des Knochens verschoben. Der Anteil des Bindegewebes erscheint deutlich vermindert. 


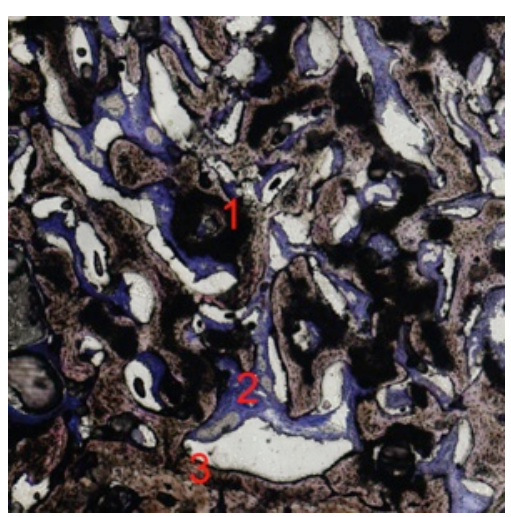

Abb. 3.10: ROI 1 nach 4 Wochen (400 $\mu \mathrm{g} / 1 \mathrm{~g} \beta$-TCP); $\beta$-TCP(1); Bindegewebe(2);Knochentrabekel(3); Original-Vergrößerung x5
Der größte Anteil neu gebildeten Knochengewebes kann in der Region direkt am ortsständigen Kieferknochen erkannt werden (Abb. 3.10). Die $\beta$-TCP-Granula sind deutlich resorbiert und durch das stark und dicht erscheinende Knochengewebe ummauert worden. Bei dem neu gebildeten Knochengewebe handelt es sich überwiegend um Geflechtknochen.

\subsubsection{Gruppe $A_{h}$}

In den Abb. 3.11 bis 3.15 ist ein Sinusbodenaugmentat dargestellt, bei dem der Wachstumsfaktor in einer Konzentration von $800 \mu \mathrm{g} / 1 \mathrm{~g} \beta$-TCP verwendet wurde.

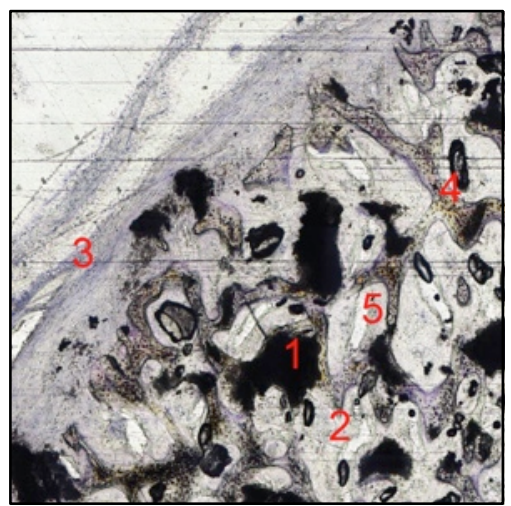

Abb. 3.11: ROI 5 nach 4 Woche (800 $\mu \mathrm{g} / 1 \mathrm{~g} \beta-\mathrm{TCP}) ; \beta-T C P(1)$; Bindegewebe(2); Kieferhöhlenschleimhaut(3); Knochentrabekel(4); Gefäßlumen(5); Original-Vergrößerung x5
Auf Abb. 3.11 ist ROI $5 \mathrm{zu}$ erkennen. Die Kieferhöhlenschleimhaut ist in diesem histologischen Schnitt nicht mehr vollständig erhalten, kann aber im oberen Bildausschnitt noch identifiziert werden. In dieser Region erkennt man die lichtundurchlässigen und daher schwarz dargestellten $\beta$ TCP-Granula. Dazwischen erkennt man vereinzelte dünne bräunlich gefärbte Knochentrabekel. 


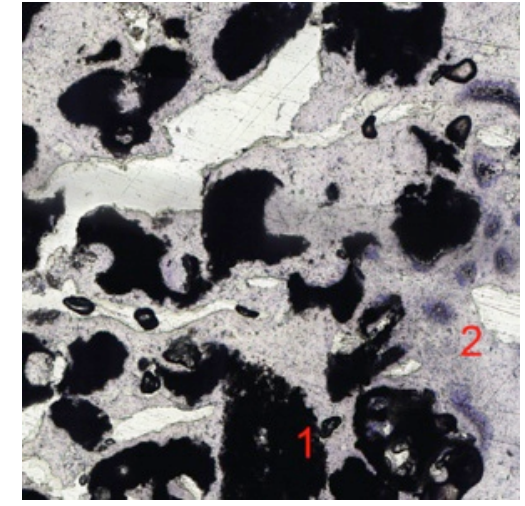

Abb. 3.12: ROI 4 nach 4 Wochen (800 $\mu \mathrm{g} / 1 \mathrm{~g} \beta$-TCP); $\beta$-TCP(1); Bindegewebe(2); Original-Vergrößerung x 5

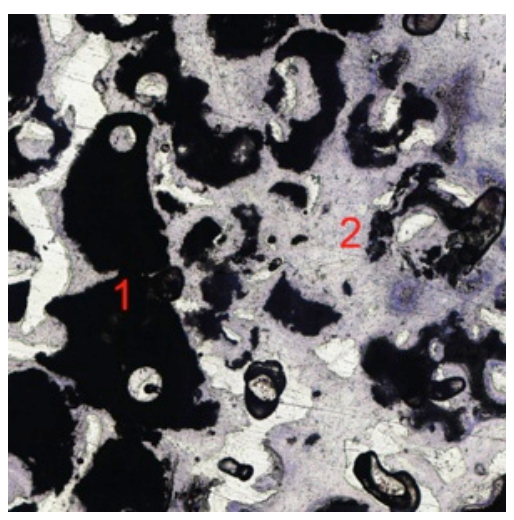

Abb. 3.13: ROI 3 nach 4 Wochen (800 $\mu \mathrm{g} / 1 \mathrm{~g} \beta-\mathrm{TCP}) ; \beta-T C P(1)$;

Bindegewebe(2);

Original-Vergrößerung x5

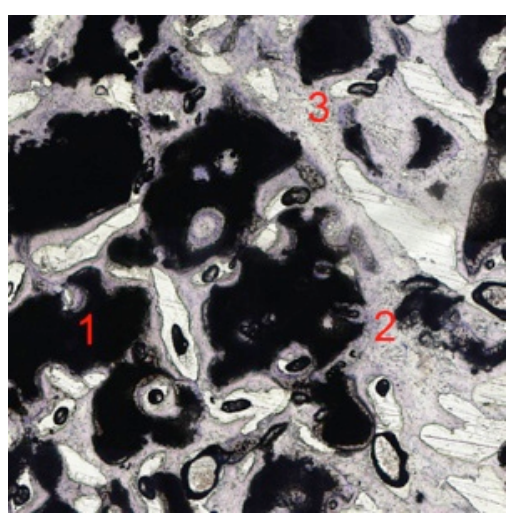

Abb. 3.14: ROI 2 nach 4 Wochen $(800 \mu \mathrm{g} / 1 \mathrm{~g} \beta$-TCP); $\beta$-TCP(1);

Bindegewebe(2); Resorption des $\beta$-TCP(3); Original-Vergrößerung $x 5$
Auf Abb. 3.12 von ROI 4 ist kein neu gebildetes Knochengewebe erkennbar. Den größten Raum nimmt das Bindegewebe mit den darin eingebetteten $\beta$-TCP-Granula ein.

Auch auf Darstellung 3.13 von der zentral im Sinusbodenaugmentat liegenden Region kann lichtmikroskopisch kein neugebildeter Knochen identifiziert werden. Ansonsten erkennt man wieder das bläulich dargestellte Bindegewebe und die darin eingelagerten $\beta$-TCP-Granula, die teilweise resorbiert erscheinen.

In ROI 2 (Abb. 3.14) sind dagegen vereinzelte Knocheninseln zu erkennen, die sich um die $\beta$-TCP-Granula organisiert haben. Das Knochenersatzmaterial erscheint teilweise resorbiert. 


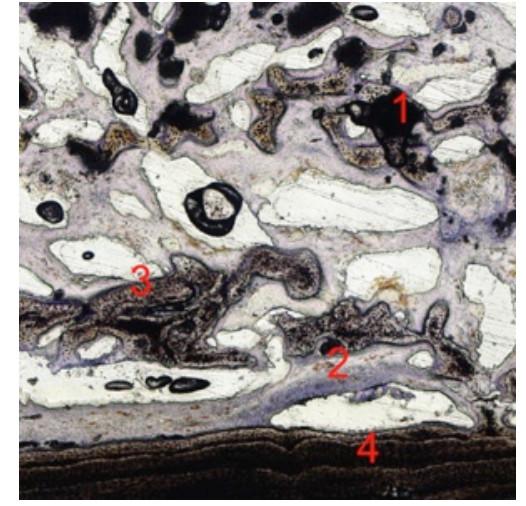

Abb. 3.15: ROI 1 nach 4 Wochen $(800 \mu g / 1 g \beta-T C P) ; \beta-T C P(1)$;

Bindegewebe(2);Knochentrabekel(3); Kieferknochen(4)

Original-Vergrößerung x5
Auf Abb. 3.15 ist die Region direkt am Übergang zum ortsständigen Kieferknochen dargestellt. Vergleicht man die einzelnen Regionen untereinander, fällt auf, dass in diesem Bereich der größte Anteil an neu gebildetem Knochen zu erkennen ist. Im kranialen Bildausschnitt sind feine Knochentrabekel zu erkennen, die zwischen dem bläulichen Bindegewebe liegen. Im kaudalen Bildabschnitt ist der ortsständige Oberkie-

ferknochen dargestellt. Dieser erscheint dicht und lamellär organisiert.

Zusammenfassend wurde bei der lichtmikroskopischen Evaluation der Sinusbodenaugmentate nach vier Wochen Einheilungszeit vor allem in den Testgruppen mit GDF-5 neu gebildetes Knochengewebe beobachtet. Die feinen Knochentrabekel lagen vereinzelt vor und hatten sich um die $\beta$-TCP-Granula organisiert. Ein lamellärer Umbau war bei diesen Präparaten noch nicht zu erkennen. Die $\beta$-TCPGranula erschienen teilweise resorbiert. Neu gebildetes Knochengewebe wurde in allen Gruppen in ROI 1 beobachtet. Mit zunehmendem Abstand zeigte sich eine Abnahme neu gebildeten Knochengewebes. Bei den Präparaten, bei denen der Wachstumsfaktor GDF-5 verwendet wurde, war insgesamt dichteres Knochengewebe zu erkennen als bei den Kontrollpräparaten. Im Vergleich der Konzentrationen untereinander erscheint unter dem Lichtmikroskop die Knochenneubildung bei

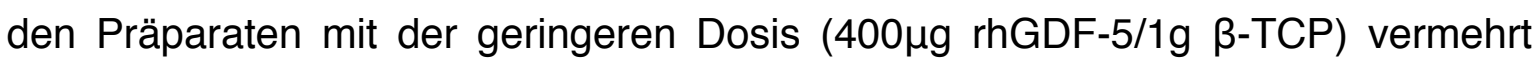
und dichter als bei denen mit der höheren Dosis $(800 \mu \mathrm{g}$ rhGDF-5/1g $\beta-T C P)$.

\subsubsection{Zwölf Wochen Beobachtungszeitraum}

\subsubsection{Kontrollgruppe}

In den Abb. 3.16 bis 3.20 ist ein Kontrollpräparat nach zwölf Wochen Einheilungszeit abgebildet. Als Augmentationsmaterial wurde $\beta$-TCP ohne rhGDF-5 verwen- 


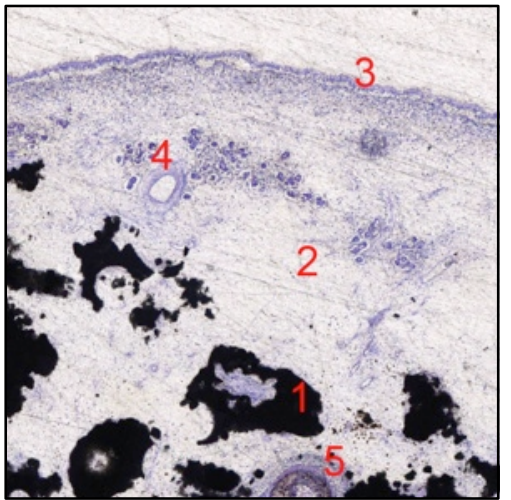

Abb. 3.16: ROI 5 nach zwölf Wochen (Kontrollpräparat); $\beta$-TCP(1);Bindegewebe(2); Kieferhöhlenschleimhaut(3);Gefäßlumen(4); Knochentrabekel(5);Original-Vergrößerung x5

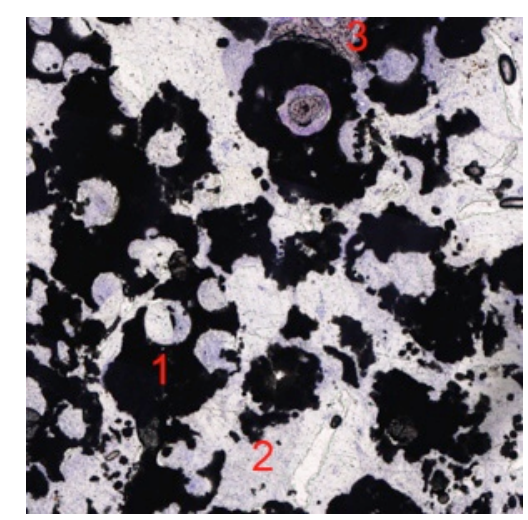

Abb. 3.17: ROI 4 nach zwölf Wochen (Kontrollpräparat); $\beta-T C P(1)$; Bindegewebe(2); Knochentrabekel(3); Original-Vergrößerung x5

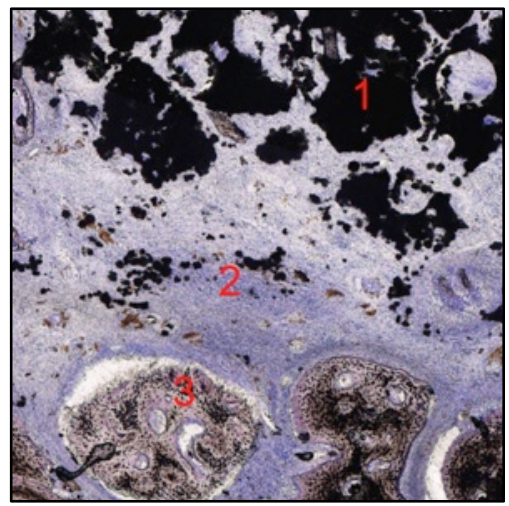

Abb. 3.18: ROI 3 nach zwölf Wochen (Kontrollpräparat); $\beta-T C P(1)$; Bindegewebe(2);Knochentrabekel(3); Original-Vergrößerung $x 5$ det. In Abb. 3.16 ist die Region direkt unterhalb der Kieferhöhlenschleimhaut dargestellt (ROI 5). Unterhalb der Membran ist ein Gefäß quer angeschnitten worden. Die Granula des $\beta$-TCP erscheinen schwarz. In dem zentralen unteren Bildabschnitt ist eine isolierte bräunlich gefärbte Knocheninsel zu erkennen. Eine Resorption und Substitution des Knochenersatzmaterials durch Knochengewebe hat nicht stattgefunden.

In der auf Abb. 3.17 dargestellten Zwischenregion (ROI 4) setzt sich das auf der oberen Abbildung erkennbare Knochengewebe im kranialen Abschnitt weiter fort. Ansonsten ist kein neu gebildetes Knochengewebe in dieser Region dargestellt.

In Abb. 3.18 ist die Region aus dem Zentrum des Augmentats zu erkennen. Im kranialen Bereich sind fast ausschließlich $\beta$-TCP-Granula mit nur wenig neuem Knochengewebe abgebildet. Im kaudalen Bereich sind die $\beta$-TCP-Granula bereits durch die kräftig erscheinenden Knocheninseln substituiert worden. 


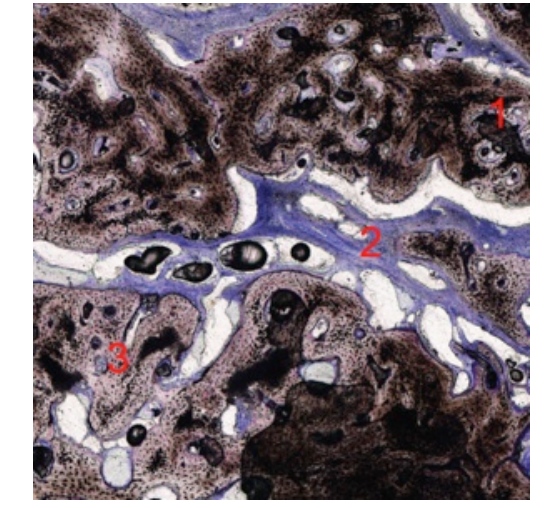

Abb. 3.19: ROI 2 nach zwölf Wochen (Kontrollpräparat); $\beta-T C P(1)$; Bindegewebe(2); Knochenlamelle(3); Original- Vergrößerung x5

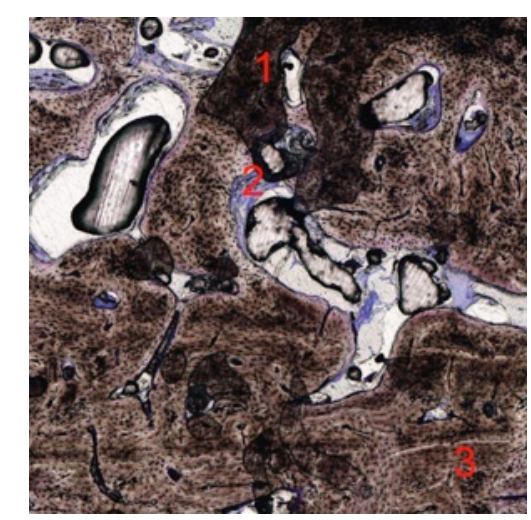

Abb. 3.20: ROI 1 nach zwölf Wochen (Kontrollpräparat); $\beta$-TCP(1); Bindegewebe(2);Knochengewebe(3); Original-Vergrößerung x 5
In ROI 2 (Abb. 3.19) nimmt der neu gebildete Knochen den größten Raum ein. Daneben ist nur noch vereinzelt Knochenersatzmaterial innerhalb des Knochengewebes erkennbar. Der abgebildete Geflechtknochen erscheint dichter als bei den Präparaten nach vier Wochen Einheilungszeit.

In Abb. 3.20 ist ROI 1 an der Grenze zum ortsständigen lamellären Kieferknochen zu erkennen. Die $\beta$-TCP-Granula sind weitestgehend resorbiert. Im kaudalen Abschnitt, an der Grenze zum ortsständigen Knochen, hat sich auch der neu gebildete Knochen bereits lamellär organisiert.

\subsubsection{Gruppe $B_{n}$}

Die Abb. 3.21 bis 3.25 zeigen ein Sinusbodenaugmentat, bei dem der Wachstumsfaktor in einer Konzentration von $400 \mu \mathrm{g} / \mathrm{gg} \beta$-TCP verwendet wurde. 


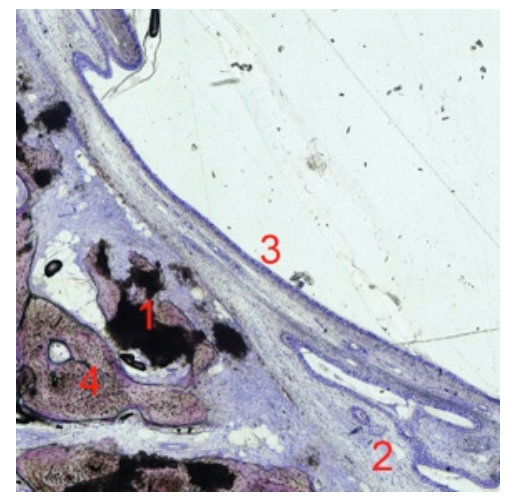

Abb. 3.21: ROI 5 nach zwölf Wochen $(400 \mu g / 1 \mathrm{~g} \beta-T C P) ; \beta-T C P(1) ;$ Bindegewebe(2);Kieferhöhlenschleimhaut(3) Knochentrabekel(4); Original-Vergrößerung x5

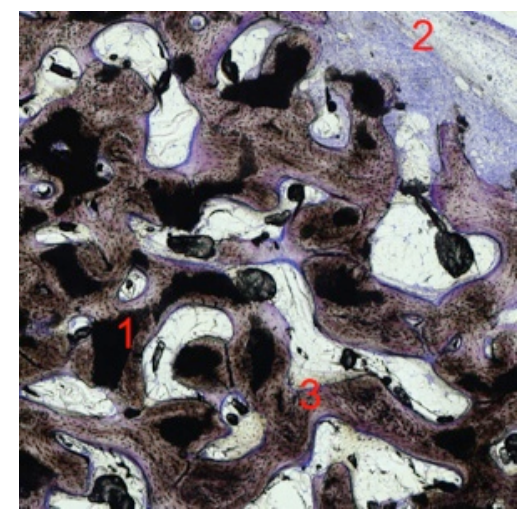

Abb. 3.22: ROI 4 nach zwölf Wochen (400 $\mu \mathrm{g} / 1 \mathrm{~g} \beta-\mathrm{TCP}) ; \beta-T C P(1)$; Bindegewebe(2); Knochen(3); Original-Vergrößerung x5

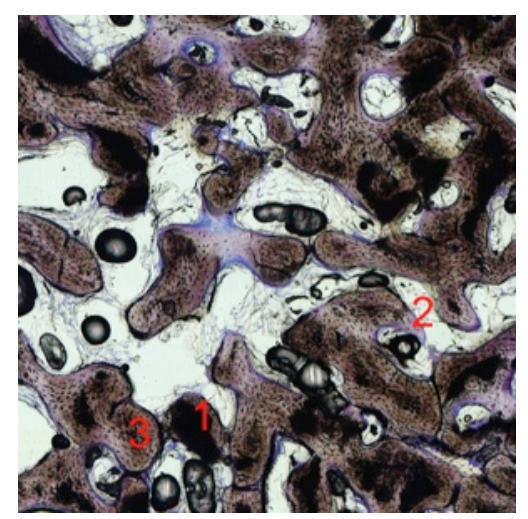

Abb. 3.23: ROI 3 nach zwölf Wochen $(400 \mu g / 1 g \beta-T C P) ; \beta-T C P(1) ;$ Bindegewebe(2);Knochentrabekel(3); Original- Vergrößerung $x 5$
Auf Abb. 3.21 ist die Region unterhalb der Kieferhöhlenschleimhaut dargestellt. Die $\beta$-TCP-Granula erscheinen deutlich resorbiert und von neugebildetem Knochen umbaut. Ein lamellärer Umbau des neu gebildeten Knochengewebes kann jedoch in dieser Region (ROI 5) nicht erkannt werden.

In ROI 4 (Abb. 3.22) nimmt das neu gebildete Knochengewebe den größten Raum ein. Die $\beta$-TCP-Granula zeigen Zeichen zunehmender Resorption und sind nur noch vereinzelt zwischen und innerhalb der Knochenbälkchen zu erkennen.

Auf Abb. 3.23 ist die Region aus dem Zentrum des Augmentats abgebildet. Wie in ROI 4 (Abb. 3.22) sind auch hier nur noch vereinzelte $\beta$-TCP-Granula erkennbar, die von neugebildetem Knochen vollständig umgeben sind. Der neu gebildete Knochen erscheint hier sehr kompakt. 


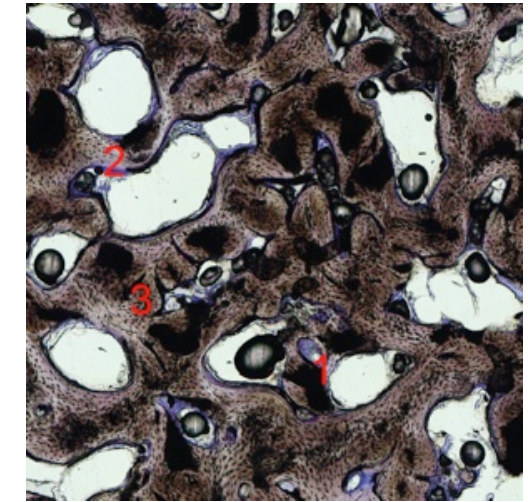

Abb. 3.24: ROI 2 nach zwölf Wochen (400 $\mu \mathrm{g} / 1 \mathrm{~g} \beta$-TCP); $\beta$-TCP(1);

Bindegewebe(2);Knochentrabekel(3); Original-Vergrößerung $x 5$

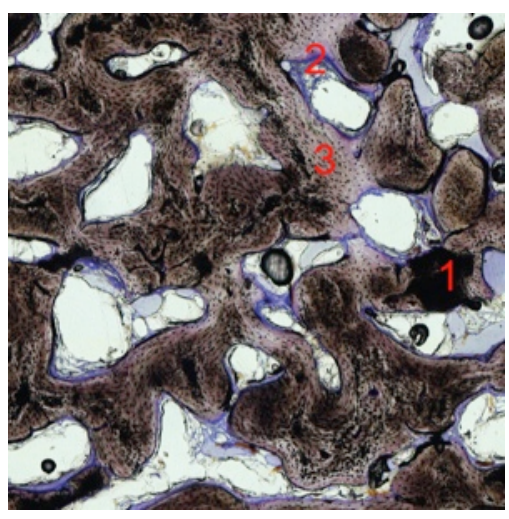

Abb. 3.25: ROI 1 nach zwölf Wochen (400 $\mu \mathrm{g} / 1 \mathrm{~g} \beta$-TCP); $\beta$-TCP(1); Bindegewebe(2);Knochengewebe(3); Original-Vergrößerung $x 5$
Die auf Abb. 3.24 zu erkennende ROI 2 ähnelt ROI 3 und 4. Das neu gebildete Knochengewebe erscheint sehr kompakt und dicht. Das Knochenersatzmaterial ist ebenfalls von dem neu gebildeten Knochen weitgehend resorbiert und ummauert worden.
Auf Abb. 3.25 ist die Region direkt am Übergang zum lokalen Kieferknochen dargestellt. Dieser ist auf dem Präparat jedoch nicht angeschnitten worden. Es scheint so, als wären die $\beta$-TCP-Granula in dieser Region fast vollständig resorbiert und durch das Knochengewebe substituiert worden. Im unteren Bildabschnitt kann teilweise ein lamellärer Umbau der Knochenbälkchen erkannt werden.

\subsubsection{Gruppe $B_{h}$}

In den Abb. 3.26 bis 3.30 ist ein Präparat dargestellt, bei dem der Wachstumsfaktor in einer Konzentration von $800 \mu \mathrm{g} / \mathrm{gg} \beta$-TCP verwendet wurde. 


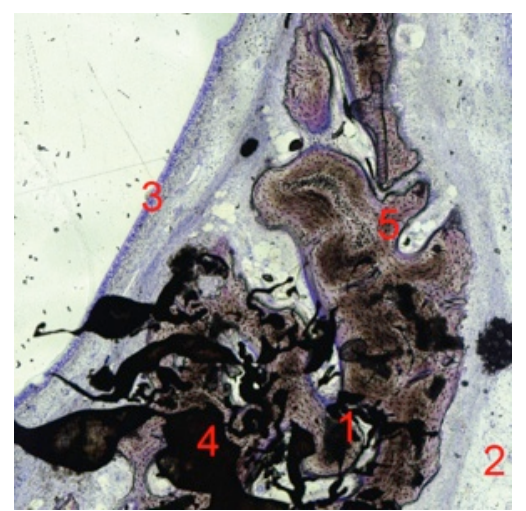

Abb. 3.26: ROI 5 nach zwölf Wochen $(800 \mu \mathrm{g} / 1 \mathrm{~g} \beta$-TCP); $\beta$-TCP (1); Bindegewebe(2); Kieferhöhlenschleimhaut(3); Färbeartefakt(4); Knochentrabekel(5); Original-Vergrößerung $x 5$

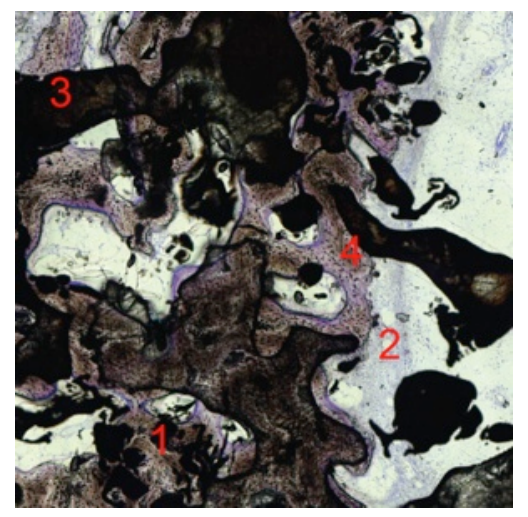

Abb. 3.27: ROI 4 nach zwölf Wochen $(800 \mu \mathrm{g} / 1 \mathrm{~g} \beta$-TCP); $\beta$-TCP(1); Bindegewebe(2); Färbeartefakt(3); Knochentrabekel(4); Original-Vergrößerung x5

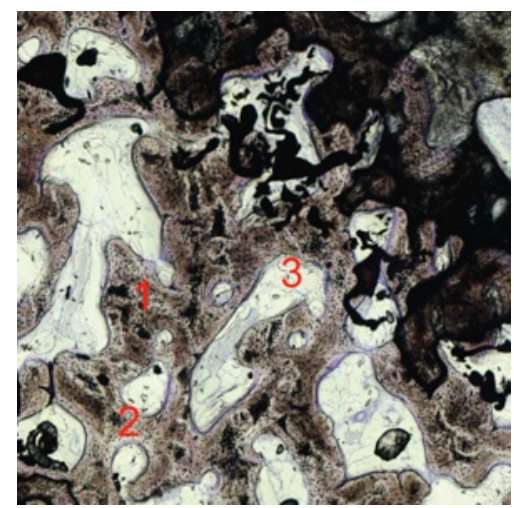

Abb. 3.28: ROI 3 nach zwölf Wochen $(800 \mu \mathrm{g} / 1 \mathrm{~g} \beta$-TCP); $\beta$-TCP (1); Knochentrabekel(2);Bindegewebe(3); Original-Vergrößerung $x 5$
Auf Abb. 3.26 ist die an die Kieferhöhlenschleimhaut angrenzende ROI 5 dargestellt. Das kompakte Knochengewebe nimmt in dieser Region einen großen Teil ein. Weiterhin ist ein Bereich zu erkennen, in dem die $\beta$-TCP-Granula nahezu vollständig von Knochengewebe umwachsen sind.

Auf Abb. 3.27 ist die Zwischenregion (ROI 4) des Augmentats abgebildet. In diesem Bereich ist kaum noch bläulich gefärbtes Bindegewebe zu erkennen. Lichtmikroskopisch scheint es so, als wären die $\beta$ TCP-Granula zu großen Teilen durch das Knochengewebe eingeschlossen und substituiert worden. Leider zeigen sich auch in diesem Ausschnitt einige Färbeartefakte.

In der zentral gelegenen Region (Abb. 3.28) sind im kranialen Bildausschnitt neben den kräftigen Knochenbälkchen noch bläuliche Bindegewebssepten und Färbeartefakte zu erkennen. Es sind nur noch vereinzelte $\beta$-TCP-Granula innerhalb der Knochenbälkchen erkennbar. 


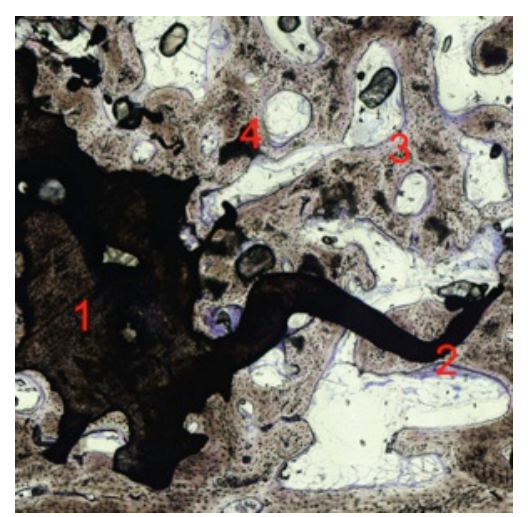

Abb. 3.29: ROI 2 nach zwölf Wochen (800 $\mu \mathrm{g} / 1 \mathrm{~g} \beta$-TCP);Färbeartefakt(1); Bindegewebe(2); Knochentrabekel(3); $\beta-T C P(4)$; Original-Vergrößerung $x 5$

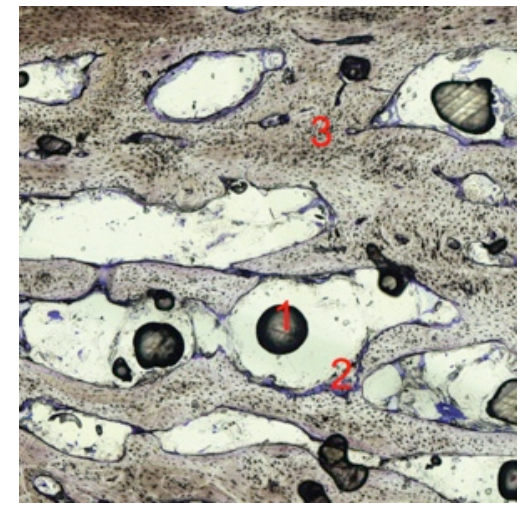

Abb. 3.30: ROI 1 nach zwölf Wochen (800 $\mu \mathrm{g} / 1 \mathrm{~g} \beta-\mathrm{TCP}) ; \beta-T C P(1)$;

Bindegewebe(2);

Knochengewebe(3);

Original-Vergrößerung $x 5$
Auch in ROI 2 (Abb. 3.29) zeigt sich eine zunehmende Resorption und Substitution der $\beta$-TCP-Granula. Der große schwarze Fleck im linken Bildausschnitt ist als Färbeartefakt zu deuten und wurde bei der Evaluation als solcher gewertet.

Auf Abb. 3.30 ist die Region direkt am Übergang zum Kieferknochen dargestellt. Die Knochenbälkchen erscheinen in dieser Region teilweise lamellär organisiert. Die $\beta$-TCP-Granula sind nur noch in kleinen Resten innerhalb der neu gebildeten Knochenbälkchen zu erkennen.

Zusammenfassend zeigte sich unter dem Lichtmikroskop bei den Augmentaten nach zwölf Wochen Einheilungszeit eine insgesamt dichtere Knochenneubildung als bei den Präparaten der jeweiligen Test- und Kontrollgruppe nach vier Wochen Einheilungszeit. Die Knochentrabekel erschienen deutlich breiter und kompakter. Die $\beta$-TCP-Granula waren von dem neu gebildeten Knochengewebe ummauert und weitgehend substituiert worden. In ROI 1 und 2 hatte sich der neu gebildete Knochen teilweise lamellär organisiert. Insgesamt zeigte sich in beiden Testgruppen im Vergleich zur der Kontrollgruppe eine dichtere Knochenneubildung. In Gruppe $B_{n}$ konnte in allen Regionen eine vergleichbare Knochendichte beobachtet 
werden. In Gruppe $B_{h}$ ähnelte der Verlauf der Knochenneubildung dem der Kontrollpräparate. Bei diesen beiden Gruppen (Kontrollgruppe, Gruppe $B_{h}$ ) hatte sich am meisten Knochen in ROI 1 gebildet. Von dort aus nahm die Dichte des neu gebildeten Knochengewebes bis zu ROI 5 weiter ab. Im Vergleich der Konzentrationen untereinander erschien der Knochen bei den Augmentaten mit der geringeren Dosis $(400 \mu \mathrm{g} / \mathrm{gg} \beta$-TCP) dichter als bei denen mit der höheren Dosis $(800 \mu \mathrm{g} / \mathrm{gg} \beta$ TCP). 


\subsection{Histomorphometrische Evaluation}

\subsubsection{Vier Wochen Beobachtungszeitraum}

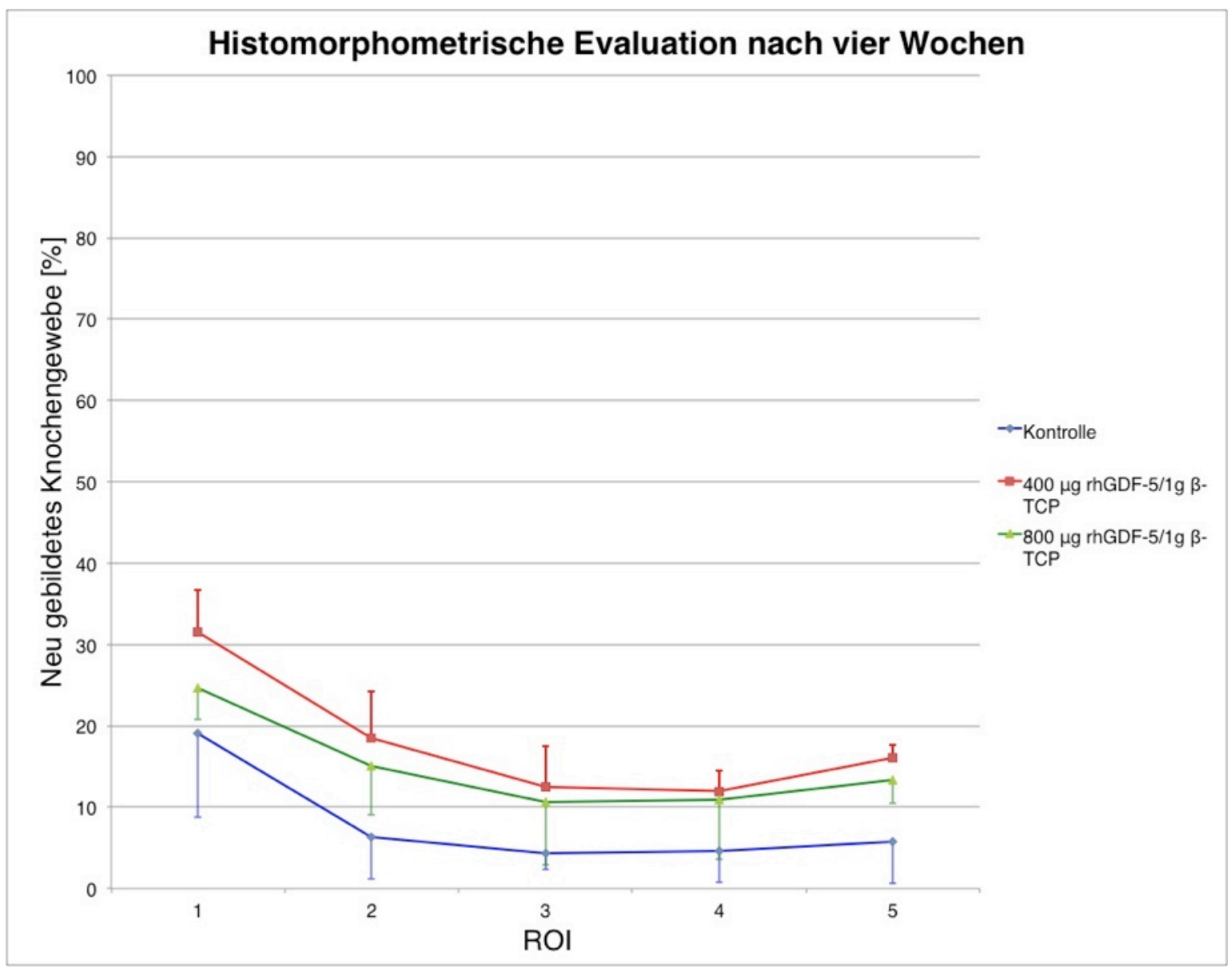

Abb. 3.31: Prozentuale Knochenneubildung nach vier Wochen;

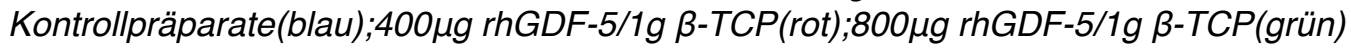

Auf Abb. 3.31 sind die Mittelwerte mit Standardabweichung aller untersuchter Gruppen nach vier Wochen Einheilungszeit dargestellt. In allen Präparaten wurde ein ähnlicher, über das gesamte Augmentat reichende Gradient der Knochenneubildung beobachtet. Daher erscheinen die Gradientenkurven annähernd parallel. Die höchsten Werte wurden in ROI 1 gemessen. Von dort aus nahmen die Werte bis zu den zentralen Regionen (ROI 3 und 4) stetig ab, um dann wieder leicht anzusteigen. 
Bei Gruppe $A_{n}(400 \mu g$ rhGDF-5/1g $\beta$-TCP) lag die prozentuale Knochenneubildung in ROI 1 bei $31,6 \%( \pm 5,2)$, in ROI 2 bei 18,5\% $( \pm 5,8)$, in ROI 3 bei $12,5 \%$ ( \pm $5,1)$, in ROI 4 bei $12 \%( \pm 2,6)$ und in ROI 5 bei 16,1\% $( \pm 1,6)$. In Gruppe $A_{h}(800 \mu g$ rhGDF-5/1g $\beta$-TCP) lagen die Mittelwerte in ROI 1 bei 24,6\% $( \pm 3,8)$, in ROI 2 bei $15,1 \%( \pm 6,1)$, in ROI 3 bei $10,6 \%( \pm 7,7)$, in ROI 4 bei $11 \%( \pm 7,4)$ und in ROI 5 bei $13,4 \%( \pm 3)$. Die prozentuale Knochenneubildung der Kontrollgruppe lag in ROI 1 bei $19,1 \%( \pm 10,3)$, in ROI 2 bei $6,3 \%( \pm 5,2)$, in ROI 3 bei $4,3 \%( \pm 1,9)$, in ROI 4 bei $4,6 \%( \pm 3,8)$ und in ROI 5 bei $5,8 \%( \pm 5,2)$.

Wie bei dem parallelen Verlauf der Kurven zu erwarten, wurde zwischen Dosis und Region keine signifikante Wechselwirkung nachgewiesen $(p=0,87)$. Statistisch war die mittlere prozentuale Knochenneubildung in Gruppe $A_{n}[18,14 \%( \pm 4,06)]$, Gruppe $A_{h}[14,94 \%( \pm 5,6)]$ und der Kontrollgruppe $[8,02 \%( \pm 5,28)]$ jedoch signifikant unterschiedlich $(p=0,023)$. Im paarweisen Vergleich zeigte sich $z w i-$ schen Gruppe $A_{n}$ und der Kontrollgruppe ein signifikanter Unterschied $(p=0,0184)$,

\begin{tabular}{|c|c|c|}
\hline ROI & ROI & Adj P \\
\hline 1 & 2 & $<0,0001$ \\
\hline 1 & 3 & $<0,0001$ \\
\hline 1 & 4 & $<0,0001$ \\
\hline 1 & 5 & $<0,0001$ \\
\hline 2 & 3 & 0,1055 \\
\hline 2 & 4 & 0,1583 \\
\hline 2 & 5 & 0,8447 \\
\hline 3 & 4 & 0,9995 \\
\hline 3 & 5 & 0,5594 \\
\hline 4 & 5 & 0,6965 \\
\hline
\end{tabular}

Tab. 2.4: Paarweiser Vergleich der ROIs nach vier Wochen; unabhängig von Konzentration und Kontrolle während der paarweise Vergleich zwischen Gruppe $A_{h}$ und der Kontrollgruppe $(p=0,09)$ und zwischen Gruppe $A_{h}$ und Gruppe $A_{n}(p=0,62)$ keinen signifikanten Unterschied aufwies. In jeder untersuchten Gruppe unterschieden sich die Werte innerhalb der einzelnen ROls signifikant voneinander $(p<0,0001)$. Der paarweise Vergleich der ROls zeigte einen siginifikanten Unterschied zwischen ROI 1 und allen anderen Regionen $(p<0,0001)$, unabhängig von der Dosis des rhGDF-5-Faktors. 


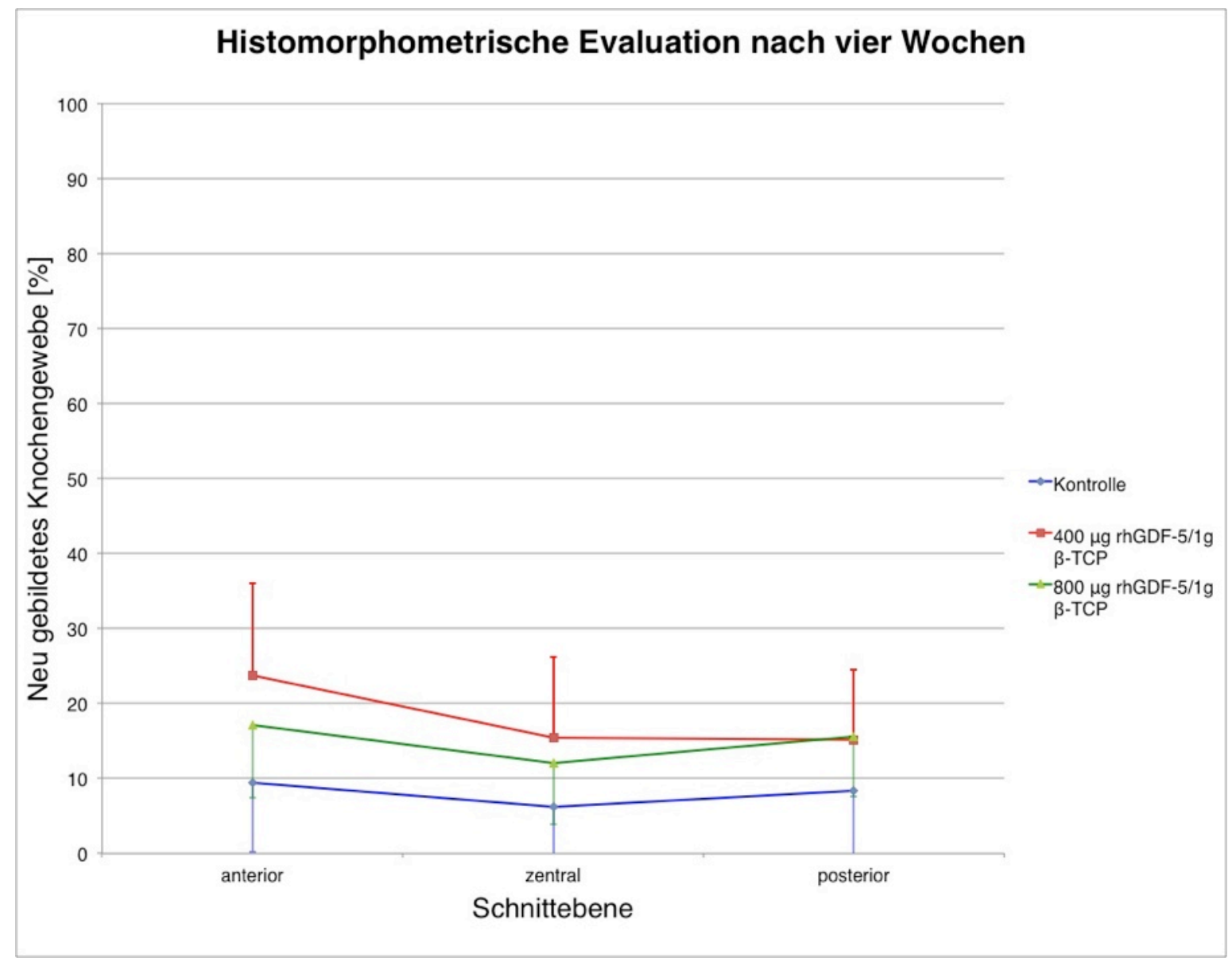

Abb. 3.32: Prozentuale Knochenneubildung aller Schnittebenen nach vier Wochen;

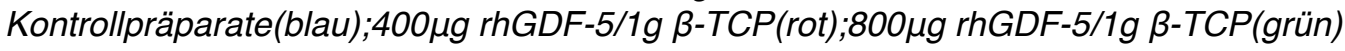

Bei der histomorphometrischen Evaluation in anterior-posteriorer Richtung ergab sich kein Unterschied zwischen den untersuchten Gruppen. Bei Gruppe $A_{h}$ reichten die Werte von $12 \%( \pm 8,2)$ in der zentralen Schnittebene über $15,7 \%( \pm 8,1)$ in der anterioren Schnittebene bis $17,1 \%( \pm 9,7)$ in der posterioren Schnittebene. In Gruppe $A_{n}$ lagen die Werte in der zentralen Ebene bei 15,5\% $( \pm 10,7)$, in der anterioren Ebene bei 15,2\% $( \pm 9,4)$ und in der posterioren Ebene bei $23,7 \%( \pm 12,4)$. In der Kontrollgruppe reichten die Werte von 6,2\% $( \pm 8,2)$ zentral bis 8,3\% $( \pm 10,2)$ anterior und $9,4 \%( \pm 9,2)$ posterior.

Zusammenfassend ergab sich bei der histomorphometrischen Evaluation nach vier Wochen Einheilungszeit im Vergleich zu der Kontrollgruppe eine verstärkte Knochenneubildung für beide Testgruppen, wobei der Unterschied jedoch nur für

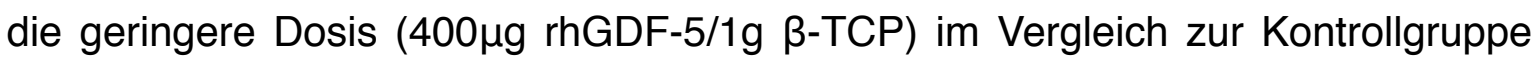
statistisch signifikant war. Bei allen untersuchten Gruppen wurde ein ähnlicher von 
ROI 1 abfallender Gradient der Knochenneubildung beobachtet. Im Vergleich der beiden Konzentrationen untereinander wurden bei der geringeren Dosis $(400 \mu \mathrm{g}$ rhGDF-5/1g $\beta$-TCP) tendenziell höhere Werte gemessen als bei der höheren Dosis $(800 \mu \mathrm{g}$ rhGDF-5/1g $\beta$-TCP); der Unterschied war jedoch nicht signifikant.

\subsubsection{Zwölf Wochen Beobachtungszeitraum}

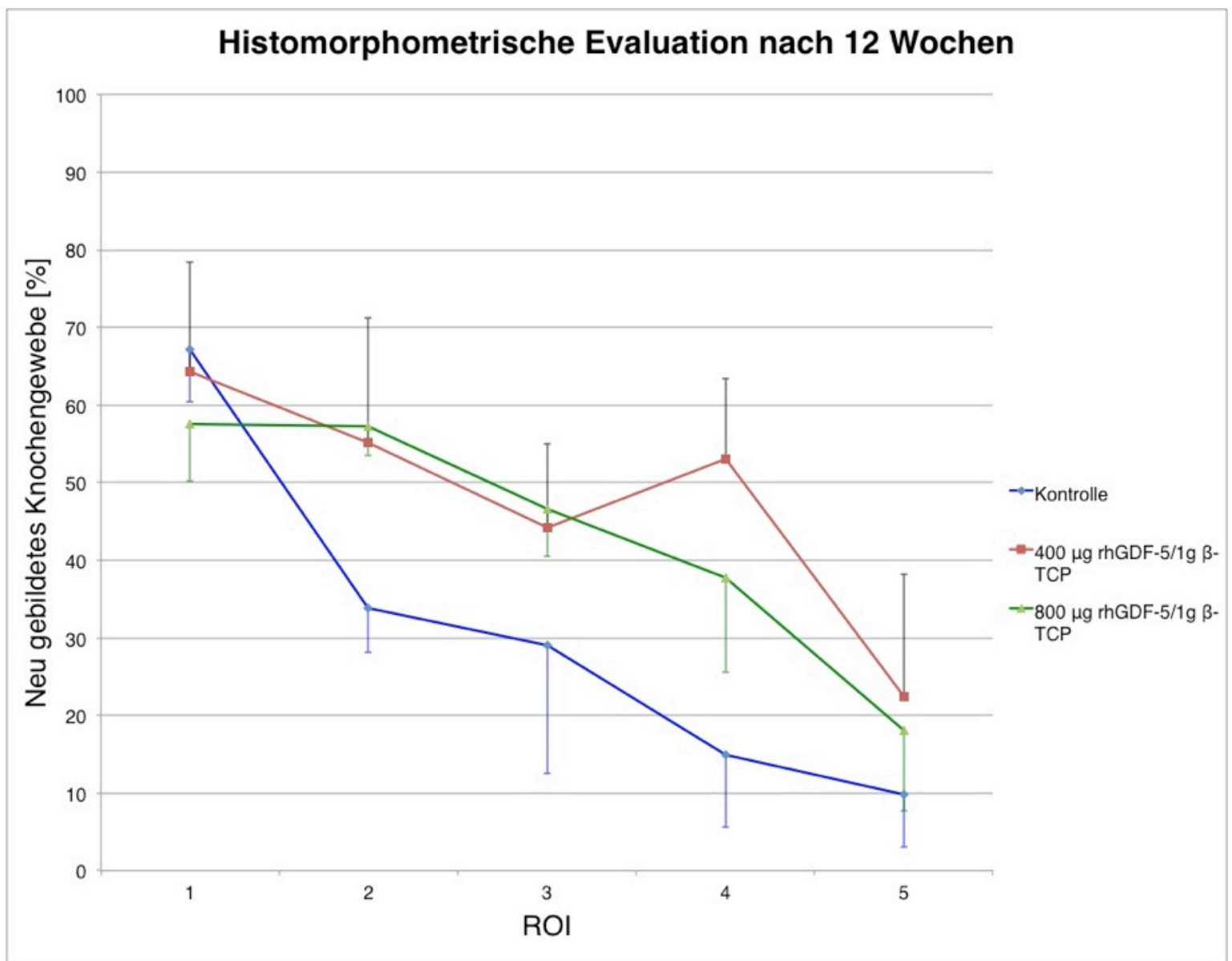

Abb. 3.33: Prozentuale Knochenneubildung nach zwölf Wochen;

Kontrollpräparate(blau);400 $\mu$ g rhGDF-5/1g $\beta$-TCP(rot);800 $\mu$ g rhGDF-5/1g $\beta$-TCP(grün)

Auf Abb. 3.33 sind die Mittelwerte mit Standardabweichung aller untersuchter Gruppen nach zwölf Wochen Einheilungszeit dargestellt. Während sich die Gradienten der Knochenneubildung der Kontrollgruppe und der Gruppe $B_{h}$ ähnelten und einen stetig abfallenden Gradienten zeigten, unterschied sich der Gradient der Gruppe $B_{n}$ von den beiden anderen Gruppen (Kontrollgruppe, Gruppe $B_{h}$ ). Bei diesen Präparaten hatte eine verstärkte Knochenneubildung in den zentralen Regio- 
nen des Augmentats stattgefunden (ROI 2, 3 und 4). In Gruppe $B_{n}$ lagen die Mittelwerte in ROI 1 bei $64,3 \%( \pm 14,2)$, in ROI 2 bei $55,2 \%( \pm 16,1)$, in ROI 3 bei $44,3 \%( \pm 10,8)$, in ROI 4 bei 53,1\% $( \pm 10,4)$ und in ROI 5 bei 22,5\% ( $\pm 15,7)$. In Gruppe $B_{h}$ lag die prozentuale Knochenneubildung in $\mathrm{ROI} 1$ bei $57,5 \%( \pm 7,4)$, in ROI 2 bei 57,3\% ( $\pm 3,9)$, in ROI 3 bei 46,6\% ( $\pm 6,1)$, in ROI 4 bei 37,7\% $( \pm 12,2)$ und in ROI 5 bei 18,1\% $( \pm 10,4)$. Bei den Kontrollpräparaten lagen die Werte in ROI 1 bei $67,2 \%( \pm 6,8)$, in ROI 2 bei $33,9 \%( \pm 5,8)$, in ROI 3 bei $29,1 \%( \pm 16,6)$, in ROI 4 bei $15 \%( \pm 9,3)$ und in ROI 5 bei $9,8 \%( \pm 6,8)$

Bei der histomorphometrischen Evaluation zeigte sich eine unterschiedliche mittlere Knochenneubildung der zwei Testgruppen $\left(B_{n} / B_{h}\right)$ und der Kontrollgruppe. Gruppe $B_{n}: 47,88 \%( \pm 13,44)$; Gruppe $B_{h}: 43,44 \%( \pm 8)$; Kontrollgruppe: $31 \%( \pm 9,06)$. Die statistische Evaluation ergab einen signifikanten Unterschied zwischen den drei Untersuchungsgruppen $(p=0,038)$. Bedingt durch die statistisch signifikante Wechselwirkung zwischen Dosis und Region $(p=0,023)$ war eine separate Auswertung jeder Dosisgruppe notwendig.

Obwohl es bei Gruppe $B_{n}$ den Anschein hatte, dass sich die Mittelwerte der einzelnen ROls signifikant unterscheiden würden, waren statistisch keine signifikanten Unterschiede nachweisbar $(p=0,11)$. In den Präparaten konnte somit statistisch eine homogene Knochenneubildung über das gesamte Augmentat nachgewiesen werden.

Für Gruppe $B_{h}$ ergaben sich statistisch signifikante Unterschiede zwischen den einzelnen ROls $(p=0,0028)$. In einem paarweisen Vergleich der einzelnen Regionen wurde ein signifikanter Unterschied zwischen ROI 1 und ROI 5 ( $p=0,0026)$, ROI 2 und ROI $5(p=0,0069)$ und ROI 3 und ROI $5(p=0,0113)$ nachgewiesen.

Auch bei der Kontrollgruppe wurden statistisch signifikante Unterschiede zwischen den einzelnen ROls beobachtet $(p<0,0001)$. In einem paarweisen Vergleich der einzelnen Regionen wurde ein signifikanter Unterschied zwischen ROI 1 und allen übrigen ROls $(0,0001<p<0,0079)$ und zwischen ROI 2 und ROI 5 ( $p=0,0307)$ nachgewiesen. 


\begin{tabular}{|c|c|c|}
\hline ROI & ROI & Adj P \\
\hline 1 & 2 & 0,0079 \\
\hline 1 & 3 & 0,0003 \\
\hline 1 & 4 & $<0,0001$ \\
\hline 1 & 5 & $<0,0001$ \\
\hline 2 & 3 & 0,9087 \\
\hline 2 & 4 & 0,1852 \\
\hline 2 & 5 & 0,0307 \\
\hline 3 & 4 & 0,5287 \\
\hline 3 & 5 & 0,0667 \\
\hline 4 & 5 & 0,8893 \\
\hline
\end{tabular}

Tab. 2.5: Paarweiser Vergleich der ROls nach zwölf Wochen; Kontrollpräparate

\begin{tabular}{|c|c|c|}
\hline ROI & ROI & Adj P \\
\hline 1 & 2 & 0,9950 \\
\hline 1 & 3 & 0,3020 \\
\hline 1 & 4 & 0,0630 \\
\hline 1 & 5 & 0,0026 \\
\hline 2 & 3 & 0,5854 \\
\hline 2 & 4 & 0,1042 \\
\hline 2 & 5 & 0,0069 \\
\hline 3 & 4 & 0,4328 \\
\hline 3 & 5 & 0,0113 \\
\hline 4 & 5 & 0,1254 \\
\hline
\end{tabular}

Tab. 2.6: Paarweiser Vergleich der ROls nach 12 Wochen; Konzentration $800 \mu \mathrm{g}$ 


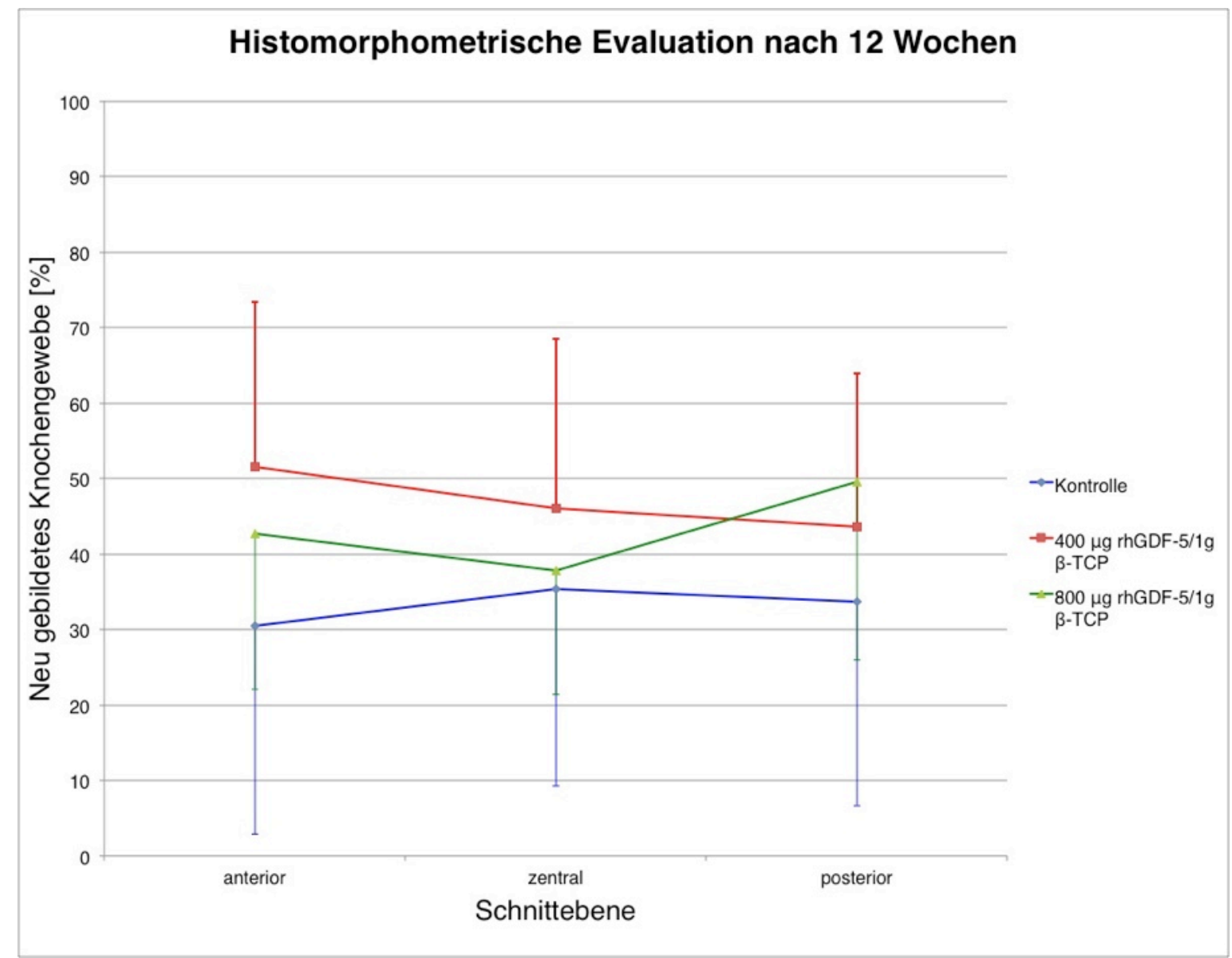

Abb. 3.34: Prozentuale Knochenneubildung aller Schnittebenen nach zwölf Wochen;

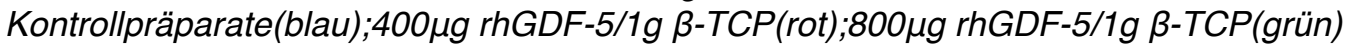

Bei der Auswertung in anterior-posteriorer Richtung war auch nach zwölf Wochen Einheilungszeit kein Unterschied zwischen den untersuchten Gruppen zu erkennen. Die Mittelwerte in Gruppe $B_{h}$ reichte von $37,8 \%( \pm 16,4)$ in der zentralen Schnittebene über $42,6 \%( \pm 20,6)$ in der anterioren Schnittebene bis $49,6 \%( \pm$ $23,7)$ in der posterioren Schnittebene. In Gruppe $B_{n}$ lagen die Werte in der zentralen Ebene bei $46 \%( \pm 22,5)$, in der anterioren Ebene bei $43,6 \%( \pm 20,3)$ und in der posterioren Ebene bei $51,5 \%( \pm 21,8)$. In der Kontrollgruppe reichten die Werte von $35,4 \%( \pm 26,1)$ zentral bis $30,5 \%( \pm 27,6)$ anterior und $33,7 \%( \pm 27,1)$ posterior.

Zusammenfassend ergab sich bei der histomorphometrischen Evaluation nach zwölf Wochen Einheilungszeit eine verstärkte Knochenneubildung innerhalb des Augmentats für beide Testgruppen im Vergleich zu der Kontrollgruppe. Weiterhin waren auch Unterschiede zwischen den beiden verwendeten Konzentrationen zu 


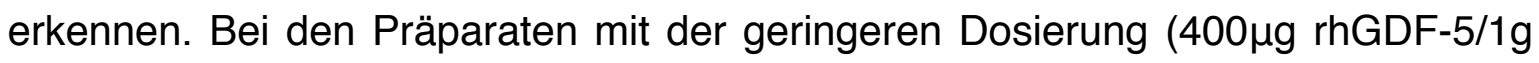
$\beta$-TCP) wurde statistisch eine homogene Knochenneubildung über das gesamte Augmentat nachgewiesen. Die Präparate mit der höheren Dosierung $(800 \mu \mathrm{g}$ rhGDF-5/1g $\beta$-TCP) und die Kontrollgruppe zeigten keine homogene Knochenneubildung, sondern signifikante Unterschiede zwischen den Regionen (ROI 1-4). Bei diesen beiden Gruppen (Kontrollgruppe, Gruppe $B_{h}$ ) nahmen die Werte von ROI 1 bis ROI 5 teilweise ab. 


\section{Diskussion}

\subsection{Studiendesign}

Ziel der vorliegenden Studie war es, eine dreidimensionale histomorphometrische Evaluation der Knochenneubildung innerhalb der Sinusbodenaugmentate durchzuführen. Eine Analyse des kompletten, anatomisch komplex aufgebauten Augmentats ist nur mit Hilfe histologischer Schnitte der gesamten Kieferhöhle möglich. Die Herstellung solcher Schnitte ist beim Menschen aus ethischen Gründen nicht durchführbar. Zu diesem Zweck wird ein Studiendesign benötigt, bei dem sowohl die anatomischen Verhältnisse der Kieferregion als auch die Physiologie des Knochengewebes mit der des Menschen vergleichbar sind.

In der Literatur werden verschiedene Tiermodelle beschrieben, die sich in Untersuchungen des Knochengewebes etabliert haben. Am häufigsten werden Hunde, Schafe, Ziegen, Schweine und Kaninchen verwendet (Pearce et al. 2007). Von den beschriebenen Spezies scheint die Knochenstruktur des Hundes der des Menschen am ähnlichsten zu sein. Auch die Haltung der Tiere ist relativ einfach. Dennoch werden Hunde aus ethischen Gesichtspunkten, als Begleittier des Menschen, immer seltener in der medizinischen Forschung eingesetzt (Pearce et al. 2007). Diese ethischen Überlegungen werden bei Schafen und Ziegen nicht gemacht, deren Fleisch auch als Nahrungsmittel dient. Ihr Körpergewicht kommt dem des Menschen sehr nahe. Auch ihre langen Röhrenknochen sind mit denen des Menschen vergleichbar. Aus diesem Grund werden mithilfe dieser Tiermodelle häufig orthopädische Fragestellungen untersucht. Studien zur dentalen Implantologie und Knochenaugmentation im kraniofazialen Bereich sind dagegen eher selten (Newman et al. 1995). Kaninchen sind in diesem Zusammenhang die am einfachsten zu handhabenden Versuchstiere. Dennoch sind die anatomischen Verhältnisse nicht repräsentativ. Unter den vorgestellten Spezies zeigt das Knochengewebe von Kaninchen die geringste Ähnlichkeit zu humanem Knochen (Pearce et al. 2007). 
Das Schwein wird in der Literatur als das Modelltier der Wahl bei Untersuchungen dentaler Implantation und Sinusbodenaugmentation beschrieben (Lee et al. 2012, Pearce et al. 2007, Roldan et al. 2004). Kommerzielle Hausschweinrassen finden aufgrund ihrer schnellen Wachstumsrate und ihres übermäßig großen Körpergewichtes jedoch nur selten Anwendung. Dieses Problem wurde durch die Züchtung von Miniaturschweinen gelöst (Pearce et al. 2007). Jedoch sind die Minipigs als Versuchstiere im Bezug auf die dentale Implantation teilweise schwierig zu handhaben, da sie sich entgegen dem Menschen nicht schonen, sondern auch auf festen Gegenständen kauen und dadurch zu einer zusätzlichen Belastung im operierten Kieferbereich führen. Die simultane Implantation erfolgte daher bei den Versuchstieren nicht, wie beim Menschen üblich, in der Achse der Zahnwurzel in den Alveolarfortsatz, sondern in die laterale Wand der Kieferhöhle. Durch dieses Vorgehen sollte sichergestellt werden, dass die Implantate in der Kieferhöhle der Tiere über die gesamte Beobachtungszeit unbelastet einheilen konnten. Die Knochenneubildung könnte sich aus diesem Grund bei den Versuchstieren innerhalb der Augmentate anders verhalten haben als die Knochenneubildung innerhalb eines Sinusbodenaugmentats beim Menschen, bei dem das Implantat an einer Stelle inseriert wird, die physiologischerweise Belastungen ausgesetzt ist. Allerdings ist bei einer simultanen Implantation und Augmentation eine unbelastete Einheilung über 4-6 Monate Standard der Therapie. Ein ähnliches methodisches Vorgehen wurde schon 2004 von Roldan und kürzlich von Lee und Mitarbeitern beschrieben (Lee et al. 2012, Roldan et al. 2004). Roldan verglich den Nutzen von platelet-rich plasma (PRP) und rhBMP-7 als Zusatz zum Augmentationsmaterial in fünf Göttinger Minipigs. Bei den Tieren wurde eine bilaterale Augmentation mit anschließender Implantation durchgeführt. Die Implantate wurden in latero-kranialer Richtung in die Kieferhöhle inseriert und heilten dort innerhalb von sechs Wochen ohne Belastung ein (Roldan et al. 2004). Lee verglich eine Kombination aus rhBMP-2 und ACS als Augmentationsmaterial mit autogenem Knochen aus dem Beckenkamm. Auch diese Untersuchung wurde an fünf Minipigs durchgeführt, bei denen eine bilaterale Sinusbodenelevation durchgeführt wurde. Die verwendeten Implantate wurden in die laterale Wand der Kieferhöhle inseriert und heilten dort ohne Belastung über acht Wochen ein (Lee et al. 2012). Ein großer Vorteil des Mi- 
nipigs liegt in der vergleichbaren Physiologie des Knochengewebes und in den ähnlichen anatomischen Verhältnissen. Hinsichtlich der Knochenanatomie, -morphologie, -regeneration und -remodellierung werden Schweine als hoch repräsentativ für das humane Knochengewebe beschrieben (Thorwarth et al. 2005). Mikroskopisch betrachtet weist das porkine Knochengewebe eine höhere Trabekeldichte auf als der humane Knochen (Mosekilde et al. 1993). Trotz dieser höheren Trabekeldichte scheint sich der lamelläre Knochen mikroskopisch kaum voneinander zu unterscheiden (Mosekilde et al. 1987). Vergleicht man die Knochenzusammensetzung beider Spezies untereinander, fällt eine ähnliche Knochenmineraldichte und Knochenmineralkonzentration auf (Aerssens et al. 1998). Unter den vorgestellten Versuchstieren scheint die Knochenremodellierung (Mosekilde et al. 1987, Mosekilde et al. 1993) und Knochenregeneration (Laiblin und Jaeschke 1979) des Schweins der des Menschen am nächsten zu kommen.

Abschließend kann festgehalten werden, dass die Knochenneubildung innerhalb eines komplexen Sinusbodenaugmentats histomorphometrisch nur mit Hilfe eines Tiermodells evaluiert werden kann. Besonders die Knochenregeneration und -remodellierung, die bei der Knochenneubildung innerhalb des Augmentats eine entscheidende Rolle spielen, scheinen sich zwischen Mensch und Schwein nur wenig zu unterscheiden. Dennoch müssen alle in einem Tiermodell erhobenen histomorphometrischen Daten kritisch hinterfragt werden und sollten als Anhaltspunkt für weiterführende klinische Untersuchungen verstanden werden.

\subsection{Untersuchungsmethode}

Um das neu gebildete Knochengewebe innerhalb eines Sinusbodenaugmentats evaluieren zu können, stehen mehrere Methoden zur Verfügung. Neben der invasiven Histomorphometrie wurden in den letzten Jahren auch nichtinvasive physikalische Verfahren, wie die quantitative Computertomographie oder die Ultraschallmessung in der Literatur beschrieben (Dalle Carbonare et al. 2005).

Die quantitative Computertomographie bietet den Vorteil, dass eine dreidimensionale Schichtung durch das Augmentat auf nichtinvasive Weise in vivo möglich ist. Dadurch kann eine räumliche Auswertung durchgeführt werden. Dennoch ist die 
Anwendung dieses Verfahrens momentan nur begrenzt möglich. Es ist schwierig, trotz hohen Auflösungsvermögens, zwischen neu gebildetem Knochen und Knochenersatzmaterial zu unterscheiden, da die Unterscheidung wegen der ähnlichen radiologischen Dichte teilweise nur mikroskopisch möglich ist. Daher sind die Ergebnisse nur annäherungsweise repräsentativ. Darüber hinaus besteht derzeit noch eine hohe Strahlenexposition, wodurch diese Methode aus Strahlenschutzgründen in der medizinischen Forschung am Menschen nicht routinemäßig eingesetzt werden kann. Ein weitere Kritikpunkt sind die hohen Kosten dieses Verfahrens und die zur Zeit geringe Verfügbarkeit der Geräte (Dalle Carbonare et al. 2005). Als weiteres nichtinvasives kostengünstiges Verfahren ohne jegliche Strahlenbelastung wurde die Ultraschallmessung beschrieben. Bei diesem Verfahren ist es aufgrund des schlechten Auflösungsvermögens nur bedingt möglich, die unterschiedlichen Gewebebestandteile, wie neugebildeten Knochen und Knochenersatzmaterial, voneinander zu unterscheiden (Chappard et al. 1999).

Bei der Knochenhistomorphometrie wird eine Knochenbiopsie mikroskopisch vermessen, um quantitative Informationen über die Struktur des Knochens zu erhalten. In der Literatur wird diese Methode als Goldstandard beschrieben (Busenlechner et al. 2009, Dalle Carbonare et al. 2005, Fuerst et al. 2004, Furst et al. 2003, Somanathan und Simunek 2006). Eine histomorphometrische Auswertung kann entweder manuell oder mit Hilfe semi- oder vollautomatischer Bildanalysesysteme durchgeführt werden (Malluche et al. 1982). In der vorliegenden Untersuchung wurde die Knochenneubildung innerhalb der Sinusbodenaugmentate auf manuelle Weise histomorphometrisch evaluiert. Ein derartiges Vorgehen bringt jedoch einige Schwierigkeiten mit sich, da es sich bei der Histomorphometrie um eine invasive Methode handelt (Dalle Carbonare et al. 2005). Um das Knochengewebe des gesamten Kieferhöhlenaugmentats studieren zu können, ist es notwendig, histologische Schliffpräparate der Kieferhöhle anzufertigen.

Das Ziel der vorliegenden Studie war es, die Knochenneubildung über den gesamten dreidimensionalen Raum des Sinusbodenaugmentats zu evaluieren. Der Sinus maxillaris ist ein räumlich komplex aufgebautes anatomisches Gebilde, das starken individuellen Schwankungen unterworfen ist. Die Mikroarchitektur des neu gebildeten Knochengewebes kann auf histologischen Schnitten jedoch nur zweidi- 
mensional betrachtet werden (Garrahan et al. 1986). Ein Rückschluss auf den räumlichen Zusammenhang ist bei der histomorphometrischen Auswertung nur durch Extrapolation mit Hilfe stereologischer Verfahren möglich (Parfitt 1983). In den letzten Jahren wurden lichtmikroskopische Verfahren entwickelt, wie die Konfokalmikroskopie (confocal laser scanning microscopy) oder die 3D-SIM-Mikroskopie (structured illumination microscopy), mit deren Hilfe eine verbesserte dreidimensionale Darstellung möglich ist. Diese Methoden haben jedoch nur eine Eindringtiefe von wenigen Millimetern und können aus diesem Grund nicht für die Untersuchung komplexer Geweben verwendet werden (Weigel et al. 2009). Um dem dreidimensionalen Charakter des Augmentats dennoch gerecht zu werden, wurden in der vorliegenden Untersuchung Schliffpräparate verschiedener Lokalisationen des Augmentats angefertigt und ausgewertet. Bei allen Präparaten wurde ein Schnitt zentral durch das inserierte Implantat und jeweils ein weiterer Schnitt anterior und posterior davon hergestellt. Diese histologischen Präparate repräsentieren jedoch nur Bereiche innerhalb des Augmentats. Aus diesem Grund ist es natürlich fraglich, inwieweit mit Hilfe einzelner weniger Schliffpräparate die Knochenneubildung innerhalb des gesamten Augmentats evaluiert werden kann.

Ein weiterer Diskussionspunkt der manuell durchgeführten histomorphometrischen Evaluation ist die starke Abhängigkeit vom Untersucher und die Ungenauigkeit der Ergebisse (Kulak und Dempster 2010). Die Auswertung dieser Studie wurde von nur einem Untersucher durchgeführt. Dieser wurde im Vorfeld darauf trainiert, das neu gebildete Knochengewebe in den histologischen Schnitten möglichst objektiv zu identifizieren. Im Rahmen der Auswertung wurde der neugebildete Knochen mit Hilfe eines Bildbearbeitungsprogramms manuell markiert und ausgemessen. In manchen Bereichen des Augmentats war es jedoch schwer, das neu gebildete Knochengewebe von dem dunkel erscheinenden Knochenersatzmaterial zu unterscheiden. Die beschriebenen Daten sind aus diesem Grund nicht vollkommen unabhängig von der subjektiven Einschätzung des Untersuchers.

Trotz dieser möglichen Nachteile des Auswertungsverfahrens wird die Knochenhistomorphometrie in der Literatur als eines der wichtigsten Werkzeuge zur Erforschung des Knochenmetabolismus beschrieben. Es ermöglicht Informationen, die zur Zeit durch kein anderes Verfahren bereitgestellt werden können (Kulak und 
Dempster 2010). Aus diesem Grund hat sich das Verfahren im klinischen Alltag und in der Wissenschaft etabliert; es wird besonders bei der Erforschung pathologischer Knochenveränderungen und bei der Interpretation der Wirkung von Medikamenten auf das Knochengewebe eingesetzt (Kulak und Dempster 2010). Wie bereits beschrieben wird eine traditionelle histomorphometrische Auswertung nur zweidimensional durchgeführt und die Ergebnisse durch stereologische Verfahren in die dritte Dimension extrapoliert (Parfitt 1983). In den letzten Jahrzehnten wurde dieses Verfahren jedoch zunehmend weiterentwickelt, um derartige Probleme zu minimieren. Dazu gehört die Entwicklung semi- und vollautomatischer Bildanalysesysteme, mit denen man in Kombination mit anspruchsvoller Stereologie-Software in der Lage ist, eine verbesserte räumliche Auswertung durchzuführen. Diese Systeme haben die manuelle Auswertungsmethode, wie sie in der vorliegenden Studie verwendet wurde, weitestgehend abgelöst (Malluche et al. 1982). Ein derartiges System stand bei der Auswertung der Augmentate nicht zur Verfügung, so dass das Knochengewebe manuell vermessen wurde. Ein weiterer Fortschritt zur Verbesserung der Knochenhistomorphometrie war die Entwicklung hochwertiger Kunstharze und damit die Möglichkeit zur Herstellung von Trenn-Dünnschliffen (Donath und Breuner 1982). Auch mineralisierte Knochengewebe können somit eingebettet und dadurch histologische Schliffe hoher Qualität und Detailgenauigkeit ohne wesentlichen Informationsverlust angefertigt werden (Frost 1958). In der vorliegenden Studie wurden die Präparate mit Hilfe der Trenn-Dünnschlifftechnik nach Donath und Breuner hergestellt, bei der das Gewebe in einem Kunstharz fixiert wird und dadurch nicht entkalzifiziert werden muss (Donath und Breuner 1982).

Zusammenfassend kann festgehalten werden, dass die Histomorphometrie, obwohl eine gewisse Ungenauigkeit mit in die Interpretation der Ergebnisse einbezogen werden muss, als Goldstandard für eine wie in dieser Studie durchgeführte Evaluation der Knochenneubildung anzusehen ist. In den letzten Jahren wurden zunehmend neuere nichtinvasive Verfahren beschrieben, die sich gegenwärtig jedoch noch nicht in der medizinischen Forschung etabliert haben und den gleichen Informationsgehalt liefern können wie eine histologische Auswertung. Eine histo- 
morphometrische Untersuchung der Sinusbodenaugmentate kann nur mit Hilfe eines Tiermodells realisiert werden. Eine Herausforderung für die Zukunft wird sein, neuere Verfahren dahingehend weiter zu entwickeln, dass eine in-vivo-Knochenevaluation beim Menschen möglich ist, die vergleichbare Informationen liefern kann wie die Histomorphometrie heute, ohne eine Schädigung durch vermehrte Strahlenexposition zu bewirken.

\subsection{Ergebnisse}

Im Rahmen der vorliegenden Studie wurde der Verlauf der Knochenneubildung innerhalb der Sinusbodenaugmentate histomorphometrisch evaluiert und die Hypothesen getestet, dass der Wachstumsfaktor GDF-5 zu einer verstärkten und homogeneren Knochenneubildung führt. Um den möglichen Einfluss von Dosis und Zeit auf die Wirkung des Faktors zu untersuchen, wurden zwei unterschiedlich starke Konzentrationen verwendet und die Auswertung nach zwei verschieden langen Beobachtungszeiten durchgeführt.

Bei der Beurteilung der Kontrollgruppe zeigte sich nach vier Wochen ein Verlauf der Knochenneubildung, der in der Literatur als typisch für osteokonduktive Augmentationsmaterialien beschrieben wurde (Furst et al. 2003, Terheyden et al. 1999). Die höchsten Raten an neu gebildetem Knochengewebe wurden in der Region nahe des ortsständigen Kieferknochens (ROI 1) gemessen. Von dort aus nahmen die Werte mit zunehmender Entfernung vom ortsständigen Knochen (ROI 5) stetig ab. Nach zwölf Wochen wurde bei der Kontrollgruppe tendenziell mehr Knochen mit ähnlicher Gradientenausbildung und minimaler Knochenneubildung in ROI 5 beobachtet. Die Ergebnisse deuten darauf hin, dass rein osteokonduktive Augmentationsmaterialien, bei größeren Augmentatvolumina, wahrscheinlich auch nach längerer Zeit nicht vollständig durch das vom umgebenden Kieferknochen ausgehende Wachstum durchbaut werden können. Die Stärke der Knochenneubildung scheint von der Makrostruktur des porösen Knochenersatzmaterials und der Struktur des zugrundeliegenden Knochengewebes abhängig zu sein (Schliephake et al. 1994). Während des Einwachsens von Knochengewebe 
konkurrieren Osteoblasten und ihre Vorläuferzellen mit schneller proliferierenden und einwachsenden Zellen aus dem umliegenden Bindegewebe. Wahrscheinlich findet aus diesem Grund eine suffiziente Knochenneubildung nur in den basalen Regionen des Augmentats in der Nähe des ortsständigen Knochens statt und schafft es nicht über das Niveau des umgebenden Knochens hinaus (Schliephake et al. 1994). Ähnliche Ergebnisse wurden bereits von Busenlechner und Fürst beschrieben (Busenlechner et al. 2009, Fuerst et al. 2004). Busenlechner und Mitarbeiter untersuchten den Verlauf der Knochenneubildung innerhalb von zwei osteokonduktiven, synthetisch hergestellten Augmentationsmaterialien (BioOss $\AA_{,}$Ostim $\left.{ }^{\circledR}\right)$. Die Augmentate wurden unter Zuhilfenahme von parallel zum Sinusboden verlaufenden Kurven in drei Interessenregionen unterteilt und histomorphometrisch evaluiert. Beide Materialien zeigten sowohl nach sechs als auch nach zwölf Wochen Beobachtungszeit einen stetig abnehmenden Gradienten von Region 1 (Bereich von 0-1mm Abstand zum Kieferknochen) bis zu Region 3 (4-5mm Abstand zum Kieferknochen) (Busenlechner et al. 2009). Fuerst untersuchte die Knochenneubildung in Sinusbodenaugmentaten an Minipigs. Als Augmentationsmaterial verwendete er mineralisierten Rinderknochen, den er mit Osteoblasten vom autogenen Beckenkammknochen vorbehandelte hatte. Auch im Rahmen dieser Untersuchung unterteilte die Arbeitsgruppe das Augmentat in drei Interessenregionen (max. 10mm Abstand zum Kieferknochen) und beschrieb eine Abnahme der Knochenneubildung in Abhängigkeit vom Abstand zum ortsständigen Knochen (Fuerst et al. 2004).

In der Untersuchung der Testgruppen wurde nach vier Wochen eine stärkere Knochenneubildung beobachtet als bei der Kontrollgruppe, wovon jedoch nur die der Niedrigdosisgruppe signifikant verbessert war $(p=0,0184)$. Der Verlauf der Knochenneubildung beider Dosisgruppen ähnelte dem der Kontrollgruppe. In allen untersuchten Gruppen konnte nach dieser Zeit keine homogene Knochenneubildung innerhalb des gesamten Augmentats nachgewiesen werden. Nach zwölf Wochen wurde bei beiden Testgruppen im Vergleich zu der Kontrollgruppe eine statistisch signifikant höhere Knochenneubildung nachgewiesen $(p=0,023)$. Von allen untersuchten Gruppe konnte nach dieser Zeit nur bei der Niedrigdosisgruppe eine ho- 
mogene Knochenneubildung innerhalb des gesamten Augmentats nachgewiesen werden.

Die Ergebnisse der Testgruppen bestätigten die Hypothese, dass der Wachstumsfaktor GDF-5 im Vergleich zu den Kontrollgruppen zu einer insgesamt verstärkten Knochenneubildung innerhalb des Augmentats führt. Jedoch waren Unterschiede zwischen den beiden Beobachtungszeiträumen zu erkennen. Der Wachstumsfaktor rhGDF-5 führte nach vier Wochen bei der Testgruppe mit der geringeren Konzentration (400 $\mathrm{gg}$ rhGDF-5/1g $\beta$-TCP) in allen Regionen (ROI 1-5) zu einer signifikant höheren Knochenneubildung als bei der entsprechenden Kontrollgruppe. Dennoch wurde bei beiden Testgruppen der für osteokonduktive Knochenersatzmaterialien beschriebene Gradient beobachtet. Dies kann dadurch erklärt werden, dass GDF-5 zwar eine osteoinduktive Wirkung hat, diese aber nicht für die Rekrutierung osteoblastärer Zellen in die zentralen Regionen des Augmentats ausreicht (Kakudo et al. 2007, Khan et al. 2005). Ähnlich Ergebnisse wurden 2007 von Kakudo beschrieben. Die Arbeitsgruppe implantierte ein mit GDF-5 beschichtetes Kollagen in Beinmuskeltaschen von Ratten. Nach drei Wochen wurde bei einer Konzentration von 500 $\mu$ gDF-5/1ml Kollagen neu gebildetes Knochengewebe an den äußeren Grenzen des Materials, angrenzend an das ortsständige Muskelgewebe, identifiziert (Kakudo et al. 2007). Die Knochenneubildung hängt maßgeblich von der Neoangiogenese ab. Möglicherweise ist eine homogene Knochenneubildung erst nach dem Einwachsen vom Kieferknochen ausgehender Gefäße in das Trägermaterial möglich, wodurch perivaskuläre, osteoinduktive Zellen durch Chemotaxis rekrutiert werden können. Aus diesem Grund kann die fehlende Gefäßbildung ein Grund für die fehlende Osteoinduktion in den zentralen Regionen des Augmentats nach der kürzeren Einheilungszeit sein (Khan et al. 2005). Nach zwölf Wochen wurde bei beiden Testgruppen ein divergenter Verlauf der Knochenneubildung innerhalb des Augmentats beobachtet. Bei den Augmentaten mit der niedrigeren Konzentration kam es zu einer statistisch homogenen Knochenneubildung innerhalb des gesamten Augmentats. Dagegen zeigte die Evaluation der Knochenneubildung innerhalb der Augmentate mit der höheren Dosierung einen abnehmenden Verlauf. 
In der vorliegenden Studie wurden zwei unterschiedlich starke Konzentrationen des Wachstumsfaktors verwendet. Nach beiden Beobachtungszeiträumen wurde bei der geringeren Dosis (400 $\mu$ g rhGDF-5/1g $\beta$-TCP) eine stärkere Knochenneu-

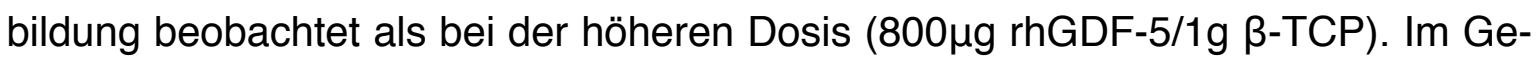
gensatz zu der niedrigeren Dosis konnte bei der höhere Konzentration des Wachstumsfaktors GDF-5 auch nach zwölf Wochen keine homogene Knochenneubildung innerhalb des gesamten Augmentats beobachtet werden. Unter Steigerung der Konzentration war keine vermehrte Knochenbildung erkennbar. Es lag keine direkte Dosis-Wirkungs-Beziehung vor. Ähnliche Ergebnisse wie in der vorliegenden Untersuchung wurden von Magit beschrieben. In einem Kaninchenmodell untersuchte die Arbeitsgruppe den dosisabhängigen Einfluss von GDF-5 auf die Knochenreifung. Dabei wurden drei verschiedene Konzentrationen des Wachstumsfaktors verwendet $\left(500 \mu \mathrm{g}, 1000 \mu \mathrm{g}\right.$ und $1500 \mu \mathrm{g} / 1 \mathrm{~cm}^{3}$ Matrix). Die beiden niedrigeren Konzentrationen $\left(500 \mu \mathrm{g}\right.$ und $1000 \mu \mathrm{g} / 1 \mathrm{~cm}^{3}$ Matrix) führten in der Untersuchung zu neu gebildetem Geflechtknochen. Bei der höheren Konzentration $\left(1500 \mu \mathrm{g} / 1 \mathrm{~cm}^{3}\right.$ Matrix) wurde nur wenig trabekulärer Knochen beschrieben (Magit et al. 2006). Kim untersuchte die osteoinduktive Wirkung von GDF-5 in Verbindung mit absorbierbaren Kollagenschwämmen bei der periodontalen Wundheilung in intraossären Defekten beim Hund. Die Arbeitsgruppe verwendete drei verschiedene Konzentrationen des Wachstumsfaktors (1 $\mu \mathrm{g}, 20 \mu \mathrm{g}, 100 \mu \mathrm{g}$ rhGDF-5/Defekt). Die beiden niedrigeren rhGDF-5-Dosen zeigten eine stärkere Wirkung als die hohe Dosis und die Kontrollgruppe ohne osteoinduktiven Faktor (Kim et al. 2009). Aus den vorliegenden Ergebnissen und der aktuellen Literatur geht hervor, dass sich die Stärke der Knochenneubildung nicht proportional zu der Dosierungsstärke zu verhalten scheint. Ein Grund dafür könnte möglicherweise die Freisetzungskinetik des Wachstumsfaktors bei höherer Konzentration aus dem Trägermaterial sein. Obwohl in der Literatur noch kontrovers über die ideale Dosierung eines derartigen Wachstumsfaktors diskutiert wird, erscheint eine kontrollierte kontinuierliche Abgabe am Ort der gewünschten Knochenneubildung entscheidend zu sein (Schliephake 2010). Oberflächlich adsorptiv beschichtete Augmentationsmaterialien geben den Wachstumsfaktor jedoch durch eine schlagartige Freisetzung (burst release) mit einem Verlust von bis zu $80 \%$ der Aktivität innerhalb der ersten 48 
Stunden nach der Implantation ab (Uludag et al. 1999). In-vitro-Untersuchungen von Poehling haben allerdings gezeigt, dass der Wachstumsfaktor GDF-5 in der hier verwendeten Kombination mit $\beta$-TCP fast vollständig innerhalb der ersten sieben Tage freigesetzt wurde (Poehling 2001).

\subsection{Schlussfolgerung}

Im Rahmen der vorliegenden Studie konnte für die Kontrollgruppen der aus der Literatur bekannte Gradient osteokonduktiver Knochenersatzmaterialien bestätigt werden. Die Ergebnisse zeigen, dass bei größeren Augmentatvolumina und innerhalb einer Einheilungszeit von drei Monaten Materialien dieser Art nicht vollständig durch vom ortsständigen Kieferknochen ausgehendes osteokonduktives Knochenwachstum durchbaut werden können. Der Wachstumsfaktor GDF-5 führte im Vergleich zu den Kontrollgruppen bei allen Testgruppen und nach beiden Beobachtungszeiten zu einer z.T. statistisch signifikant verstärkten Knochenneubildung. Trotz Steigerung der Knochenneubildung zeigte sich nach vier Wochen eine gradielle Abnahme der Knochenneubildung in Abhängigkeit vom Abstand zum Lagerknochen, wie bei osteokonduktiven Materialien typisch. Nach einer längeren Einheilungsdauer zeigte sich bei der geringeren Konzentration eine homogene Knochenneubildung. Möglicherweise ist der Fortschritt der Vaskularisation nach zwölf Wochen eine Bedingung für die homogene Knochenneubildung. Die Ergebnisse legen nahe, dass die Steigerung der Knochenneubildung nicht direkt proportional zu der Konzentration des Wachstumsfaktors ist. In der vorliegenden Untersuchung wurde eine stärkere und homogene Knochenneubildung bei der niedrigen Dosierung des Wachstumsfaktors beobachtet. Anscheinend kann der osteoinduktive Effekt durch eine weitere Steigerung der Konzentration nicht weiter begünstigt werden, wie in anderen Studien ebenfalls erwähnt (Magit et al. 2006). Möglicherweise erlaubt auch die Freisetzungskinetik des durch Adsorption befestigten Wachstumsfaktors bei höheren Konzentrationen keine weitere Steigerung der osteoinduktiven Potenz. 


\section{Zusammenfassung}

Mit Bezug auf die zahnärztliche Implantologie gehört die Sinusbodenaugmentation zu einer häufig durchgeführten präimplantologischen Operation, um das Implantatlager des Oberkiefers aufzubauen. In den letzten Jahren wurden zunehmend synthetische Knochenersatzmaterialien entwickelt und untersucht, um die Entnahmemorbidität bei autogenen Transplantaten zu umgehen. Besondere Aufmerksamkeit wird derzeit Materialkombinationen aus synthetischem Knochenersatzmaterial mit osteoinduktiv wirkenden Wachstumsfaktoren geschenkt, die neben der Osteokonduktion eine Knochenneubildung induzieren. Das Ziel der vorliegenden Untersuchung bestand darin, die Knochenneubildung innerhalb des Sinusbodenaugmentats dreidimensional zu untersuchen und die osteoinduktive Wirkung des Wachstumsfaktors GDF-5 zu evaluieren.

Die Studie wurde als Tiermodell an zwölf adulten Göttinger Minipigs durchgeführt. In einem randomisierten split mouth design wurde die eine Kieferhöhle der Tiere mit dem alloplastischen Knochenersatzmaterial $\beta$-TCP augmentiert, während auf der kontralateralen Seite eine Materialkombination aus $\beta$-TCP und dem osteoinduktiv wirkenden syntetisch hergestellten Wachstumsfaktor rhGDF-5 verwendet wurde. Um den Einfluss von Dosis und Zeit auf die Wirkung des Faktors zu evalu-

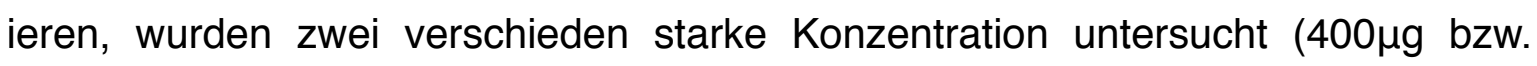
$800 \mu \mathrm{g}$ rhGDF-5/1g $\beta$-TCP) und die Studie nach zwei unterschiedlichen Beobachtungszeiträumen durchgeführt (vier und zwölf Wochen). Nach Ablauf der Beobachtungszeiträume wurden histologische Schliffpräparate der Kieferhöhlen mit den enthaltenen Sinusbodenaugmentaten angefertigt. Das neu gebildete Knochengewebe wurde anschließend manuell histologisch markiert und computerassistiert metrisch ausgewertet.

Nach vier Wochen Einheilungszeit wurde eine im Vergleich zu den Kontrollpräparaten verbesserte Knochenneubildung in beiden Testgruppen beobachtet, wovon

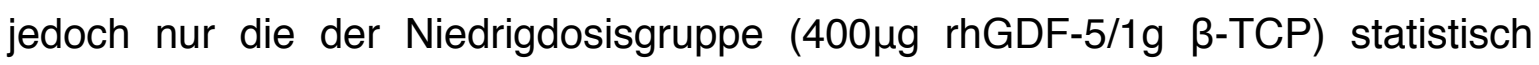
signifikant war $(p=0,0184)$. Dennoch ähnelte der Gradient der Knochenneubildung 
beider Dosisgruppen dem der Kontrollgruppe, mit einem vom ortsständigen Knochen abnehmenden Verlauf. Eine homogene Knochenneubildung innerhalb des gesamten Augmentats konnte bei keiner der untersuchten Gruppen nach diesem Zeitraum festgestellt werden.

Nach zwölf Wochen Einheilungszeit war die Knochenneubildung beider Testgruppen signifikant höher als bei der Kontrollgruppe $(p=0,023)$. Bei der Niedrigdosis-

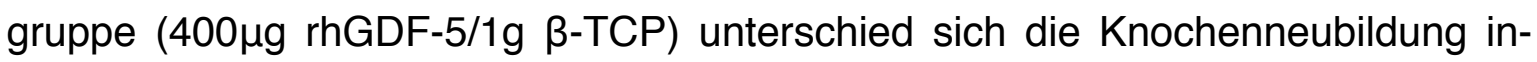
nerhalb der untersuchten Regionen (ROI 1-5) nicht signifikant voneinander $(p=0,11)$. Bei diesen Präparaten konnte statistisch somit eine homogene Knochenneubildung innerhalb des gesamten Augmentats nachgewiesen werden. Der Gradient der Hochdosisgruppe (800 $\mu$ g rhGDF-5/1g $\beta$-TCP) ähnelte dem der Kontrollgruppe. Die höchsten Werte wurden in der Region nahe dem ortsständigen Kieferknochen gemessen. Von dort aus nahmen die Werte stetig ab. Für diese beiden Gruppen konnte keine homogene Knochenneubildung innerhalb des Augmentats nachgewiesen werden.

Die Ergebnisse der Kontrollgruppen ohne Wachstumsfaktor bestätigten den in der Literatur beschriebenen Verlauf der Knochenneubildung rein osteokonduktiver Augmentationsmaterialien (Busenlechner et al. 2009, Fuerst et al. 2004, Furst et al. 2003, Terheyden et al. 1999). Eine suffiziente Knochenneubildung findet bei größeren Augmentatvolumina und innerhalb einer Einheilungszeit von drei Monaten nur in den basalen Regionen des Augmentats, in der Nähe des ortsständigen Knochens statt. Die Ergebnisse der Testgruppen bestätigten die Hypothese, dass der Wachstumsfaktor GDF-5 im Vergleich zu den Kontrollgruppen zu einer stärkeren Knochenneubildung führt. Dennoch zeigte der Verlauf der Knochenneubildung beider Testgruppen nach vier Wochen immer noch einen, mit der Kontrollgruppe vergleichbaren, osteokonduktiven Charakter, allerdings mit z.T. statistisch signifikant erhöhten Knochenneubildungen. Erst nach zwölf Wochen führte der Faktor bei der Niedrigdosisgruppe zu einer homogenen Knochenneubildung innerhalb des gesamten Augmentats. Der Wachstumsfaktor führte dagegen bei der Hochdosisgruppe auch nach zwölf Wochen nicht zu einer statistisch homogenen Knochenneubildung innerhalb des gesamten Augmentats. Wie in der Literatur beschrieben, scheint sich die Stärke der Knochenneubildung nicht proportional zu 
der Dosierungsstärke zu verhalten (Kim et al. 2009, Magit et al. 2006). Ein Grund dafür könnte die Freisetzungskinetik des Wachstumsfaktors aus dem adsorptiv beschichteten Trägermaterial sein (Schliephake 2010). 


\section{Literaturverzeichnis}

Aerssens J, Boonen S, Lowet G und Dequeker J (1998): Interspecies differences in bone composition, density, and quality: potential implications for in vivo bone research. Endocrinology 139, 663-670

Albrektsson T und Johansson C (2001): Osteoinduction, osteoconduction and osseointegration. Eur Spine J 10 Suppl 2, S96-101

Arosarena $\mathrm{O}$ und Collins W (2005): Comparison of BMP-2 and -4 for rat mandibular bone regeneration at various doses. Orthod Craniofac Res $\underline{8}, 267-276$

Atwood DA (1971): Reduction of residual ridges: a major oral disease entity. J Prosthet Dent 26, 266-279

Baldini N, De Sanctis M und Ferrari M (2011): Deproteinized bovine bone in periodontal and implant surgery. Dent Mater 27, 61-70

Barboza EP, Duarte ME, Geolas L, Sorensen RG, Riedel GE und Wikesjo UM (2000): Ridge augmentation following implantation of recombinant human bone morphogenetic protein-2 in the dog. J Periodontol $\underline{71}$, 488-496

Benke D, Olah A und Mohler H (2001): Protein-chemical analysis of Bio-Oss bone substitute and evidence on its carbonate content. Biomaterials $\underline{22}, 1005-$ 1012

Bianchi J, Fiorellini JP, Howell TH, Sekler J, Curtin H, Nevins ML und Friedland B (2004): Measuring the efficacy of rhBMP-2 to regenerate bone: a radiographic study using a commercially available software program. Int J Periodontics Restorative Dent 24, 579-587

Blair VP: Surgery and disease of the mouth and jaws. Mosby, St Louis, 1918

Boyapati L und Wang HL (2006): The role of platelet-rich plasma in sinus augmentation: a critical review. Implant Dent 15, 160-170

Boyne PJ und James RA (1980): Grafting of the maxillary sinus floor with autogenous marrow and bone. J Oral Surg $\underline{38}, 613-616$

Boyne PJ, Marx RE, Nevins M, Triplett G, Lazaro E, Lilly LC, Alder M und Nummikoski $P$ (1997): A feasibility study evaluating rhBMP-2/absorbable collagen sponge for maxillary sinus floor augmentation. Int $\mathrm{J}$ Periodontics Restorative Dent 17, 11-25

Boyne PJ, Lilly LC, Marx RE, Moy PK, Nevins M, Spagnoli DB und Triplett RG (2005): De novo bone induction by recombinant human bone morphogenetic protein-2 (rhBMP-2) in maxillary sinus floor augmentation. J Oral MaxiIlofac Surg $\underline{63}$, 1693-1707

Bramlage CP, Haupl T, Kaps C, Bramlage P, Muller GA und Strutz F (2005): [Bone morphogenetic proteins in the skeletal system]. Z Rheumatol $\underline{64}, 416-422$

Busenlechner D, Huber CD, Vasak C, Dobsak A, Gruber R und Watzek G (2009): Sinus augmentation analysis revised: the gradient of graft consolidation. Clin Oral Implants Res 20, 1078-1083

Buxton P, Edwards C, Archer CW und Francis-West P (2001): Growth/differentiation factor-5 (GDF-5) and skeletal development. J Bone Joint Surg Am 83-A Suppl 1, S23-30 
Cameron HU, Macnab I und Pilliar RM (1977): Evaluation of biodegradable ceramic. J Biomed Mater Res 11, 179-186

Cawood Jl und Howell RA (1988): A classification of the edentulous jaws. Int J Oral Maxillofac Surg 17, 232-236

Chang SC, Hoang B, Thomas JT, Vukicevic S, Luyten FP, Ryba NJ, Kozak CA, Reddi AH und Moos M, Jr. (1994): Cartilage-derived morphogenetic proteins. New members of the transforming growth factor-beta superfamily predominantly expressed in long bones during human embryonic development. J Biol Chem 269, 28227-28234

Chappard C, Berger G, Roux C und Laugier P (1999): Ultrasound measurement on the calcaneus: influence of immersion time and rotation of the foot. Osteoporos Int $\underline{9}$, 318-326

Cheng H, Jiang W, Phillips FM, Haydon RC, Peng Y, Zhou L, Luu HH, An N, Breyer B, Vanichakarn P (2003): Osteogenic activity of the fourteen types of human bone morphogenetic proteins (BMPs). J Bone Joint Surg Am $\underline{85-A}$, 1544-1552

Cho YB, Moon SJ, Chung CH und Kim HJ (2011): Resorption of labial bone in maxillary anterior implant. J Adv Prosthodont $\underline{3}$, 85-89

Clayton KB und Sullivan AM (2007): Differential effects of GDF5 on the medial and lateral rat ventral mesencephalon. Neurosci Lett 427, 132-137

Cochran DL, Jones AA, Lilly LC, Fiorellini JP und Howell H (2000): Evaluation of recombinant human bone morphogenetic protein-2 in oral applications including the use of endosseous implants: 3-year results of a pilot study in humans. J Periodontol 71, 1241-1257

Dalle Carbonare L, Valenti MT, Bertoldo F, Zanatta M, Zenari S, Realdi G, Lo Cascio V und Giannini S (2005): Bone microarchitecture evaluated by histomorphometry. Micron 36, 609-616

Del Fabbro M, Testori T, Francetti L und Weinstein R (2004): Systematic review of survival rates for implants placed in the grafted maxillary sinus. Int $\mathrm{J}$ Periodontics Restorative Dent 24, 565-577

Donath K und Breuner G (1982): A method for the study of undecalcified bones and teeth with attached soft tissues. The Sage-Schliff (sawing and grinding) technique. J Oral Pathol 11, 318-326

Ekert O, Kunkel M, Wegener J und Wagner W (1999): Der Oberkiefer - das schlechtere Implantatlager? Mund Kiefer GesichtsChir 3, 43 - 47

Everman DB, Bartels CF, Yang Y, Yanamandra N, Goodman FR, Mendoza-Londono JR, Savarirayan R, White SM, Graham JM, Jr., Gale RP (2002): The mutational spectrum of brachydactyly type C. Am J Med Genet 112, 291-296

Fiorellini JP, Howell TH, Cochran D, Malmquist J, Lilly LC, Spagnoli D, Toljanic J, Jones A und Nevins M (2005): Randomized study evaluating recombinant human bone morphogenetic protein-2 for extraction socket augmentation. $\mathrm{J}$ Periodontol $\underline{76}$, 605-613

Foitzik C und Stamm M (1997): Einsatz von phasenreinem B-Tricalciumphosphat zur Auffüllung von ossären Defekten - Biologische Materialvorteile und klinische Erfahrungen. Quintessenz 10, 1365-1377

Foitzik C und Staus H (1999): Phasenreines B-Trikalziumphosphat zum Knochenersatz bei parodontaler Indikation. Quintessenz 므, 1049 - 1058 
Frost HM (1958): Preparation of thin undecalcified bone sections by rapid manual method. Stain Technol 33, 273-277

Fuerst G, Tangl S, Gruber R, Gahleitner A, Sanroman F und Watzek G (2004): Bone formation following sinus grafting with autogenous bone-derived cells and bovine bone mineral in minipigs: preliminary findings. Clin Oral Implants Res $\underline{15}, 733-740$

Furst G, Gruber R, Tangl S, Zechner W, Haas R, Mailath G, Sanroman F und Watzek G (2003): Sinus grafting with autogenous platelet-rich plasma and bovine hydroxyapatite. A histomorphometric study in minipigs. Clin Oral Implants Res $\underline{14}, 500-508$

Galois L, Mainard D, Cohen P, Pfeffer F, Traversari R und Delagoutte JP (2000): [Filling of bone defects with tricalcium phosphate beta in traumatology]. Ann Chir $\underline{125}$, 972-981

Galois L, Mainard D und Delagoutte JP (2002): Beta-tricalcium phosphate ceramic as a bone substitute in orthopaedic surgery. Int Orthop 26, 109-115

Garrahan NJ, Mellish RW und Compston JE (1986): A new method for the two-dimensional analysis of bone structure in human iliac crest biopsies. J Microsc 142, 341-349

Gruber RM, Ludwig A, Merten HA, Achilles M, Poehling S und Schliephake H (2008): Sinus floor augmentation with recombinant human growth and differentiation factor-5 (rhGDF-5): a histological and histomorphometric study in the Goettingen miniature pig. Clin Oral Implants Res 19, 522-529

Gruber RM, Ludwig A, Merten HA, Pippig S, Kramer FJ und Schliephake H (2009): Sinus floor augmentation with recombinant human growth and differentiation factor-5 (rhGDF-5): a pilot study in the Goettingen miniature pig comparing autogenous bone and rhGDF-5. Clin Oral Implants Res 20, 175-182

Herberg S, Siedler M, Pippig S, Schuetz A, Dony C, Kim CK und Wikesjo UM (2008): Development of an injectable composite as a carrier for growth factor-enhanced periodontal regeneration. J Clin Periodontol 35, 976-984

Hoexter DL (2002): Bone regeneration graft materials. J Oral Implantol $\underline{28}, 290-$ 294

Horch H, Sader R und Kolk A (2004): Synthetische, phasenreine Beta-Trikalziumphosphat-Keramik (Cerasorb) zur Knochenregeneration bei der rekonstruktiven Chirurgie der Kiefer - Eine klinische Langzeitstudie mit Literaturüber-sicht. Deutsche Zahnärztliche Zeitschrift 59, 680-686

Howell TH, Fiorellini J, Jones A, Alder M, Nummikoski P, Lazaro M, Lilly L und Cochran D (1997): A feasibility study evaluating rhBMP-2/absorbable collagen sponge device for local alveolar ridge preservation or augmentation. Int J Periodontics Restorative Dent 17, 124-139

Hurley FM, Costello DJ und Sullivan AM (2004): Neuroprotective effects of delayed administration of growth/differentiation factor-5 in the partial lesion model of Parkinson's disease. Exp Neurol 185, 281-289

Jung BA, Yildizhan F und Wehrbein H (2008): Bone-to-implant contact of orthodontic implants in humans--a histomorphometric investigation. Eur J Orthod $\underline{30}, 552-557$

Jung RE, Glauser R, Scharer P, Hammerle CH, Sailer HF und Weber FE (2003): Effect of rhBMP-2 on guided bone regeneration in humans. Clin Oral Implants Res $\underline{14}, 556-568$ 
Kakudo N, Wang YB, Miyake S, Kushida S und Kusumoto K (2007): Analysis of osteochondro-induction using growth and differentiation factor-5 in rat muscle. Life Sci 81, 137-143

Kärcher H (2000): Mikrochirurgischer Knochenersatz. Mund Kiefer GesichtsChir $\underline{4}$, 322-330

Katthagen B: Knochenregeneration mit Knochenersatzmaterialien. Springer- Verlag, Berlin 1986

Khan SN, Cammisa FP, Jr., Sandhu HS, Diwan AD, Girardi FP und Lane JM (2005): The biology of bone grafting. J Am Acad Orthop Surg 13, 77-86

Kim TG, Wikesjo UM, Cho KS, Chai JK, Pippig SD, Siedler M und Kim CK (2009): Periodontal wound healing/regeneration following implantation of recombinant human growth/differentiation factor-5 (rhGDF-5) in an absorbable collagen sponge carrier into one-wall intrabony defects in dogs: a dose-range study. J Clin Periodontol $\underline{36}, 589-597$

Klein C, Driessen A und de Groot K (1984): Relationship between the degradation behaviour of calcium phosphate ceramics and their physical-chemical characteristics and ultrastructural geometry. Biomaterials $\underline{5}, 157$ - 160

Kulak CA und Dempster DW (2010): Bone histomorphometry: a concise review for endocrinologists and clinicians. Arq Bras Endocrinol Metabol 54, 87-98

Laiblin C und Jaeschke G (1979): [Clinical chemistry examinations of bone and muscle metabolism under stress in the Gottingen miniature pig--an experimental study]. Berl Munch Tierarztl Wochenschr 92, 124-128

Lee J, Susin C, Rodriquez NA, De Stefano J, Prasad HS, Buxton AN und Wikesjö UME (2012): Sinus augmentation using rhBMP-2/ACS in a mini-pig model: relative efficacy of autogenous fresh particulate iliac bone grafts. (Clin Oral Implants Res, im Druck)

Linder J, Longhurst P und Johnson N (1981): A paraffin-celloidin embedding method for studying soft-hard tissue interfaces. Arch Oral Biol 26, 753-755

Magit DP, Maak T, Trioano N, Raphael B, Hamouria Q, Polzhofer G, Drespe I, Albert TJ und Grauer JN (2006): Healos/recombinant human growth and differentiation factor-5 induces posterolateral lumbar fusion in a New Zealand white rabbit model. Spine (Phila Pa 1976) 31, 2180-2188

Malluche HH, Sherman D, Meyer W und Massry SG (1982): A new semiautomatic method for quantitative static and dynamic bone histology. Calcif Tissue Int 34, 439-448

Martuscelli R, Maltarello MC, Maraldi NM, Sbordone C und Sbordone L (2008): Histological and clinical survey of polylactic-polyglycolic acid and dextrane copolymer in maxillary sinus lift: a pilot in vivo study. Int $\mathrm{J}$ Immunopathol Pharmacol 21, 687-695

Merten HA, Gruber, R. M., Nitsch, A., Ludwig, A., Schliephake, H. (2003): Evaluation oralchirurgischer Augmentationsmaterialien - Ein tierexperimentell- histomorphometrischer Vergleich. Implantologie 11, 215-236

Miranda DA, Blumenthal NM, Sorensen RG, Wozney JM und Wikesjo UM (2005): Evaluation of recombinant human bone morphogenetic protein-2 on the repair of alveolar ridge defects in baboons. J Periodontol $\underline{76}, 210-220$

Mosekilde L, Kragstrup J und Richards A (1987): Compressive strength, ash weight, and volume of vertebral trabecular bone in experimental fluorosis in pigs. Calcif Tissue Int $\underline{40}, 318-322$ 
Mosekilde L, Weisbrode SE, Safron JA, Stills HF, Jankowsky ML, Ebert DC, Danielsen CC, Sogaard CH, Franks AF, Stevens ML (1993): Calcium-restricted ovariectomized Sinclair S-1 minipigs: an animal model of osteopenia and trabecular plate perforation. Bone 14, 379-382

Nafe R und Schlote W (2004): Histomorphometry of brain tumours. Neuropathol Appl Neurobiol 30, 315-328

Nakagawa N, Saegusa Y, Abe S, Miura Y und Yoshiya S (2006): The effectiveness of RA wrist fusion using Beta-TCP without autogenous iliac bone grafting: a report of four cases. Hand Surg 11, 71-75

Newman E, Turner AS und Wark JD (1995): The potential of sheep for the study of osteopenia: current status and comparison with other animal models. Bone 16, 277S-284S

Norton MR, Odell EW, Thompson ID und Cook RJ (2003): Efficacy of bovine bone mineral for alveolar augmentation: a human histologic study. Clin Oral Implants Res 14, 775-783

Nussbaum V (1875): Ueber die Behandlung unglücklicher Vorkommnisse nach einfachen und komplizierten Beinbrüchen, insbesondere über Knochentransplantationen. Ärztliches Intelligenzblatt (ed. Graf, V., Kerschensteiner, Ranke, H., Rothmund, V., Schleisse, V. und Seitz, München 1875), 72-75

Ollier L: Traité experimental et clinique de la regénération des os et de la production artificielle du tissu osseux. Masson, Paris 1867, 11

Parfitt AM: Bone histomorphometry: techniques and interpretation; in: The Physiologic and Clinical Significance of Bone Histomorphometric Data, R. R. Recker, CRC Press, Boca Raton 1983, 143-224

Pearce Al, Richards RG, Milz S, Schneider E und Pearce SG (2007): Animal models for implant biomaterial research in bone: a review. Eur Cell Mater 13, 1-10

Poehling S: Enhancement of bone growth by coating of osteoinductive beta-tricalcium phosphate (beta-TCP) with recombinant human growth factor-5 (rhGDF-5); auf: 2nd European Conference on Bone Morphogenetic Proteins, Zagreb, 26.-30.09.2001; Croatian Calcified Tissue Society, 2001, Zagreb

Poehling S, Pippig SD, Hellerbrand K, Siedler M, Schutz A und Dony C (2006): Superior effect of MD05, beta-tricalcium phosphate coated with recombinant human growth/differentiation factor-5, compared to conventional bone substitutes in the rat calvarial defect model. J Periodontol $\underline{77}, 1582-1590$

Pruss A, Knaepler H, Katthagen BD, Frommelt L und European U (2005): [Consequence of European Directive 2004/23/EC for bone banks in Germany]. Orthopade 34, 1160, 1162-1166, 1168

Reddi AH, Wientroub S und Muthukumaran N (1987): Biologic principles of bone induction. Orthop Clin North Am 18, 207-212

Rogers GF und Greene AK (2012): Autogenous bone graft: basic science and clinical implications. J Craniofac Surg 23, 323-327

Roldan JC, Jepsen S, Schmidt C, Knuppel H, Rueger DC, Acil Y und Terheyden H (2004): Sinus floor augmentation with simultaneous placement of dental implants in the presence of platelet-rich plasma or recombinant human bone morphogenetic protein-7. Clin Oral Implants Res 15, 716-723 
Sagawa H, Itoh S, Wang W und Yamashita K (2010): Enhanced bone bonding of the hydroxyapatite/beta-tricalcium phosphate composite by electrical polarization in rabbit long bone. Artif Organs 34, 491-497

Sailer HF und Weber FE (2000): [Bone substitutes]. Mund Kiefer Gesichtschir 4 Suppl 1, S384-391

Scher EL, Day RB und Speight PM (1999): New bone formation after a sinus lift procedure using demineralized freeze-dried bone and tricalcium phosphate. Implant Dent $\underline{8}, 49-53$

Schliephake H (2010): Application of bone growth factors--the potential of different carrier systems. Oral Maxillofac Surg 14, 17-22

Schliephake H, Neukam FW, Hutmacher D und Becker J (1994): Enhancement of bone ingrowth into a porous hydroxylapatite-matrix using a resorbable polylactic membrane: an experimental pilot study. J Oral Maxillofac Surg $\underline{52}$, 57-63

Schuckert KH und Osadnik M (2011): Bone Tissue Engineering in Oral Surgery: A New Method of Bone Development in Periodontal Surgery. Tissue Eng Part C Methods

Sigurdsson TJ, Nygaard L, Tatakis DN, Fu E, Turek TJ, Jin L, Wozney JM und Wikesjo UM (1996): Periodontal repair in dogs: evaluation of rhBMP-2 carriers. Int J Periodontics Restorative Dent 16, 524-537

Simunek A, Cierny M, Kopecka D, Kohout A, Bukac J und Vahalova D (2005): The sinus lift with phycogenic bone substitute. A histomorphometric study. Clin Oral Implants Res $\underline{16}$, 342-348

Somanathan RV und Simunek A (2006): Evaluation of the success of beta-tricalciumphosphate and deproteinized bovine bone in maxillary sinus augmentation using histomorphometry: a review. Acta Medica (Hradec Kralove). $\underline{49}$, 87-89

Storm EE, Huynh TV, Copeland NG, Jenkins NA, Kingsley DM und Lee SJ (1994): Limb alterations in brachypodism mice due to mutations in a new member of the TGF beta-superfamily. Nature $\underline{368}, 639-643$

Summers RB (1994): A new concept in maxillary implant surgery: the osteotome technique. Compendium 15, 152, 154-156, 158 passim; quiz 162

Summers RB (1995): The osteotome technique: Part 4--Future site development. Compend Contin Educ Dent 16, 1090, 1092 passim; 1094-1096, 1098, quiz 1099

Tatum H, Jr. (1986): Maxillary and sinus implant reconstructions. Dent Clin North Am $\underline{30}, 207-229$

Terheyden H, Jepsen S, Moller B, Tucker MM und Rueger DC (1999): Sinus floor augmentation with simultaneous placement of dental implants using a combination of deproteinized bone xenografts and recombinant human osteogenic protein-1. A histometric study in miniature pigs. Clin Oral Implants Res 10 , 510-521

Thorwarth M, Schultze-Mosgau S, Kessler P, Wiltfang J und Schlegel KA (2005): Bone regeneration in osseous defects using a resorbable nanoparticular hydroxyapatite. J Oral Maxillofac Surg 63, 1626-1633

Tomford WW und Mankin HJ (1999): Bone banking. Update on methods and materials. Orthop Clin North Am $\underline{30}, 565-570$ 
Uludag H, D'Augusta D, Palmer R, Timony G und Wozney J (1999): Characterization of rhBMP-2 pharmacokinetics implanted with biomaterial carriers in the rat ectopic model. J Biomed Mater Res 46, 193-202

Urist MR (1965): Bone: formation by autoinduction. Science 150, 893-899

Urist MR und Strates BS (1971): Bone morphogenetic protein. J Dent Res $\underline{50}$, $1392-1406$

Urist MR, DeLange RJ und Finerman GA (1983): Bone cell differentiation and growth factors. Science 220, 680-686

Wallace SS und Froum SJ (2003): Effect of maxillary sinus augmentation on the survival of endosseous dental implants. A systematic review. Ann Periodontol $\underline{8}, 328-343$

Weigel A, Schild D und Zeug A (2009): Resolution in the ApoTome and the confocal laser scanning microscope: comparison. J Biomed Opt 14, 014022

Weng D, Poehling S, Pippig S, Bell M, Richter EJ, Zuhr O und Hurzeler MB (2009): The effects of recombinant human growth/differentiation factor-5 (rhGDF-5) on bone regeneration around titanium dental implants in barrier membrane-protected defects: a pilot study in the mandible of beagle dogs. Int J Oral Maxillofac Implants 24, 31-37

Wikesjo UM, Razi SS, Sigurdsson TJ, Tatakis DN, Lee MB, Ongpipattanakul B, Nguyen T und Hardwick R (1998): Periodontal repair in dogs: effect of recombinant human transforming growth factor-beta1 on guided tissue regeneration. J Clin Periodontol 25, 475-481

Woo I und Le BT (2004): Maxillary sinus floor elevation: review of anatomy and two techniques. Implant Dent 13, 28-32

Younger EM und Chapman MW (1989): Morbidity at bone graft donor sites. J Orthop Trauma $\underline{3}, 192-195$ 


\section{Anhang}

\subsection{Histomorphometrische Daten}

\begin{tabular}{|c|c|c|c|c|c|c|}
\hline $\mathbf{P}$ & Konzentration & ROI 1 & ROI 2 & ROI 3 & ROI 4 & ROI 5 \\
\hline 1 & 0 & 37,59 & 3,92 & 4,63 & 22,33 & 19,62 \\
\hline 2 & 0 & 21,41 & 8,63 & 5,58 & 15,49 & 23,68 \\
\hline 3 & 0 & 18,39 & 1,39 & 2,49 & 0,63 & 0,54 \\
\hline 4 & 0 & 18,62 & 13,95 & 10,94 & 9,63 & 15,05 \\
\hline 5 & 0 & 5,35 & 0,28 & 0,44 & 0,06 & 0,02 \\
\hline 6 & 0 & 8,98 & 0,07 & 4,28 & 8,43 & 0,56 \\
\hline 1 & 400 & 21,83 & 20,25 & 15,77 & 15,05 & 19,83 \\
\hline 2 & 800 & 20,62 & 6,79 & 3,50 & 2,08 & 2,06 \\
\hline 3 & 400 & 31,04 & 19,87 & 15,37 & 13,60 & 13,29 \\
\hline 4 & 800 & 33,28 & 25,59 & 22,94 & 24,50 & 23,62 \\
\hline 5 & 800 & 27,41 & 19,00 & 11,43 & 21,33 & 12,06 \\
\hline 6 & 400 & 62,82 & 35,70 & 30,91 & 16,15 & 23,89 \\
\hline 7 & 0 & 66,08 & & 52,91 & & 8,15 \\
\hline 8 & 0 & 56,27 & & 55,74 & & 6,96 \\
\hline 9 & 0 & 49,52 & 8,06 & 6,21 & 24,71 & 20,32 \\
\hline 10 & 0 & 85,22 & & 39,54 & & 0,38 \\
\hline 11 & 0 & 74,91 & & 0,69 & & 0,00 \\
\hline 12 & 0 & 61,73 & 41,33 & 4,35 & 0,08 & 7,47 \\
\hline 7 & 800 & 57,26 & 56,75 & 46,95 & 46,50 & 17,48 \\
\hline 8 & 800 & 78,45 & & 42,58 & & 9,74 \\
\hline 9 & 400 & 45,75 & 46,68 & 45,40 & 44,94 & 20,56 \\
\hline 10 & 400 & 86,24 & & 51,29 & & 6,87 \\
\hline 11 & 800 & 51,24 & 68,38 & 40,54 & 30,29 & 8,20 \\
\hline 12 & 400 & 63,13 & 68,38 & 70,11 & 74,94 & 36,31 \\
\hline
\end{tabular}

Tab. 7.1: Prozentualer Knochenanteil in allen ROIs (Anteriore Schnittebene) 


\begin{tabular}{|c|c|c|c|c|c|c|}
\hline $\mathbf{P}$ & Konzentration & ROI 1 & ROI 2 & ROI 3 & ROI 4 & ROI 5 \\
\hline 1 & 0 & 32,83 & & 14,04 & & 13,83 \\
\hline 2 & 0 & 22,37 & 10,09 & 2,30 & 0,11 & 1,32 \\
\hline 3 & 0 & 13,50 & 6,62 & 1,26 & 0,39 & 0,00 \\
\hline 4 & 0 & 11,34 & 10,22 & 0,52 & 1,18 & 0,41 \\
\hline 5 & 0 & 2,17 & 0,13 & 0,27 & 0,00 & 0,83 \\
\hline 6 & 0 & 19,59 & 2,09 & 2,98 & 0,61 & 1,62 \\
\hline 1 & 400 & 29,15 & 8,42 & 0,67 & 6,00 & 11,17 \\
\hline 2 & 800 & 23,15 & 1,20 & 0,00 & 0,00 & 9,11 \\
\hline 3 & 400 & 37,01 & 27,32 & 20,61 & 19,54 & 26,38 \\
\hline 4 & 800 & 24,18 & 19,23 & 21,67 & 15,43 & 9,04 \\
\hline 5 & 800 & 15,46 & 10,88 & 2,68 & 9,54 & 18,69 \\
\hline 6 & 400 & 19,38 & 5,97 & 3,54 & 4,58 & 12,52 \\
\hline 7 & 0 & 71,58 & & 67,25 & & 25,95 \\
\hline 8 & 0 & 65,90 & & 44,01 & & 1,25 \\
\hline 9 & 0 & 63,96 & 6,29 & 3,44 & 49,39 & 6,96 \\
\hline 10 & 0 & 64,81 & & 40,69 & & 0,42 \\
\hline 11 & 0 & 56,38 & & 8,98 & & 0,00 \\
\hline 12 & 0 & 67,75 & 57,09 & 36,89 & 9,70 & 29,66 \\
\hline 7 & 800 & 54,93 & 52,00 & 45,70 & 27,58 & 30,77 \\
\hline 8 & 800 & 56,75 & & 48,12 & & 17,56 \\
\hline 9 & 400 & 44,81 & 31,36 & 37,98 & 40,42 & 20,22 \\
\hline 10 & 400 & 86,53 & & 25,53 & & 2,43 \\
\hline 11 & 800 & 58,64 & 38,54 & 36,14 & 20,74 & 3,58 \\
\hline 12 & 400 & 71,77 & 70,44 & 53,90 & 62,51 & 50,51 \\
\hline
\end{tabular}

Tab. 7.2: Prozentualer Knochenanteil in allen ROIs (Zentrale Schnittebene)

\begin{tabular}{|c|c|c|c|}
\hline Konzentration & anterior & zentral & posterior \\
\hline 0 & 9,43 & 6,17 & 8,32 \\
\hline 400 & 23,69 & 15,48 & 15,16 \\
\hline 800 & 17,08 & 12,02 & 15,65 \\
\hline
\end{tabular}

Tab. 7.3: Prozentualer Knochenanteil aller Schnittebenen nach vier Wochen 


\begin{tabular}{|c|c|c|c|c|c|c|}
\hline $\mathbf{P}$ & Konzentration & ROI 1 & ROI 2 & ROI 3 & ROI 4 & ROI 5 \\
\hline 1 & 0 & 39,44 & 5,14 & 1,16 & 0,77 & 3,33 \\
\hline 2 & 0 & 41,20 & 14,71 & 11,43 & 3,33 & 7,53 \\
\hline 3 & 0 & 13,41 & 1,67 & 1,49 & 1,92 & 1,02 \\
\hline 4 & 0 & 15,09 & 21,99 & 4,91 & 5,11 & 14,04 \\
\hline 5 & 0 & 8,47 & 5,26 & 7,03 & 0,24 & 0,62 \\
\hline 6 & 0 & 13,54 & 2,87 & 1,51 & 0,57 & 0,92 \\
\hline 1 & 400 & 24,12 & 7,09 & 3,96 & 9,97 & 11,84 \\
\hline 2 & 800 & 28,00 & 16,48 & 4,83 & 1,05 & 17,52 \\
\hline 3 & 400 & 28,11 & 31,13 & 21,34 & 13,71 & 14,74 \\
\hline 4 & 800 & 31,42 & 23,92 & 18,27 & 16,43 & 8,79 \\
\hline 5 & 800 & 18,01 & 12,31 & 9,68 & 8,38 & 19,58 \\
\hline 6 & 400 & 30,76 & 10,25 & 0,00 & 9,25 & 11,10 \\
\hline 7 & 0 & 80,32 & 32,85 & 0,00 & 0,00 & 0,00 \\
\hline 8 & 0 & 52,61 & 32,60 & 53,94 & 19,69 & 3,61 \\
\hline 9 & 0 & 68,54 & 66,86 & 15,94 & 1,20 & 1,41 \\
\hline 10 & 0 & 84,62 & & 48,72 & & 36,02 \\
\hline 11 & 0 & 71,91 & & 19,83 & & 0,00 \\
\hline 12 & 0 & 67,22 & 30,77 & 24,81 & 35,37 & 27,12 \\
\hline 7 & 800 & 79,23 & 74,86 & 71,40 & 75,69 & 49,52 \\
\hline 8 & 800 & 49,61 & & 29,65 & & 10,73 \\
\hline 9 & 400 & 49,16 & & 44,38 & & 27,59 \\
\hline 10 & 400 & 71,13 & & 19,04 & & 0,00 \\
\hline 11 & 800 & 31,69 & & 58,15 & & 15,19 \\
\hline 12 & 400 & 60,32 & 66,46 & 50,85 & 53,00 & 37,76 \\
\hline
\end{tabular}

Tab. 7.4: Prozentualer Knochenanteil in allen ROIs (Posteriore Schnittebene)

\begin{tabular}{|c|c|c|c|}
\hline Konzentration & anterior & zentral & posterior \\
\hline 0 & 30,48 & 35,38 & 33,69 \\
\hline 400 & 51,47 & 46,03 & 43,61 \\
\hline 800 & 42,64 & 37,77 & 49,61 \\
\hline
\end{tabular}

Tab. 7.5: Prozentualer Knochenanteil aller Schnittebenen nach zwölf Wochen 


\subsection{Statistische Daten}

\subsubsection{Vier Wochen}

\begin{tabular}{|c|c|c|c|c|c|c|}
\hline Effect & Num DF & Den DF & Chi-Square & F Value & Pr $>$ ChiSq & Pr $>$ F \\
\hline ROI & 4 & 39 & 111,22 & 27,81 & $<0,0001$ & $<0,0001$ \\
\hline Konzentration & 2 & 39 & 8,26 & 4,13 & 0,0161 & 0,0236 \\
\hline ROIKonzentration & 8 & 39 & 3,78 & 0,47 & 0,8765 & 0,8681 \\
\hline H_he_MW & 1 & 39 & 2,64 & 2,64 & 0,1044 & 0,11 \\
\hline
\end{tabular}

Tab. 7.6: Typ III Test; Wechselwirkungen nach vier Wochen

\begin{tabular}{|c|c|c|c|c|c|c|c|c|c|c|}
\hline Konzentration & Konzentration & Estimate & Pr $>$ ItI & Adjustment & Adj P & Alpha & Lower & Upper & $\begin{array}{c}\text { Adj } \\
\text { Lower }\end{array}$ & $\begin{array}{c}\text { Adj } \\
\text { Upper }\end{array}$ \\
\hline 0 & 400 & $-17,6070$ & 0,0069 & Tukey-Kramer & 0,0184 & 0,05 & $-30,0848$ & $-5,1293$ & $-32,6363$ & $-2,5777$ \\
\hline 0 & 800 & $-12,9790$ & 0,0371 & Tukey-Kramer & 0,0913 & 0,05 & $-25,1424$ & $-0,8156$ & $-27,6296$ & 1,6717 \\
\hline 400 & 800 & 4,6280 & 0,3566 & Tukey-Kramer & 0,6230 & 0,05 & $-5,4058$ & 14,6619 & $-7,4576$ & 16,7137 \\
\hline
\end{tabular}

Tab. 7.7: Konzentrationsvergleich nach vier Wochen

\begin{tabular}{|c|c|c|c|c|c|c|c|c|c|}
\hline ROI & ROI & Estimate & Pr $>$ ItI & Adjustment & Adj P & Lower & Upper & Adj Lower & Adj Upper \\
\hline 1 & 2 & 11,5180 & $<0,0001$ & Tukey-Kramer & $<0,0001$ & 7,9422 & 15,0938 & 6,4629 & 16,5731 \\
\hline 1 & 3 & 15,9837 & $<0,0001$ & Tukey-Kramer & $<0,0001$ & 12,4279 & 19,5394 & 10,9569 & 21,0104 \\
\hline 1 & 4 & 15,6081 & $<0,0001$ & Tukey-Kramer & $<0,0001$ & 12,0323 & 19,1839 & 10,5530 & 20,6632 \\
\hline 1 & 5 & 13,3209 & $<0,0001$ & Tukey-Kramer & $<0,0001$ & 9,7652 & 16,8767 & 8,2941 & 18,3477 \\
\hline 2 & 3 & 4,4656 & 0,0157 & Tukey-Kramer & 0,1055 & 0,8898 & 8,0414 & $-0,5895$ & 9,5207 \\
\hline 2 & 4 & 4,0900 & 0,0253 & Tukey-Kramer & 0,1583 & 0,5343 & 7,6458 & $-0,9367$ & 9,1168 \\
\hline 2 & 5 & 1,8029 & 0,3141 & Tukey-Kramer & 0,8447 & $-1,7729$ & 5,3787 & $-3,2522$ & 6,8580 \\
\hline 3 & 4 & $-0,3756$ & 0,8329 & Tukey-Kramer & 0,9995 & $-3,9514$ & 3,2002 & $-5,4307$ & 4,6795 \\
\hline 3 & 5 & $-2,6627$ & 0,1379 & Tukey-Kramer & 0,5594 & $-6,2185$ & 0,8930 & $-7,6895$ & 2,3640 \\
\hline 4 & 5 & $-2,2871$ & 0,2034 & Tukey-Kramer & 0,6965 & $-5,8629$ & 1,2886 & $-7,3423$ & 2,7680 \\
\hline
\end{tabular}

Tab. 7.8: Paarweiser Vergleich aller ROls nach vier Wochen 


\subsubsection{Zwölf Wochen}

\begin{tabular}{|c|c|c|c|c|c|c|}
\hline Effect & Num DF & Den DF & Chi-Square & F Value & Pr $>$ ChiSq & Pr $>$ F \\
\hline ROI & 4 & 31 & 93,02 & 23,26 & $<0,0001$ & $<0,0001$ \\
\hline Konzentration & 2 & 31 & 7,81 & 3,90 & 0,0202 & 0,0308 \\
\hline ROI*Konzentration & 7 & 31 & 19,59 & 2,80 & 0,0065 & 0,0223 \\
\hline H_he_MW & 1 & 31 & 0,18 & 0,18 & 0,6737 & 0,6766 \\
\hline
\end{tabular}

Tab. 7.9: Typ III Test; Wechselwirkungen nach zwölf Wochen

Weil die Wechselwirkung „ROI*Konzentration“ signifikant war wurde eine separate Auswertung der verschiedenen Konzentrationen durchgeführt.

\subsubsection{Kontrollgruppe}

\begin{tabular}{|c|c|c|c|c|c|c|}
\hline Effect & Num DF & Den DF & Chi-Square & F Value & Pr $>$ ChiSq & Pr $>$ F \\
\hline ROI & 4 & 15 & 86,71 & 21,68 & $<0,0001$ & $<0,0001$ \\
\hline H_he_MW & 1 & 15 & 0,58 & 0,58 & 0,4459 & 0,4578 \\
\hline
\end{tabular}

Tab. 7.10: Typ III Test; Wechselwirkungen nach zwölf Wochen (Kontrollgruppe)

\begin{tabular}{|c|c|c|c|c|c|c|c|c|c|c|}
\hline ROI & ROI & Estimate & Pr $>$ Itl & Adjustment & Adj P & Alpha & Lower & Upper & Adj Lower & Adj Upper \\
\hline 1 & 2 & 31,4392 & 0,0010 & Tukey-Kramer & 0,0079 & 0,05 & 14,8918 & 47,9865 & 7,4663 & 55,4120 \\
\hline 1 & 3 & 38,0781 & $<0,0001$ & Tukey-Kramer & 0,0003 & 0,05 & 24,0138 & 52,1424 & 17,7026 & 58,4536 \\
\hline 1 & 4 & 50,3737 & $<0,0001$ & Tukey-Kramer & $<0,0001$ & 0,05 & 33,8263 & 66,9210 & 26,4008 & 74,3466 \\
\hline 1 & 5 & 57,4253 & $<0,0001$ & Tukey-Kramer & $<0,0001$ & 0,05 & 43,3610 & 71,4895 & 37,0497 & 77,8008 \\
\hline 2 & 3 & 6,6389 & 0,4059 & Tukey-Kramer & 0,9087 & 0,05 & $-9,9084$ & 23,1863 & $-17,3340$ & 30,6118 \\
\hline 2 & 4 & 18,9345 & 0,0333 & Tukey-Kramer & 0,1852 & 0,05 & 1,7094 & 36,1597 & $-6,0203$ & 43,8894 \\
\hline 2 & 5 & 25,9861 & 0,0044 & Tukey-Kramer & 0,0307 & 0,05 & 9,4387 & 42,5335 & 2,0132 & 49,9590 \\
\hline 3 & 4 & 12,2956 & 0,1341 & Tukey-Kramer & 0,5287 & 0,05 & $-4,2517$ & 28,8430 & $-11,6773$ & 36,2685 \\
\hline 3 & 5 & 19,3472 & 0,0103 & Tukey-Kramer & 0,0667 & 0,05 & 5,2829 & 33,4115 & $-1,0283$ & 39,7227 \\
\hline 4 & 5 & 7,0516 & 0,3781 & Tukey-Kramer & 0,8893 & 0,05 & $-9,4958$ & 23,5989 & $-16,9213$ & 31,0244 \\
\hline
\end{tabular}

Tab. 7.11: Paarweiser Vergleich aller ROls nach zwölf Wochen (Kontrollgruppe) 


\subsubsection{Gruppe $B_{n}$}

\begin{tabular}{|c|c|c|c|c|c|c|}
\hline Effect & Num DF & Den DF & Chi-Square & F Value & Pr $>$ ChiSq & Pr $>$ F \\
\hline ROI & 4 & 5 & 13,16 & 3,29 & 0,0105 & 0,1118 \\
\hline H_he_MW & 1 & 5 & 1,51 & 1,51 & 0,2194 & 0,2740 \\
\hline
\end{tabular}

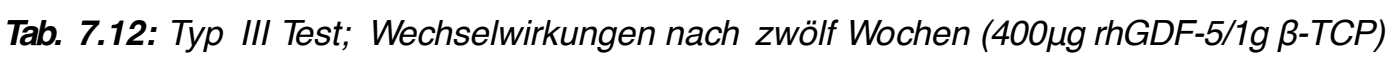

\subsubsection{Gruppe $B_{h}$}

\begin{tabular}{|c|c|c|c|c|c|c|}
\hline Effect & Num DF & Den DF & Chi-Square & F Value & Pr $>$ ChiSq & Pr $>$ F \\
\hline ROI & 4 & 5 & 80,70 & 20,17 & $<0,0001$ & 0,0028 \\
\hline H_he_MW & 1 & 5 & 0,46 & 0,46 & 0,4972 & 0,5273 \\
\hline
\end{tabular}

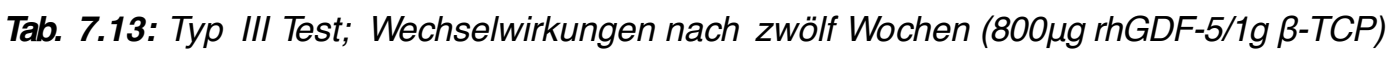

\begin{tabular}{|c|c|c|c|c|c|c|c|c|c|c|}
\hline ROI & ROI & Estimate & Pr $>$ Itl & Adjustment & Adj P & Alpha & Lower & Upper & Adj Lower & Adj Upper \\
\hline 1 & 2 & 2,1047 & 0,7300 & Tukey-Kramer & 0,9950 & 0,05 & $-12,7158$ & 16,9252 & $-21,0233$ & 25,2327 \\
\hline 1 & 3 & 10,9522 & 0,0764 & Tukey-Kramer & 0,3020 & 0,05 & $-1,6873$ & 23,5917 & $-8,7723$ & 30,6767 \\
\hline 1 & 4 & 21,7167 & 0,0131 & Tukey-Kramer & 0,0630 & 0,05 & 6,8962 & 36,5371 & $-1,4113$ & 44,8446 \\
\hline 1 & 5 & 39,4472 & 0,0005 & Tukey-Kramer & 0,0026 & 0,05 & 26,8077 & 52,0867 & 19,7227 & 59,1717 \\
\hline 2 & 3 & 8,8475 & 0,1855 & Tukey-Kramer & 0,5854 & 0,05 & $-5,9730$ & 23,6680 & $-14,2805$ & 31,9755 \\
\hline 2 & 4 & 19,6120 & 0,0225 & Tukey-Kramer & 0,1042 & 0,05 & 4,1318 & 35,0921 & $-4,5455$ & 43,7694 \\
\hline 2 & 5 & 37,3425 & 0,0013 & Tukey-Kramer & 0,0069 & 0,05 & 22,5220 & 52,1629 & 14,2145 & 60,4704 \\
\hline 3 & 4 & 10,7645 & 0,1209 & Tukey-Kramer & 0,4328 & 0,05 & $-4,0560$ & 25,5849 & $-12,3635$ & 33,8925 \\
\hline 3 & 5 & 28,4950 & 0,0022 & Tukey-Kramer & 0,0113 & 0,05 & 15,8555 & 41,1345 & 8,7705 & 48,2195 \\
\hline 4 & 5 & 17,7305 & 0,0276 & Tukey-Kramer & 0,1254 & 0,05 & 2,9100 & 32,5510 & $-5,3975$ & 40,8585 \\
\hline
\end{tabular}

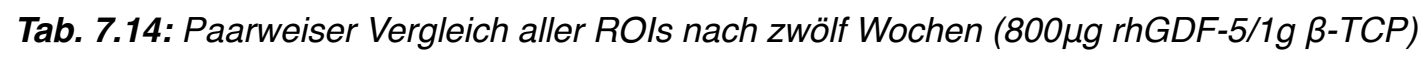

Während bei Gruppe $B_{n}$ ein homogenes Ergebnis über alle ROls erzielt wurde, wurden bei der Kontrollgruppe und der Gruppe $B_{h}$ signifikante Unterschiede zwischen den ROls nachgewiesen. 


\section{Danksagung}

An dieser Stelle möchte ich mich bei all denjenigen Menschen bedanken, die mich während meiner Promotion begleitet und unterstützt haben. Ganz besonders danke ich Herrn PD. Dr. Dr. Rudolf Matthias Gruber für die Vergabe des Themas, die hervorragende Betreuung sowie die Ansprechbarkeit und Hilfsbereitschaft bei Fragen und Problemen. Herrn Prof. Dr. Dr. Henning Schliephake danke ich für die Erlaubnis die Einrichtungen und Geräte der Abteilung Mund-, Kiefer- und Gesichtschirurgie für die durchgeführten Untersuchungen nutzen zu dürfen. Aus der Abteilung Medizinische Statistik der Universität Göttingen danke ich Frau Dr. Katharina Lange für die statistischen Berechnungen der Messergebnisse, sowie die umfassende Betreuung. Ganz besonders danke ich meinen Eltern Harald- und Lieselotte Brockmeyer, meiner Schwester Dr. Claudia Brockmeyer und meiner Lebensgefährtin Dr. Tatjana Khromov für das Korrekturlesen der Dissertationsschrift und für die jahrelange liebevolle Unterstützung und den Rückhalt, ohne den das Studium und die Promotion nicht möglich gewesen wäre. 